Universidade de São Paulo

Faculdade de Filosofia, Ciências e Letras de Ribeirão Preto Departamento de Química

Programa de Pós-Graduação em Química

\title{
“Adsorção de colato em hidróxidos duplos lamelares de magnésio e alumínio: efeito da temperatura, pH e força iônica do meio"
}

José Francisco Naime Filho

Dissertação apresentada à Faculdade de Filosofia,

Ciências e Letras de Ribeirão Preto da Universidade de São Paulo, como parte das exigências para a obtenção do título de Mestre em Ciências, Área: Química

RIBEIRÃO PRETO - SP 
1. Introdução

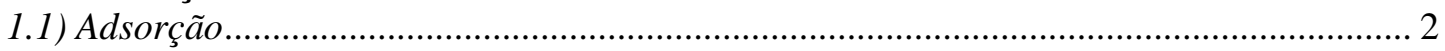

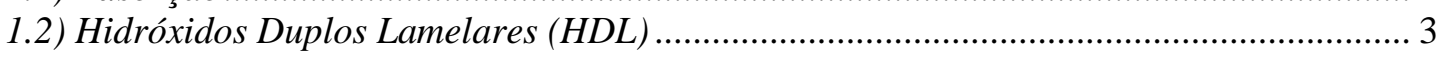

1.3) Propriedades e Aplicações dos Hidróxidos Duplos Lamelares. ........................................ 9

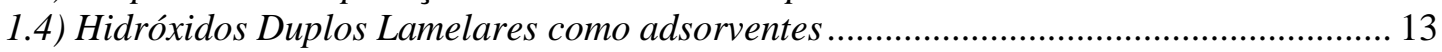

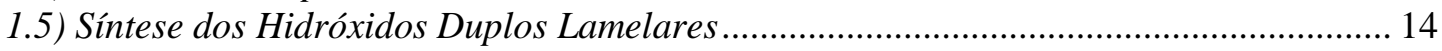

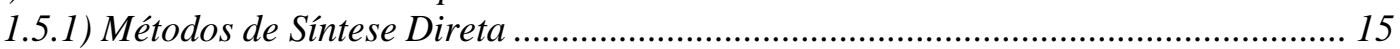

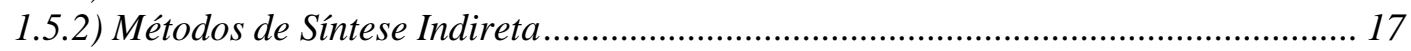

1.6) Modelos Gerais para o Estudo de Adsorção................................................................. 19

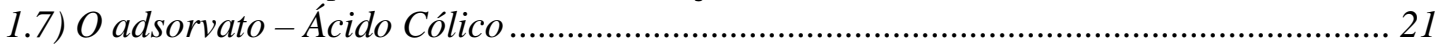

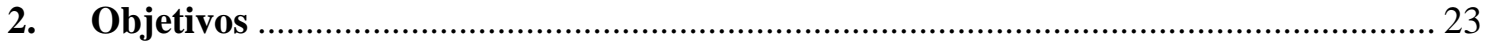

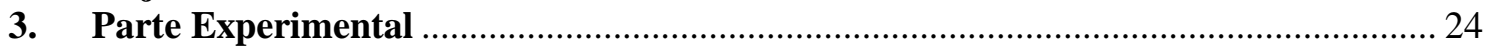

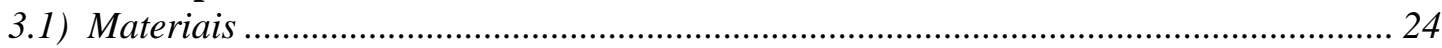

3.2) Preparação do $\mathrm{HDL} \mathrm{MgAlCO}_{3}$, o adsorvente ............................................................ 24

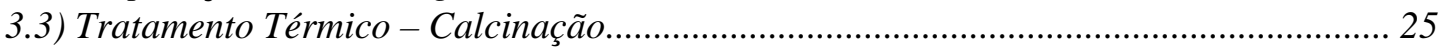

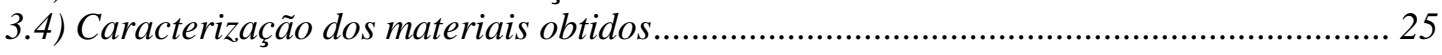

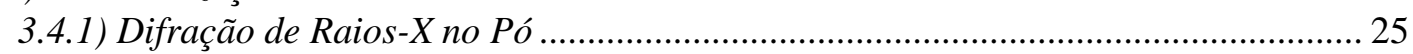

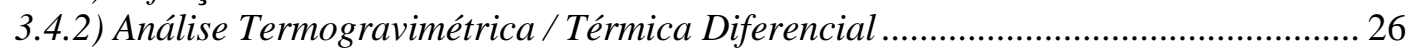

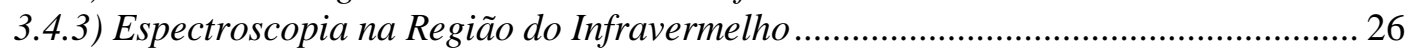

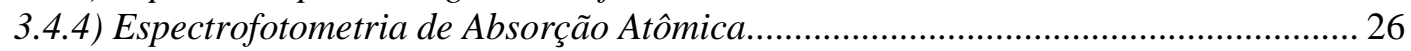

3.4.5) Espectrofotometria na Região do Ultravioleta-Visível ............................................2 27

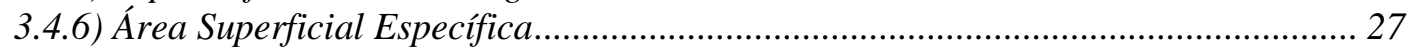

3.4.7) Microscopia Eletrônica de Varredura …................................................................. 27

3.4.8) Potencial Eletrocinético e Potencial de Carga Zero ................................................. 28

3.5) Quantificação dos Ânions Colato..................................................................................... 29

3.6) Estudo da adsorção e sorção dos ânions colato em $\mathrm{MgAlCO}_{3}-\mathrm{HDL}$ em função do

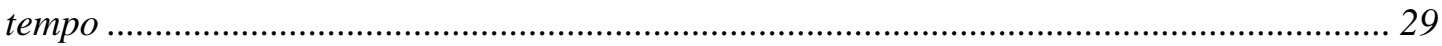

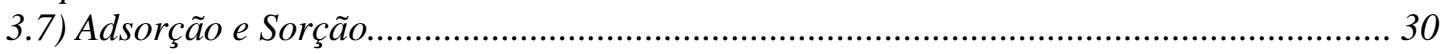

3.7.1) Determinação das isotermas de adsorção / sorção..................................................... 30

3.8) Forma de Tratamento de Dados...................................................................................... 31

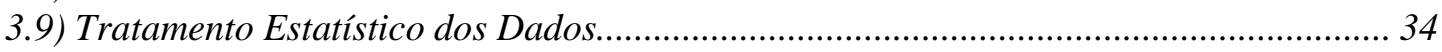

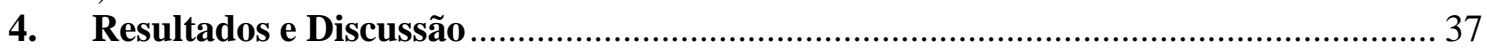

4.1) Preparação e caracterização do adsorvente $\mathrm{MgAlCO}_{3}$-HDL......................................... 37

4.2) Estudo da adsorção de ânions colato em $\mathrm{MgAlCO}$ - $\mathrm{HDL}$ em função do tempo - estudo

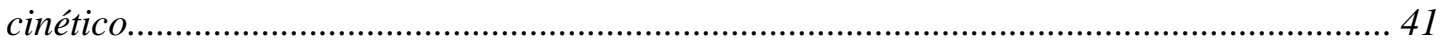

4.3) Adsorção dos ânions colato em $\mathrm{MgAlCO}_{3}-\mathrm{HDL}$....................................................... 50

4.3.1) Influência da temperatura e do $\mathrm{pH}$.......................................................................... 51

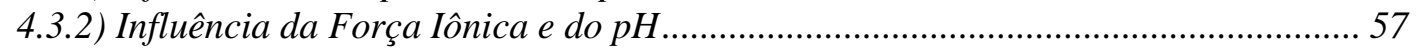

4.3.3) Influência da Temperatura e da Força Iônica ........................................................... 62

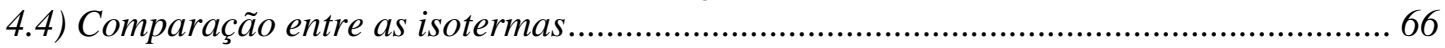

4.5) Tratamento Estatístico dos Dados - Análise Multivariacional....................................... 68

4.5.1) Cálculo dos efeitos principais (efeitos de primeira ordem)...................................... 69

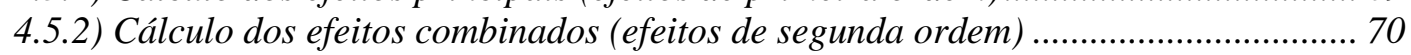

4.6) Otimização do processo de adsorção - Experimentos a $288 \mathrm{~K}$........................................ 72

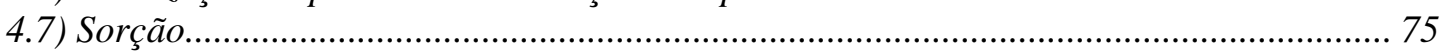

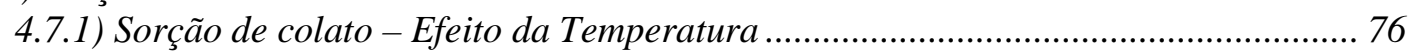

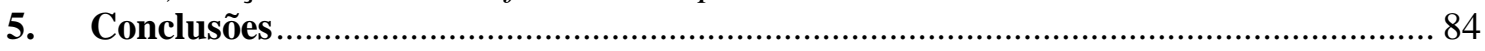

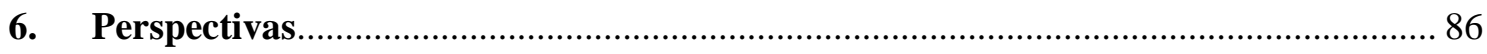

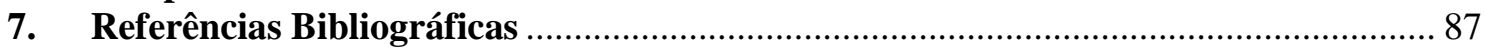

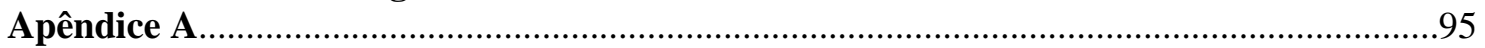




\section{Índice de Figuras}

Figura 1.1. Representação esquemática de uma lamela de $\mathrm{Mg}(\mathrm{OH})_{2}$....................................... 4

Figura 1.2. Representação esquemática da estrutura do tipo da hidrotalcita ............................... 5

Figura 1.3. Representação esquemática dos polítipos obtidos para os HDL............................... 6

Figura 1.4. Representação esquemática dos domínios contendo água nos HDL........................ 9

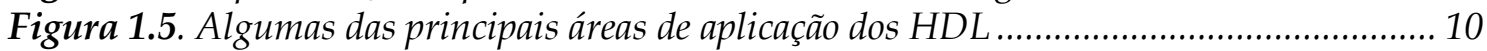

Figura 1.6: Sistema de classificação de isotermas proposto por Giles. ....................................... 20

Figura 1.7. Representação da estrutura molecular do ácido cólico............................................ 22

Figura. 3.1: Exemplo para o cálculo do tamanho de partículas do HDL por DRXP: $\mathrm{Mg}-\mathrm{Al}-\mathrm{CO}_{3}-$

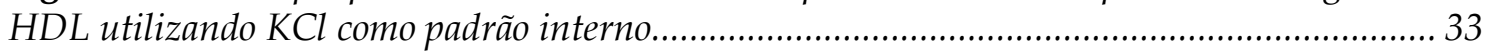

Figura 4.1. a) Difratograma de raios X no pó (DRXP) para: a) o $M g A l C \mathrm{C}_{3}-\mathrm{HDL}$ após tratamento hidrotérmico; b) para o $\mathrm{MgAlCO}_{3}$-HDL após tratamento térmico (calcinação)........ 37

Figura 4.2. Curvas de TA e DTA para o $\mathrm{MgAlCO}$ - $\mathrm{HDL}$ após o tratamento hidrotérmico ..... 38

Figura 4.3. Espectros IV-TF para o $\mathrm{MgAlCO}_{3}-\mathrm{HDL}$ : a)após tratamento hidrotérmico; b) calcinado ......

Figura 4.4. Isotermas BET para o MgAlCO3-HDL: a) após o $\mathrm{TH} ; b)$ calcinado........................ 40

Figura 4.5. Variação do Potencial Eletrocinético em função do $p H$, para suspensões do HDL em

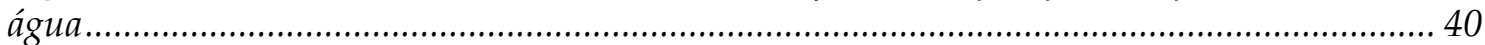

Figura 4.6. Imagens de $\mathrm{MEV}$ para o $\mathrm{MgAlCO}_{3}-\mathrm{HDL}$. a) não calcinado $(5.000 x)$; b) não

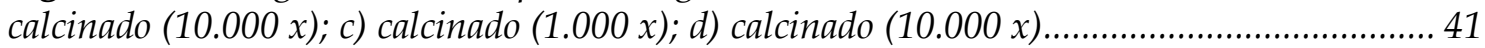

Figura 4.7. Curvas de adsorção de ânions colato em $\mathrm{MgAlCO}_{3}-\mathrm{HDL}$ em função do tempo em diferentes condições. a) em diferentes temperaturas (298 e 323K); b) na presença e na ausência de $\mathrm{NaCl}$ no meio; c) em diferentes valores de $p H$ das soluções iniciais de colato $(7,0 \mathrm{e}$ 10,0).Curva de evolução temporal do $\mathrm{pH}$ do sobrenadante (d), após a adsorção, em diversas condições

42

Figura 4.8. DRXP para o HDL original em diversas condições. a) puro; b) adsorvido com colato a $298 \mathrm{~K} \mathrm{em} \mathrm{pH} 10$; c) adsorvido a $323 \mathrm{~K} \mathrm{em} \mathrm{pH} \mathrm{7;} \mathrm{d)} \mathrm{adsorvido} \mathrm{a} 298 \mathrm{~K} \mathrm{em} \mathrm{pH} 7$ com adição de

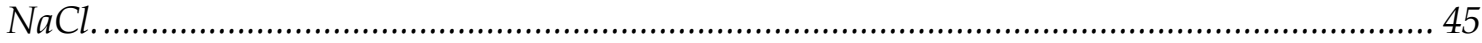

Figura 4.9. Espectro na região do infravermelho para o HDL original. a) puro; b) adsorvido com colato a $298 \mathrm{~K} \mathrm{em} \mathrm{pH} 10$; c) adsorvido a $323 \mathrm{~K} \mathrm{em} \mathrm{pH} \mathrm{7;} \mathrm{d)} \mathrm{adsorvido} \mathrm{a} 298 \mathrm{~K} \mathrm{em} \mathrm{pH} 7 \mathrm{com}$ adição de $\mathrm{NaCl}$..... 46

Figura 4.10. Curvas de adsorção e de sorção de colato em $\mathrm{MgAlCO}_{3}-\mathrm{HDL}$ ou no material calcinado, em função do tempo em diferentes condições de temperatura. Comparação entre as taxas de remoção de íons pelo HDL original e calcinado ............................................................ 48

Figura 4.11. DRXP para o HDL calcinado em diversas condições. a) puro; b) adsorvido a 323

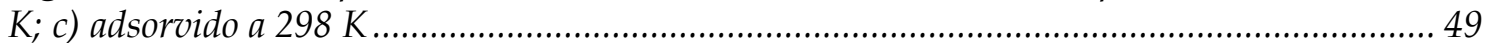

Figura 4.12. DRXP para o colato de sódio puro..................................................................... 50

Figura 4.13. Isotermas de adsorção de colato em HDL, a 298 e 323 K. a) $p H$ 7,0; b) pH 10,0.. 51

Figura 4.14. Potecial eletrocinético em função da adsorção de colato em HDL, a 298 e 323 K. a)

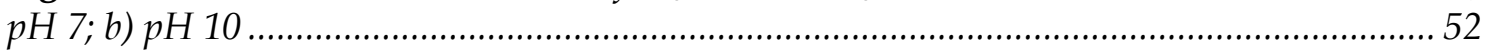

Figura 4.15. Variação do $\mathrm{pH}$ do sobrenadante em função da adsorção de colato em HDL, a 298 e

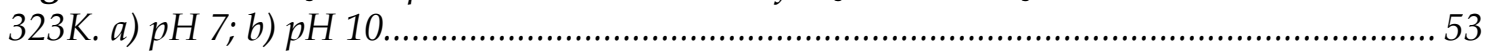

Figura 4.16. DRXP para o HDL adsorvido com colato em diferentes condições. a) puro; $b$ ) adsorvido a $323 \mathrm{~K} \mathrm{a} \mathrm{pH} \mathrm{7;} \mathrm{c)} \mathrm{adsorvido} \mathrm{a} 298 \mathrm{~K} \mathrm{a} \mathrm{pH} 7$.......................................................... 54 Figura 4.17. Espectros na região do infravermelho para o HDL adsorvido com colato em diferentes condições. a) puro; b) adsorvido a $323 \mathrm{~K} \mathrm{a} \mathrm{pH} \mathrm{7;} \mathrm{c)} \mathrm{adsorvido} \mathrm{a} 298 \mathrm{~K} \mathrm{a} \mathrm{pH} 7$.......... 55 Figura 4.18. Isotermas de adsorção de colato em $\mathrm{HDL}$, a $298 \mathrm{~K}$ com e sem adição de $\mathrm{NaCl}$ a) $\mathrm{pH}$ 7,0; b) $p H$ 10,0. 57

Figura 4.19. Potencial Eletrocinético em função da adsorção de colato em HDL, a $298 \mathrm{~K}$ com e sem adição de $\mathrm{NaCl}$. a) $\mathrm{pH} \mathrm{7;} \mathrm{b)} \mathrm{pH} 10$...... 
Figura 4.20. Variação do $p H$ em função da adsorção de colato em HDL, com e sem adição de $0,1 \mathrm{M}$ de $\mathrm{NaCl}$ no meio. a) $\mathrm{pH} 7$; b) $\mathrm{pH} 10$......

Figura 4.21. DRXP para o HDL adsorvido com colato em diferentes condições. a) puro; $b$ ) adsorvido a $298 \mathrm{~K}, \mathrm{pH} 10$; c) adsorvido a $298 \mathrm{~K}$ a $\mathrm{pH} 7$.

Figura 4.22. Espectros de IV-TF para o HDL adsorvido com colato em diferentes condições. a) puro; b) adsorvido a $298 \mathrm{~K} \mathrm{e} \mathrm{pH} \mathrm{10;} \mathrm{c)} \mathrm{adsorvido} \mathrm{a} 298 \mathrm{~K} \mathrm{e} \mathrm{pH} 7$.

Figura 4.23. Isotermas de adsorção de colato em $\mathrm{HDL}$, a $\mathrm{pH}$ 7,0 com e sem adição de $\mathrm{NaCl}$ a) $298 K ; b) 323 K$ 62

Figura 4.24. Potencial Eletrocinético em função da adsorção de colato em HDL, (pH inicial das soluções igual a 7,0) com e sem adição de $\mathrm{NaCl}$. a) $298 \mathrm{~K}$; b) 323K. 63

Figura 4.25. Variação do $\mathrm{pH}$ em função da adsorção de colato em HDL, com e sem adição de

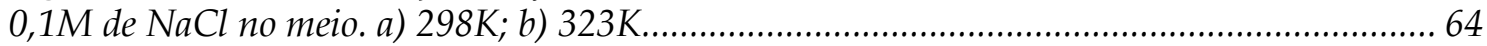

Figura 4.26. DRXP para o HDL adsorvido com colato em diferentes condições. a) puro; $b$ ) $323 \mathrm{~K}$ e presença de 0,1M de $\mathrm{NaCl}$; c) $298 \mathrm{~K}$ e presença de 0,1M de $\mathrm{NaCl}$ 65

Figura 4.27. Isotermas relativas a adsorção de colato em $\mathrm{MgAlCO}_{3}-\mathrm{HDL}$, considerando todas as variáveis analisadas.... 66

Figura 4.28. Esquema de Adsorção de Colato por Interações Eletrostáticas .............................. 68 Figura 4.29. Comparação das isotermas de adsorção de colato a $288 \mathrm{~K}$ e $298 \mathrm{~K}$. a) $\mathrm{pH} 7$, com adição de $0,1 \mathrm{M}$ de $\mathrm{NaCl}$; b) pH 7, sem adição de $\mathrm{NaCl}$.......................................................... 72 Figura 4.30. Potencial eletrocinético em função da adsorção de colato em HDL, à 288 e $298 \mathrm{~K}$ em $\mathrm{pH}$ 7. a) com adição de $0,1 \mathrm{M}$ de $\mathrm{NaCl}$; b) sem adição de $\mathrm{NaCl}$........................................... 74 Figura 4.31. DRXP (à esquerda) e IV-TF (à direita) para o HDL adsorvido com colato a $288 \mathrm{~K}$.

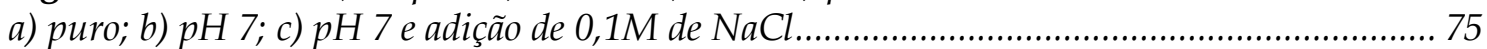
Figura 4.32. Representação esquemática do processo de calcinação/sorção................................. 76 Figura 4.33. Sorção de colato no HDL calcinado a 298 e 323 K. a) Isotermas; b) Potencial Eletrocinético em função da sorção

Figura 4.34. Isotermas de sorção de colato no HDL calcinado à 298 e 288 K. a) Isotermas; b) Potencial Eletrocinético em função da sorção

Figura 4.35. Variação do $\mathrm{pH}$ do sobrenadante em função da sorção de colato em HDL, à 288, 298 e $323 K$.

Figura 4.36. DRXP para o HDL sorvido com colato em diferentes temperaturas. a) regenerado

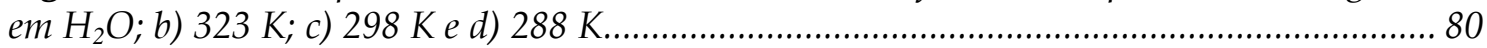

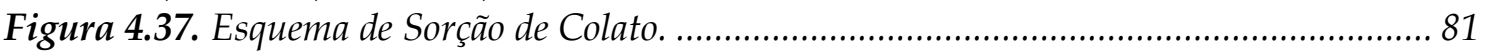
Figura 4.38. IV-TF para o HDL sorvido com colato em diferentes temperaturas. a) regenerado em $\mathrm{H}_{2} \mathrm{O}$; b) $323 \mathrm{~K}$; c) $298 \mathrm{Ke}$ d) $288 \mathrm{~K}$ 


\section{Índice de Tabelas}

Tabela 1.1: Combinações de cátions divalentes e trivalentes em HDL...................................... 7

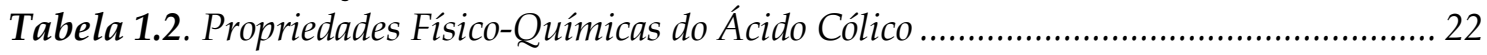

Tabela 3.1. Níveis dos fatores para os experimentos de adsorção ........................................... 35

Tabela 3.2. Matriz experimental para os experimentos de adsorção de colato em $\mathrm{MgAlCO}_{3}-$

HDL......

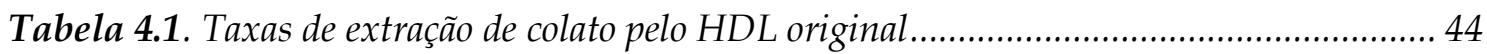

Tabela 4.2. Tamanho médio dos cristalitos para o HDL adsorvido com colato (estudo cinético)

Tabela 4.3. Taxas de extração de colato pelo HDL calcinado .................................................... 48

Tabela 4.4. Tamanho médio dos cristalitos para o HDL adsorvido com colato variando o pH e a

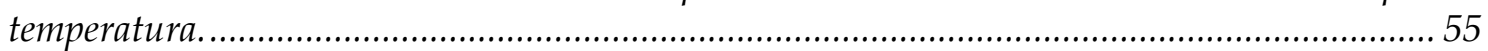

Tabela 4.5. Dados sobre a quantidade máxima adsorvida pelo HDL não-calcinado, em diversas condiçôes, considerando-se a influência da temperatura e do $\mathrm{pH}$............................................56

Tabela 4.6. Tamanho médio dos cristalitos para o HDL adsorvido com colato variando a força iônica e o $\mathrm{pH}$. 60

Tabela 4.7. Dados sobre a quantidade máxima adsorvida pelo HDL não-calcinado, em diversas condições, considerando-se a influência da temperatura e do $\mathrm{pH}$.....

Tabela 4.8. Tamanho médio dos cristalitos para o HDL adsorvido com colato variando a temperatura e a força iônica do meio.

Tabela 4.9. Dados sobre a quantidade máxima adsorvida pelo HDL não-calcinado, em diversas condições, considerando-se a influência da temperatura e da força iônica..... 66 Tabela 4.10. Matriz experimental para os experimentos de adsorção de colato em $\mathrm{MgAlCO}_{3}-$ HDL e suas variáveis respostas (adsorção máxima e eficiência de adsorção).

Tabela 4.11. Valores absolutos dos efeitos principais na adsorção de colato em $\mathrm{MgAlCO}_{3}-$ HDL e sua influência (em \%) no processo, baseado em duas respostas (adsorção máxima e eficiência de adsorção)

Tabela 4.12. Valores absolutos dos efeitos combinados na adsorção de colato em $\mathrm{MgAlCO}_{3}-$ HDL e sua influência (em \%) no processo baseado em duas respostas (adsorção máxima e eficiência de adsorção)

Tabela 4.13. Dados sobre a quantidade máxima adsorvida pelo HDL não-calcinado, em diversas condições (experimentos a $288 \mathrm{~K}$ ).

Tabela 4.14. Dados sobre a quantidade máxima sorvida pelo HDL calcinado, em diversas

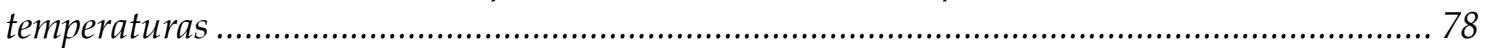

Tabela A.1. Detalhes sobre os reagentes utilizados...............................................................95 


\section{Introducão}

\section{1) Adsorção}

A adsorção pode ser descrita como fenômeno do acúmulo de espécies (adsorvato) sobre uma superfície (adsorvente).

A utilidade da adsorção tem uma longa história e sua primeira aplicação foi notada no Antigo Egito. No entanto, o uso racional do fenômeno, considerando os propósitos industriais, começou no século XVIII, quando o químico sueco Carl Wilhelm Scheele descobriu, em 1773, que gases ficavam aprisionados nos poros dos sólidos. Mais tarde, em 1794, o acadêmico russo Lowitz descobriu que o carvão, quando imerso em uma solução de ácido tartárico, mudava de cor pela adsorção dos contaminantes orgânicos.

A descoberta do processo de adsorção seletiva pelo cientista russo Tswett, em 1903, originou uma nova técnica analítica que é a adsorção cromatográfica. Tswett recomendou esse processo para a separação de várias misturas. Amplas investigações de adsorção continuaram durante a Primeira Guerra Mundial no sentido de proteger os seres humanos dos agentes tóxicos introduzidos no ar.

As experiências e pesquisas de guerra, feitas na década de 1930, levaram ao desenvolvimento de tecnologias para a obtenção de carvão ativo que é um dos adsorventes mais utilizados.

No presente, a produção de novos adsorventes, catalisadores e trocadores de íons são extremamente relacionados com ciência de materiais, que podem ser considerados como uma tecnologia estratégica para o século XXI. A teoria de adsorção iniciou-se com o trabalho fundamental de Langmuir e tem sido extensivamente estudada durante os últimos setenta anos e hoje constitui em um dos assuntos importantes da química moderna de superfície. ${ }^{1}$

A adsorção é um dos processos mais eficientes no tratamento de efluentes, empregado pelas indústrias para reduzir a concentração de compostos poluentes, tanto orgânicos como inorgânicos.

Poluentes orgânicos em solos e suprimentos de água potável têm se tornado sério problema ambiental. Proteção e recuperação de solos e aqüíferos contaminados por compostos orgânicos requerem esforços adicionais em pesquisa no desenvolvimento de 
materiais adsorventes naturais ou sintéticos que efetivamente removam esses poluentes. ${ }^{2}$ Ahmaruzzaman e Sharma (2005) utilizaram materiais de baixo custo como resíduos de carvão na adsorção de fenol em efluentes. Nesse estudo, foram usados os modelos de isoterma de Langmuir, de Freudlich e de Redlich-Peterson. ${ }^{3}$

Outros materiais adsorventes amplamente pesquisados são as zeólitas. As zeólitas são importantes adsorventes em processos comerciais incluindo o tratamento de água, a separação de gases, e craqueamento de hidrocarbonetos de cadeia longa para produzirem gasolina de alta octanagem. ${ }^{4}$

O processo de adsorção pode ser dividido em duas classes: adsorção física e adsorção química. Na adsorção física, também conhecida como fisiossorção, a interação entre adsorvente e adsorvato é do tipo de van der Waals. Essa interação tem como característica um longo alcance, porém fraca, sendo que a energia envolvida, quando uma partícula é assim adsorvida, é da mesma magnitude da entalpia de condensação. Na adsorção química, também conhecida como quimiossorção, as partículas se aderem à superfície por meio de uma ligação química (usualmente covalente) e tendem a ocupar sítios que maximizem seu número de coordenação com o substrato. A entalpia de quimiossorção é muito maior que a observada na fisiossorção. ${ }^{5}$

\section{2) Hidróxidos Duplos Lamelares (HDL)}

Os Hidróxidos Duplos Lamelares, tanto naturais quanto sintéticos, podem ser denominados de diversas maneiras, tais como: hidróxidos metálicos mistos, compostos do tipo hidrotalcita e argilas aniônicas.

Hidróxidos Duplos Lamelares são minerais pouco abundantes na natureza, sendo o mais comum a hidrotalcita, que é constituída principalmente de hidróxido duplo lamelar de magnésio e alumínio, contendo carbonato intercalado. Pode ser encontrado em depósitos salinos, o que evidencia que altas condições de temperatura e pressão não são absolutamente necessárias para sua obtenção. Minerais da família das argilas aniônicas são reportados por mineralogistas desde o início do século passado. Os principais relatos datam de 1926 (Kurnakov e Chernykh); 1930 (Aminoff e Broomè); 1933 (Read e Dixon) e 1941 (Frondell). Entretanto, o primeiro relato que trata da existência desses materiais ocorreu na Suécia em 1842, com a descoberta de um mineral 
branco que podia ser facilmente macerado resultando em um pó semelhante ao talco, daí o nome hidrotalcita. ${ }^{6-8}$

Devido ao grande número de combinações entre cátions e ânions possíveis, uma ampla gama de HDL pode ser obtida em laboratório. Esses compostos podem ser representados pela seguinte fórmula geral:

$$
\left[\mathrm{M}_{1-\mathrm{x}}^{\mathrm{II}} \mathrm{M}_{\mathrm{x}}^{\mathrm{III}}(\mathrm{OH})_{2}\right]^{+} \mathrm{A}_{\mathrm{x} / \mathrm{m}}^{\mathrm{m}-} \cdot \mathrm{nH}_{2} \mathrm{O}
$$

onde:

$\mathbf{M}^{\text {II }}$ representa um cátion divalente;

$\mathbf{M}^{\mathrm{III}}$ representa um cátion trivalente;

$\mathbf{A}^{\mathbf{m}-}$ representa o ânion intercalado com carga $\mathbf{~ m}^{-}$.

Que pode ser simplificada e representada por:

$$
\mathrm{M}^{\mathrm{II}} \mathrm{M}^{\mathrm{III}} \mathrm{A}-\mathrm{HDL}
$$

A princípio, a caracterização da estrutura dos HDL foi detalhadamente elaborada por Allmann ${ }^{9}$ e Taylor ${ }^{10}$ estudando monocristais de piroaurita e esjorgrenita. Entretanto, o HDL mais estudado até hoje é a hidrotalcita e seus similares sintéticos.

Para que se tenha um melhor entendimento da estrutura de um Hidróxido Duplo Lamelar, pode-se partir de um composto com estrutura bastante similar, a brucita, um mineral constituído de $\mathrm{Mg}(\mathrm{OH})_{2}$. Nesse mineral, os íons magnésio são octaédricamente coordenados por hidroxilas, com as unidades octaédricas compartilhando arestas, formando camadas infinitas, como representado na figura 1.1. Nesse caso, as camadas são empilhadas umas sobre as outras, por meio de ligações de hidrogênio.

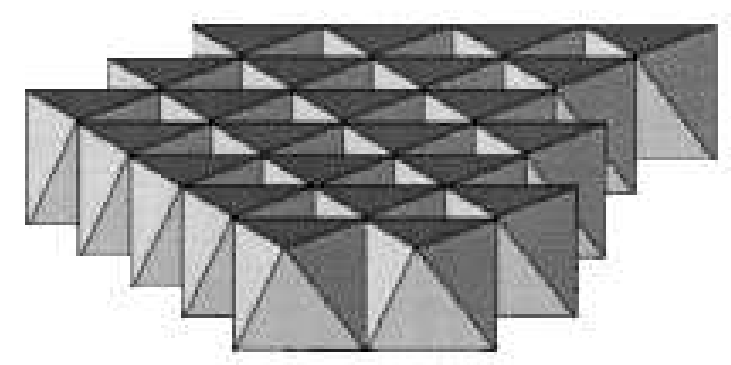

Figura 1.1. Representação esquemática de uma lamela de $\mathrm{Mg}(\mathrm{OH})_{2}$.

Se uma parcela dos íons magnésio na estrutura da brucita são isomórficamente substituídos por cátions de maior carga (cátions trivalentes, como por exemplo $\mathrm{Al}^{3+}$ ou 
$\mathrm{Cr}^{3+}$ ), então a carga da lamela passa a ser positiva, sendo necessário a presença de ânions para neutralizar essa carga. A intercalação de ânions hidratados, entre as lamelas, possibilitará o balanceamento dessa carga residual com o empilhamento das mesmas, resultando na estrutura característica dos Hidróxidos Duplos Lamelares, representada pela estrutura da hidrotalcita que está esquematizada na figura 1.2. Uma enorme variedade de ânions, orgânicos ou inorgânicos, pode ocupar o domínio interlamelar dos HDL.

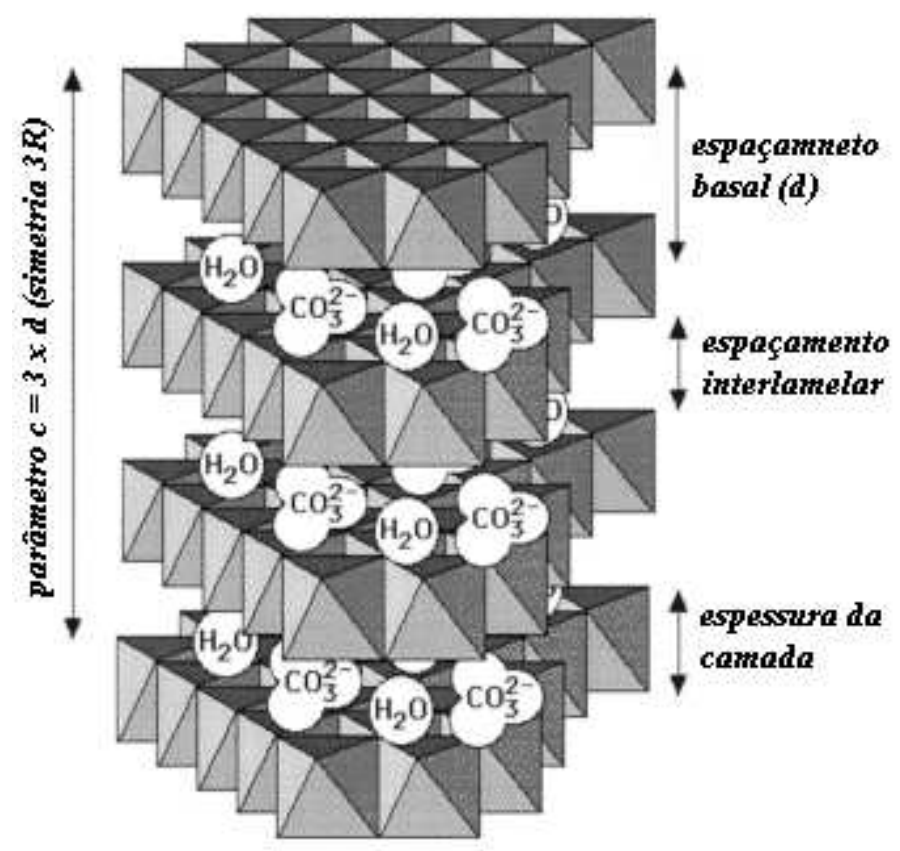

Figura 1.2. Representação esquemática da estrutura do tipo da hidrotalcita.

A estrutura descrita anteriormente (empilhamento de lamelas positivamente carregadas, neutralizadas por ânions no domínio interlamelar) é comum a todos os Hidróxidos Duplos Lamelares. ${ }^{10}$ Os HDL são classificados no sistema cristalino hexagonal, com exceção da proporção $\mathrm{M}^{\mathrm{II}} / \mathrm{M}^{\mathrm{III}}=1$, que pertence ao sistema ortorrômbico. A análise por difração de raios-X no pó resulta em difratogramas com padrões característicos, apresentando reflexões $(00 \ell)$ relacionadas com o empilhamento das camadas, reflexões $(h k 0)$ associadas à organização da estrutura no interior das lamelas e reflexões $(0 k \ell)$ relacionadas com a ordenação de uma lamela em relação à outra. Conforme a ordenação do empilhamento no sistema hexagonal são possíveis três polítipos: 3R, com distância interlamelar igual a c/3, encontrados na maioria dos HDL naturais ou sintéticos; $2 \mathrm{H}$, com distância interlamelar igual a c/2, mais raro e associado 
à formação em altas temperaturas e pressões ${ }^{7,11}$ e $1 \mathrm{H}$, com distância interlamelar igual a c, bastante raro e associado a HDL altamente hidratados, freqüentemente intercalados com ânion sulfato $(\mathrm{d} \approx 11 \AA$ A). A figura 1.3 ilustra a diferença entre os politipos apresentados.
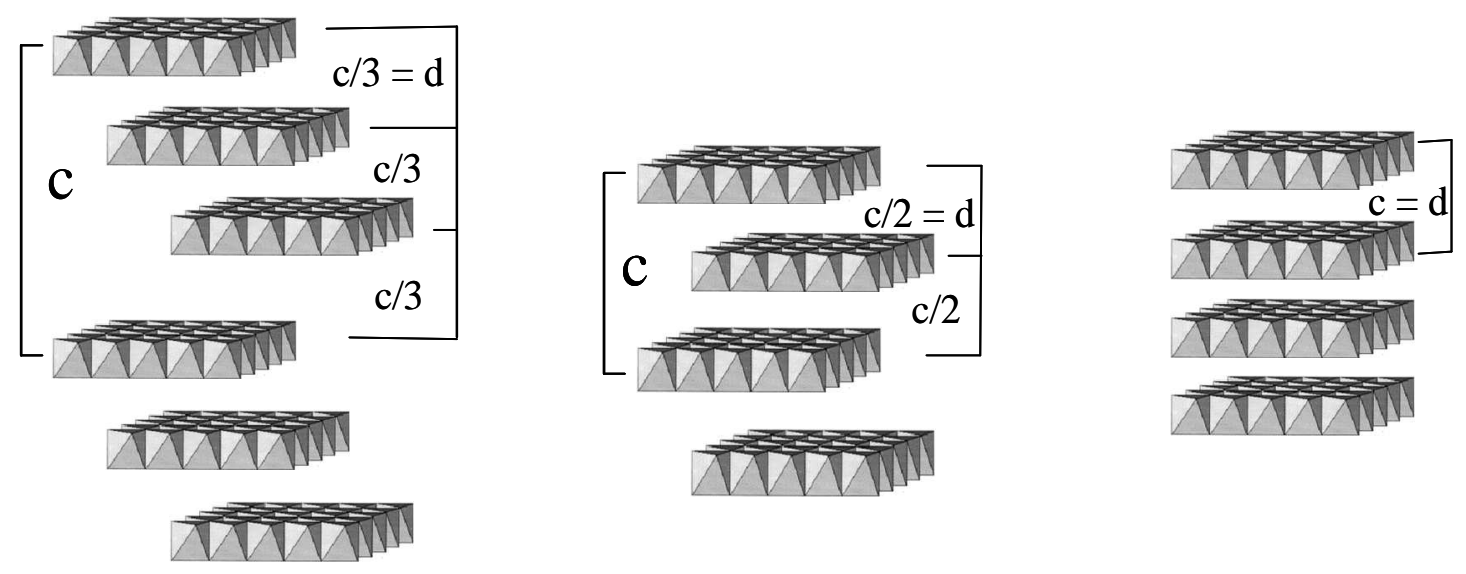

Figura 1.3. Representação esquemática dos polítipos obtidos para os HDL.

O espaçamento basal para um HDL com simetria 3R é igual à espessura da camada mais o tamanho do ânion interlamelar. Essa espessura da camada varia, numa faixa de 4,5 a 4,8 $\AA$, com a composição dos cations. A distância interlamelar depende da dimensão, da orientação dos ânions entre as camadas, da hidratação e da interação entre os mesmos. Quando a simetria é do tipo $1 \mathrm{H}$ ou $2 \mathrm{H}$, o resultado da soma da espessura da lamela com o tamanho do ânion interlamelar é menor que o espaçamento basal obtido. Feitknecht ${ }^{12}$ atribui este fato à presença de moléculas de água entre o ânion e a lamela.

Os cátions metálicos formadores da estrutura devem apresentar coordenação octaédrica e uma faixa de raio iônico normalmente entre 0,50 e 0,74 $\AA$. Em alguns casos, os cátions podem apresentar coordenação tetraédrica, entretanto, a estabilização das camadas é menor. ${ }^{13-16}$ A tabela 1.1 apresenta combinações de cátions utilizados na obtenção de HDL. ${ }^{6}$ 
Tabela 1.1: Combinações de cátions divalentes e trivalentes em HDL.

\begin{tabular}{|c|c|c|c|c|c|c|c|c|c|c|c|c|c|c|c|}
\hline Cátion & \multicolumn{15}{|c|}{ Trivalente } \\
\hline Divalente & Al & $\mathrm{Fe}$ & $\mathrm{Cr}$ & Co & Mn & $\mathrm{Ni}$ & Sc & Ga & $\mathrm{Ti}^{*}$ & La & V & Sb & $\mathbf{Y}$ & In & $Z r^{\star}$ \\
\hline Mg & $\checkmark$ & $\checkmark$ & $\checkmark$ & $\checkmark$ & $\checkmark$ & & $\checkmark$ & $\checkmark$ & & $\checkmark$ & $\checkmark$ & $\checkmark$ & $\checkmark$ & $\checkmark$ & $\checkmark$ \\
\hline $\mathbf{N i}$ & $\checkmark$ & $\checkmark$ & $\checkmark$ & $\checkmark$ & $\checkmark$ & $\checkmark$ & & $\checkmark$ & & $\checkmark$ & & & & & \\
\hline Zn & $\checkmark$ & & $\checkmark$ & & & $\checkmark$ & & & & & & & & & \\
\hline $\mathrm{Cu}$ & $\checkmark$ & & $\checkmark$ & & & & & & & & & & & & \\
\hline Co & $\checkmark$ & $\checkmark$ & $\checkmark$ & $\checkmark$ & & & & & $\checkmark$ & $\checkmark$ & & & & & \\
\hline Mn & $\checkmark$ & & $\checkmark$ & & $\checkmark$ & & & $\checkmark$ & & & & & & & \\
\hline $\mathrm{Fe}$ & $\checkmark$ & $\checkmark$ & & & & & & & & & & & & & \\
\hline $\mathrm{Ca}$ & $\checkmark$ & & & & & & & & & & & & & & \\
\hline $\mathrm{Li}^{\star \star}$ & $\checkmark$ & & & & & & & & & & & & & & \\
\hline Cd & $\checkmark$ & & & & & & & & & & & & & & \\
\hline
\end{tabular}

A razão entre os cátions di e trivalentes $\left(\mathrm{M}^{\mathrm{II}} / \mathrm{M}^{\mathrm{III}}\right)$ nos HDL pode variar em um intervalo de 1 a 6 , correspondendo a uma faixa de $0,14 \leq \mathrm{x} \leq 0,5$ no parâmetro $\mathrm{x}$ da fórmula geral (onde $\left.\mathrm{x}=\mathrm{M}^{\mathrm{III}} /\left(\mathrm{M}^{\mathrm{II}}+\mathrm{M}^{\mathrm{III}}\right)\right)^{17}$. Essa razão determina a densidade de carga da lamela do HDL, e tem influência sobre propriedades como organização estrutural e capacidade de troca iônica. Uma redução nesta razão resulta num aumento da densidade de carga da lamela e, conseqüentemente, a intercalação de uma quantidade relativamente maior de ânions, uma vez que para cada cátion trivalente tem-se na intercamada uma quantidade equivalente (em termos de cargas) de ânions. Um aumento dessa razão implica na redução da densidade de carga e, portanto na quantidade relativa de ânions. Nesse caso, os ânions podem estar suficientemente espaçados para que poros sejam formados entre eles, disponibilizando assim a área interna dos HDL. De acordo com Vaccari, somente é possível obter HDL puros com uma razão entre os cátions de $0,2 \leq x \geq 0,34$. Para razões fora deste intervalo, compostos com diferentes estruturas têm sido observados ${ }^{7}$. Em HDL como os de $\mathrm{Mg}$ e $\mathrm{Al}$ formados com valores de $\mathrm{x}$ menores que 0,33, os octaedros de Al não são vizinhos. Quando o valor de x aumenta, ocorre um aumento no número de octaedros de $\mathrm{Al}$ vizinhos, conduzindo à formação de $\mathrm{Al}(\mathrm{OH})_{3}$. Do mesmo modo, baixos valores de $\mathrm{x}$ produzem uma alta densidade nos octaedros de $\mathrm{Mg}$ das lamelas do HDL, que atuam como um núcleo para a formação de $\mathrm{Mg}(\mathrm{OH})_{2}$.

Estudos empregando difração de raios-X em monocristal ${ }^{9},{ }^{1} \mathrm{H} \mathrm{RMN}^{18,19}$ e EXAFS $^{20}$ revelam a natureza altamente desordenada do domínio interlamelar. Os ânions e as moléculas de água na região interlamelar são dispostos ao acaso e são livres para se 
mover pela quebra de suas interações (ligações de hidrogênio) e formação de outras ${ }^{7}$. Baseado nesse comportamento, muitos autores consideram o domínio interlamelar dos HDL como um estado quase líquido. ${ }^{6,9,20}$

A natureza dos ânions capazes de compensar a carga residual positiva das lamelas dos HDL é quase ilimitada. Entretanto, quando o ânion de interesse não é carbonato, torna-se mais difícil obter materiais puros e cristalinos, pois é preciso evitar, durante a síntese, a contaminação da solução aquosa por esses ânions oriundos do $\mathrm{CO}_{2}$ $\operatorname{atmosférico~}^{21}$.

Uma ampla variedade de ânions já foi intercalada dentre elas: ânions inorgânicos $\left(\mathrm{F}^{-}, \mathrm{Cl}^{-}, \mathrm{Br}^{-}, \mathrm{I}^{-},\left(\mathrm{ClO}_{4}\right)^{-},\left(\mathrm{NO}_{3}\right)^{-},\left(\mathrm{ClO}_{3}\right)^{-},\left(\mathrm{IO}_{3}\right)^{-}, \mathrm{OH}^{-},\left(\mathrm{CO}_{3}\right)^{-},\left(\mathrm{SO}_{4}\right)^{-},\left(\mathrm{S}_{2} \mathrm{O}_{3}\right)^{2-},\left(\mathrm{WO}_{4}\right)^{2-}\right.$, $\left.\left(\mathrm{CrO}_{4}\right)^{2-}\right)$; ânions complexos $\left(\left[\mathrm{Fe}(\mathrm{CN})_{6}\right]^{3-},\left[\mathrm{Fe}(\mathrm{CN})_{6}\right]^{4-},\left[\mathrm{SiO}(\mathrm{OH})_{3}\right]^{-}\right)$; ânions organoinorgânicos (sulfatos, sulfonatos, fosfonatos); carboxilatos (tereftalato, benzoato, ânions de ácidos graxos); polímeros aniônicos (poli(acrilato), poli(acrilonitrila), poli(estireno-sulfonato)); macrociclos (ftalocianinas e porfirinas); compostos lamelares $\left(\left(\mathrm{Mg}_{2} \mathrm{Al}(\mathrm{OH})^{6+} \cdot\left[\mathrm{Mg}_{3}(\mathrm{OH})_{2} / \mathrm{Si}_{3} \mathrm{AlO}_{10}\right]^{-}\right)\right.$; biomoléculas (peptídeos, ATP); dentre outras.

Na preparação de HDL, um fator de extrema importância é a capacidade de estabilização da estrutura lamelar que o ânion a ser intercalado apresenta. Quanto maior essa capacidade, mais facilmente o HDL se formará. Ânions inorgânicos simples seguem a seguinte seqüência de interação (e, conseqüentemente, facilidade de intercalação) com as lamelas:

$$
\mathrm{CO}_{3}{ }^{2-}>\mathrm{OH}^{-}>\mathrm{F}^{-}>\mathrm{Cl}^{-}>\mathrm{SO}_{4}^{-}>\mathrm{Br}^{-}>\mathrm{NO}_{3}^{-}>\mathrm{I}^{-}
$$

A estrutura dos HDL é altamente influenciada pela natureza (tamanho, carga, geometria) e a distribuição (orientação em relação às lamelas) dos ânions intercalados, determinando o espaçamento interlamelar ${ }^{6,22}$.

As moléculas de água nos HDL encontram-se no domínio interlamelar, juntamente com os ânions (águas de hidratação, ou intrínseca) e também entre os cristalitos e adsorvida na superfície (extrínseca). As moléculas intrínsecas fazem parte da estrutura cristalina do HDL, enquanto que as extrínsecas têm sua quantidade dependente da umidade relativa da atmosfera com a qual o HDL está em contato. ${ }^{6,23} \mathrm{O}$ estado de hidratação global é dado pela soma das moléculas presentes nos domínios intrínseco e extrínseco. A figura 1.4 mostra uma esquematização dos domínios das moléculas de água nos HDL. 


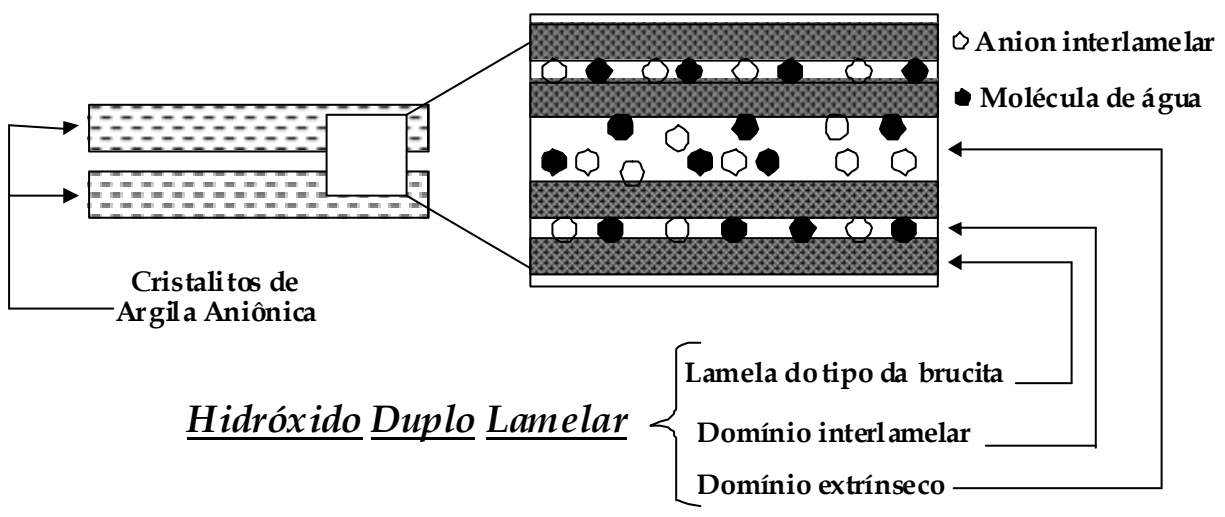

Figura 1.4. Representação esquemática dos domínios contendo água nos HDL.

A quantidade de água nos HDL é determinada por análise termogravimétrica e a perda de água de hidratação ocorre numa faixa de temperatura ${ }^{24}$. As temperaturas limites desta faixa são relacionadas com a composição e o método de síntese do material. HDL que foram secos a vácuo ou ao ar, começam a perder água desde a temperatura ambiente. HDL com cristalitos muito pequenos tendem a adsorver grandes quantidades de água da atmosfera. Muitos autores consideram a massa perdida pelo HDL, até aproximadamente $373 \mathrm{~K}$, como proveniente da água adsorvida (extrínseca). ${ }^{7,25-27}$

Os HDL não apresentam propriedades de expansão interlamelar para intercalar moléculas neutras e grandes quantidades de água, devido à forte interação eletrostática entre as lamelas e os ânions interlamelares. ${ }^{17} \mathrm{~A}$ inserção de moléculas polares é possível, quando as lamelas são separadas por ânions volumosos intercalados, como o composto $\mathrm{Zn}_{2} \mathrm{Cr}(\mathrm{OH})_{6}\left(\mathrm{C}_{12} \mathrm{H}_{25} \mathrm{SO}_{4}\right) \cdot 12 \mathrm{H}_{2} \mathrm{O}$, com espaçamento basal de $26,15 \AA$, que expande este espaçamento para 44,9 $\AA$ em presença de $\mathrm{C}_{16} \mathrm{H}_{33} \mathrm{OH}{ }^{23}$ No caso de tensoativos aniônicos, a orientação do ânion ocorre de modo que a cabeça polar fique próxima da lamela e a calda apolar, voltada para o interior do domínio interlamelar gerando uma região hidrofóbica na intercamada. ${ }^{22}$ Existe ainda na literatura uma revisão que trata da presença de sais neutros como $\mathrm{MgSO}_{4}, \mathrm{NiSO}_{4}$ e $\mathrm{Na}_{2} \mathrm{SO}_{4}$, em argilas aniônicas naturais. ${ }^{17}$

\section{3) Propriedades e Aplicações dos Hidróxidos Duplos Lamelares.}

Devido à grande variedade de combinações possíveis entre cátions e ânions, os HDL apresentam notáveis propriedades estruturais, químicas e físicas que conferem a 
estes materiais e seus produtos de decomposição térmica, uma gama de aplicações bastante extensa em áreas diversificadas. Algumas das principais áreas de aplicação dos HDL são mostradas na figura $1.5 .^{7}$

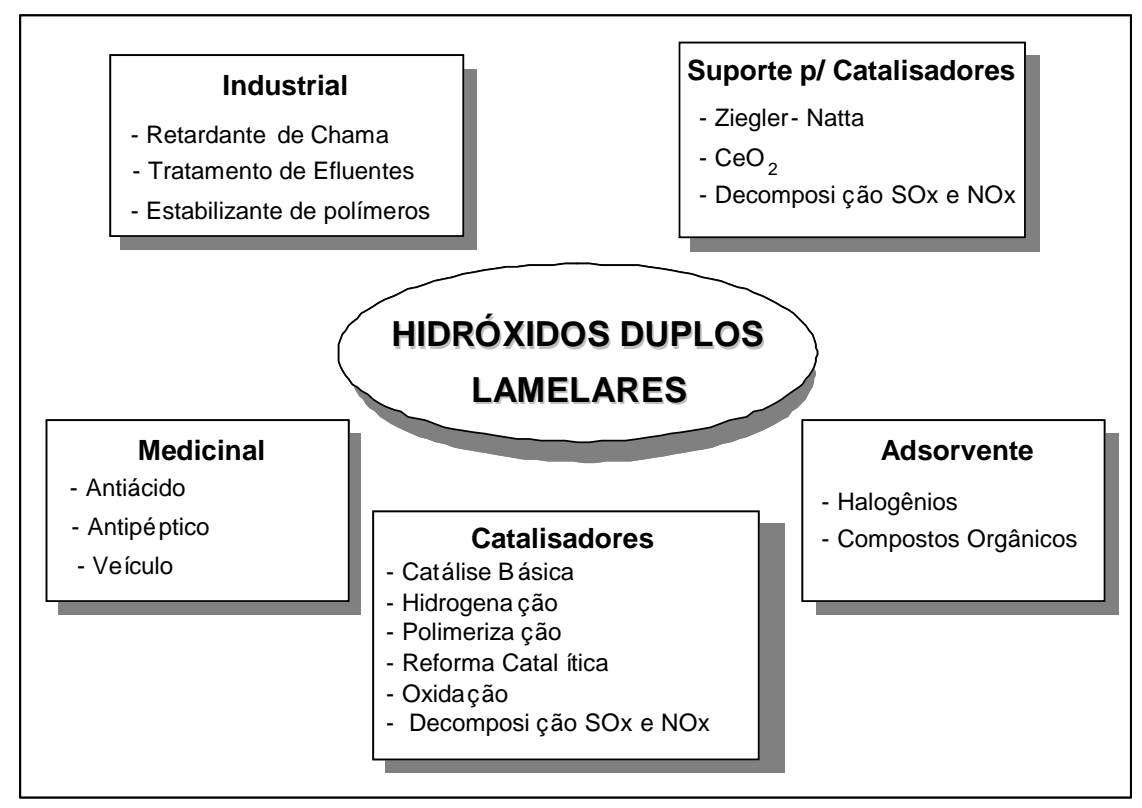

Figura 1.5. Algumas das principais áreas de aplicação dos $H D L$.

Os produtos de decomposição térmica obtidos pelo processo de calcinação do HDL são os óxidos metálicos $\left(\mathrm{M}^{2+} \mathrm{O}\right)$ e óxidos mistos $\left(\mathrm{M}^{2+} \mathrm{M}^{3+}\right)_{2} \mathrm{O}_{4}$, além da possibilidade de formação de espinélios como $\mathrm{MgAl}_{2} \mathrm{O}_{4}$, quando calcinados em temperaturas entre 873 e 1073 K. A estabilidade térmica desses materiais é avaliada por análise termogravimétrica e térmica diferencial. Entretanto, é difícil descrever um comportamento geral para a decomposição térmica, por causa da diversidade de composição apresentada por estes materiais. ${ }^{6,7,28}$

A hidrotalcita e seus similares sintéticos são os HDL mais estudados quanto a sua estabilidade térmica. ${ }^{29}$ As etapas e a sequiência de decomposição térmica podem variar conforme a razão entre os cátions ${ }^{30}$, mas, de um modo geral, obedece à sequiência: $i$ ) a perda de água adsorvida; $i i)$ a perda da água de hidratação; iii) a decomposição de parte dos grupos hidroxilas (desidroxilação) e decomposição do ânion interlamelar; iv) a decomposição dos grupos hidroxilas residuais. Em muitos casos, essas faixas se sobrepõem, tornando impossível uma distinção clara entre as mesmas. ${ }^{11,31}$

Os óxi-hidróxidos obtidos por calcinação apresentam superfície básica, sendo excelentes catalisadores heterogêneos. Os de $\mathrm{Mg}$-Al, por exemplo, têm importância particular, pois podem substituir compostos alcalinos, no desenvolvimento de catalisadores sólidos que não afetam o meio ambiente e são facilmente reciclados. 
Ainda em catálise, os HDL são empregados como suporte para catalisadores, podendo suportá-los de duas formas: $i$ ) adsorvido na superfície do HDL ou ii) intercalado entre as lamelas de hidróxido duplo lamelar. ${ }^{31-33}$

Os HDL também são aplicados como estabilizadores para polímeros como, por exemplo, polietileno (PE), polipropileno (PP) e poli-(cloreto de vinila) (PVC), trazendo como benefícios maior resistência térmica, maior resistência à chama e maior estabilidade frente à radiação ultravioleta. Podem agir como retardantes de chama por dois modos de ação: $i$ ) pela diluição do polímero, reduzindo a quantidade total de material que pode entrar em combustão, e ii) pela liberação de uma grande quantidade de gases não combustíveis $\left(\mathrm{CO}_{2}\right.$ e $\left.\mathrm{H}_{2} \mathrm{O}\right)$ quando aquecidos, reduzindo a concentração de $\mathrm{O}_{2}$ na superfície do material em combustão. ${ }^{7,34}$

A condutividade elétrica dos HDL está ligada à mobilidade dos ânions interlamelares. Estudos revelam que a condutividade de alguns ânions em HDL de [Zn$\mathrm{Cr}-\mathrm{A}]$, onde $\mathrm{A}$ é $\mathrm{F}^{-}, \mathrm{Cl}^{-}, \mathrm{Br}^{-}, \mathrm{I}^{-}, \mathrm{CO}_{3}^{2-}, \mathrm{NO}_{3}^{-}$, ou $\mathrm{OH}^{-}$, está relacionada com a relação carga/raio dos ânions e também com a sua geometria. ${ }^{35}$ Os HDL têm sido empregados na preparação de eletrodos modificados, com vantagens sobre eletrodos comerciais, como: maior estabilidade química e mecânica, melhor capacidade de transferência de carga, tornando a reação eletroquímica mais facilmente reversível, e superfície de recobrimento do eletrodo bastante homogênea. A intercalação de ânions eletroativos em HDL tem possibilitado estudos eletroquímicos comparativos entre o ânion intercalado na matriz do HDL (eletrodo modificado) e o ânion livre. Também tem sido investigada a influência do tipo e da proporção dos cátions metálicos $\mathrm{M}^{\mathrm{II}}$ e $\mathrm{M}^{\mathrm{III}}$ neste tipo de material. ${ }^{36,37}$

As propriedades texturais são influenciadas pelas variáveis no processo de síntese tais como: tempo e temperatura do tratamento hidrotérmico, velocidade de adição e concentração das soluções utilizadas. Essas variáveis afetam a coagulação, a forma e a porosidade das partículas obtidas, dificultando uma generalização. Os parâmetros mais freqüentemente observados serão discutidos a seguir.

A porosidade e a área superficial específica dos HDL são de grande importância para sua aplicabilidade como adsorventes e catalisadores. Na literatura científica, encontram-se valores na faixa de 50 a $100 \mathrm{~m}^{2} \mathrm{~g}^{-1}$ para este tipo de material ${ }^{6,7}$, sendo que o domínio interlamelar não está disponível devido a sua alta densidade de carga, estabilizada pela presença de ânions e moléculas de água. Quando ânions orgânicos são 
intercalados, estes valores tendem a diminuir pela possibilidade de adsorção destes ânions na superfície, preenchendo os poros de menor diâmetro. ${ }^{22,38}$ Quando a síntese é realizada em temperaturas mais altas, uma diminuição na área superficial é observada, podendo chegar até apenas $12 \mathrm{~m}^{2} \mathrm{~g}^{-1} \cdot{ }^{25}$

Os poros são superficiais, não interconectados e situados nas faixas de microporos $(\phi<20 \AA)$ e mesoporos $(20<\phi<500 \AA) .{ }^{11,39,40}$ Em HDL puros, obtêm-se poros com diâmetros entre 75 e $300 \AA$ A. Quando calcinados a 723 K, observa-se um grande número de poros entre 20 e $40 \AA$, resultando em um considerável aumento na área superficial. ${ }^{39}$

A morfologia, avaliada por microscopia eletrônica de varredura e transmissão, mostra partículas achatadas, como escamas, podendo exibir partículas muito pequenas, em formato de esferas, em casos onde o material é pouco ordenado. ${ }^{39,41-43}$

O tamanho de partículas dos HDL tem sido pouco estudado e comentado na literatura, encontrando-se apenas medidas obtidas através da largura à meia altura dos picos obtidos no difratograma de raios-X no pó. Essa técnica não considera a agregação entre os cristalitos, de modo que um valor médio, e não uma distribuição do tamanho das partículas é calculado. Os valores assim reportados variam entre 134 e $1653 \AA$, para um $\mathrm{Mg}-\mathrm{Al}-\mathrm{CO}_{3}-\mathrm{HDL}(\mathrm{Mg} / \mathrm{Al}=3)$, com tratamento hidrotérmico, variando entre $313 \mathrm{e}$ $473 \mathrm{~K}^{7}$

A capacidade de troca aniônica dos HDL é uma propriedade dependente da razão entre os cátions metálicos $\mathrm{M}^{\mathrm{II}}$ e $\mathrm{M}^{\mathrm{III}}$ e da massa molecular dos cátions e ânions envolvidos. Entretanto, a troca nunca é $100 \%$ efetiva, devido a fatores como a capacidade dos ânions envolvidos em estabilizar a estrutura lamelar. ${ }^{44}$ A reação de troca iônica é realizada por meio do simples contato por um tempo determinado (> 24 horas) de uma suspensão do HDL precursor em solução aquosa, contendo excesso do ânion de interesse. $\mathrm{O}$ pH da solução pode favorecer ou não a troca e deve ser compatível com a faixa de estabilidade do HDL precursor e do ânion. ${ }^{45}$

O termo "efeito memória" descreve a propriedade de regeneração da estrutura lamelar, característica apenas em HDL dos sistemas Mg-Al e Zn-Al intercalados com ânions que se decompõem termicamente. Quando calcinados à temperatura adequada (determinada por análise termogravimétrica e normalmente variando entre 673 e $823 \mathrm{~K}$ ), esses materiais formam oxi-hidróxidos mistos, que ao serem colocados em uma solução aquosa, podem intercalar os ânions ali presentes, formando um novo HDL intercalado com os ânions que se encontravam em solução. Essa propriedade depende da temperatura de calcinação, pois acima de $873 \mathrm{~K}$, os HDL perdem a capacidade de 
regeneração, devido à decomposição completa das hidroxilas, produzindo fases cristalinas estáveis dos óxidos. Em HDL dos sistemas mencionados, a etapa de eliminação de água não causa mudanças na morfologia cristalina, ou esfoliação da estrutura lamelar, preservando a microestrutura lamelar após a decomposição térmica e possibilitando a reconstituição da estrutura lamelar do precursor com um ânion interlamelar de interesse. ${ }^{46}$

A regeneração estrutural pode ocorrer pelo contato com água, do óxido misto formado após a calcinação, produzindo um HDL intercalado com grupos hidroxilas provenientes da hidrólise. A regeneração também pode ocorrer pela simples exposição da suspensão aquosa do HDL calcinado ao dióxido de carbono da atmosfera, com intercalação de ânions carbonato. ${ }^{17}$

A região interlamelar dos HDL fornece um novo meio para reações fotoquímicas de moléculas fotoativas. As propriedades fotoquímicas e fotofísicas de compostos intercalados têm mostrado a ocorrência de fotodimerização e fotoisomerização entre as lamelas. $^{47}$

$\mathrm{Na}$ área farmacêutica, as aplicações concentram-se nos agentes atuantes no suco gástrico (antiácidos), mais especificamente com $\mathrm{MgAlCO}_{3}$-HDL. Estudos realizados in vitro e in vivo confirmam a eficácia do HDL como antiácido, atuando na inibição da ação do $\mathrm{HCl}$ e da pepsina no suco gástrico. ${ }^{48-50}$

Uma outra aplicação no campo medicinal tem sido como veículo na administração de drogas. A droga pode ser apenas misturada ou intercalada (se for um ânion) no HDL. Em ambos os casos, o HDL atua como veículo e também como antiácido, minimizando efeitos colaterais como irritação da mucosa do estômago. Se a droga é intercalada no HDL, tem-se ainda a vantagem da liberação gradual da mesma. ${ }^{51-53}$

\section{4) Hidróxidos Duplos Lamelares como adsorventes}

Os HDL têm sido utilizados como adsorventes em vários processos, para remoção de diferentes espécies aniônicas de soluções aquosas. Dentre essas utilizações, podemos destacar: a remoção de ânions de água utilizada para refrigeração de reatores nucleares, remoção de óxidos de enxofre de misturas gasosas, remoção de corantes de suco de beterraba na fabricação de açúcar, purificação da cicloexanona pela remoção de subprodutos ácidos orgânicos, dentre outras. ${ }^{7}$ 
São três os mecanismos de remoção de compostos em soluções: adsorção, absorção e sorção. A adsorção é um processo relacionado com interações entre o adsorvato e a superfície do adsorvente, interações essas que podem ser físicas e/ou químicas. Nesse caso não há alteração da estrutura do adsorvente. Normalmente, o HDL utilizado é aquele em que o ânion interlamelar possui baixa tendência à troca, como o carbonato.

A absorção acontece quando o substrato entra na estrutura interna do sólido. A absorção pode ocorrer através da regeneração de um HDL previamente calcinado, ou pela substituição do ânion interlamelar.

A sorção ocorre na regeneração de um precursor calcinado de HDL que apresenta a propriedade "efeito memória". Neste caso, o processo de sorção envolve a absorção do ânion no domínio interlamelar, acompanhado de adsorção do mesmo na superfície do material regenerado. A sorção pode ocorrer também pelo processo de troca aniônica concomitante com a adsorção, no material sem ser calcinado, quando o ânion interlamelar tem menor capacidade de estabilização das lamelas do que o ânion que foi adicionado à suspensão.

O que se observa normalmente é a contribuição de mais de um desses processos na remoção de compostos de uma dada solução. Finalmente, a própria síntese direta de HDL tem sido utilizada para remoção de ânions e cátions de soluções, por meio da formação de compostos intercalados com os mesmos. ${ }^{7}$

Exemplos recentes do uso de HDL como adsorventes incluem a separação de gases $^{54,55}$, e a remoção de tensoativos ${ }^{56,57}$ e crômio (VI) ${ }^{58}$ de soluções aquosas. No caso da remoção de tensoativos, foi constatado que os HDL apresentam uma capacidade de adsorção muito maior que adsorventes comerciais, como a alumina. Exemplos da remoção de contaminantes de soluções aquosas por sorção ou troca iônica incluem tensoativos ${ }^{59}$, crômio $(\mathrm{VI})^{60}$, iodeto ${ }^{61,62}$, tetraóxido de Tecnécio $\left(\mathrm{TcO}_{4}^{-}\right)$e tetraóxido de Rênio $\left(\mathrm{ReO}_{4}^{-}\right)^{62}$, triclorofenol e trinitrofenol. ${ }^{63}$

\section{5) Síntese dos Hidróxidos Duplos Lamelares}

Desde o primeiro trabalho ${ }^{64}$, publicado em 1942, vários métodos foram desenvolvidos e vêm sendo empregados na síntese de HDL. Apesar de serem raros na natureza, a preparação de HDL em escala laboratorial ou industrial é relativamente 
simples e economicamente viável. Os métodos de síntese de HDL podem ser escolhidos em função da composição requerida e classificados em duas categorias: i) métodos diretos (método sal-base, método sal-óxido, síntese hidrotérmica, hidrólise induzida, síntese eletroquímica, método sol-gel) ${ }^{6,7,11,24}$ e ii) métodos indiretos: (método de troca iônica em solução, troca iônica em meio ácido, troca iônica por regeneração de material calcinado e troca aniônica com a formação de um sal entre os tensoativos.)

\subsection{1) Métodos de Síntese Direta}

O método do sal-base ou coprecipitação é e mais utilizado na síntese de HDL. Este consiste na precipitação simultânea do hidróxido de dois ou mais cátions metálicos di e trivalentes. Pode ser empregado de duas maneiras diferentes: coprecipitação a pH variável (crescente ou decrescente) e coprecipitação a pH constante. , $7,11,68^{-10}$

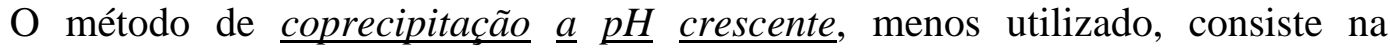
titulação de uma solução alcalina $\left(\mathrm{NaOH}\right.$ e/ou $\left.\mathrm{Na}_{2} \mathrm{CO}_{3}\right)$ contendo o ânion a ser intercalado sobre uma solução de sais dos cátions. Sua desvantagem é a dificuldade em

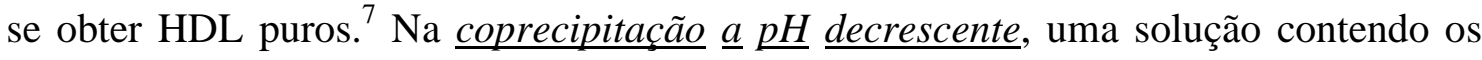
sais dos cátions é adicionada sobre outra, contendo base e o ânion a ser intercalado. É um método simples que apresenta ótimos resultados, principalmente na síntese de HDL contendo ânions simples como carbonato.

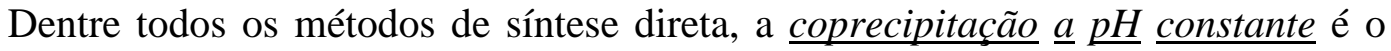
mais utilizado para preparar HDL, quando se faz necessário um bom controle das condições de síntese. Consiste na adição de uma solução contendo sais dos cátions sobre uma solução contendo o ânion a ser intercalado, onde o pH é mantido constante pela adição concomitante de uma solução de $\mathrm{NaOH}$ ou KOH. Esse método permite a obtenção de condições ótimas para a síntese de materiais cristalinos e puros. ${ }^{6,7,22}$

Para se obter um material mais bem ordenado, é importante controlar variáveis como: concentração, velocidade de adição, grau de agitação, o pH final da suspensão obtida (método de $\mathrm{pH}$ variável), o pH durante a adição (método de $\mathrm{pH}$ constante) e a temperatura durante a síntese. Na maioria dos casos, a coprecipitação é feita à temperatura ambiente (inferior a $303 \mathrm{~K}$ ). A adição é normalmente realizada sob forte agitação.

Muitas vezes, a otimização dos métodos de síntese não basta para a obtenção de HDL bem ordenados e com boa pureza de fase. O tratamento hidrotérmico (TH) é 


\section{Introdução}

normalmente empregado para melhorar a organização estrutural do precipitado. Logo após a precipitação, o sólido é lavado para retirada dos precursores não reagidos e outros possíveis contaminantes. Em seguida, é suspenso novamente em água deionizada (ou em uma solução concentrada do ânion de interesse) e colocado em um reator, onde é mantido sobre temperatura e pressão controladas. ${ }^{7,69} \mathrm{Na}$ maioria dos casos, o tratamento hidrotérmico, na presença do vapor de água, aumenta muito a organização estrutural do HDL, desde que a temperatura de decomposição do material não seja atingida.

Miyata e colaboradores estudaram o efeito do tratamento hidrotérmico em HDL do sistema $\left[\mathrm{Mg}-\mathrm{Al}-\mathrm{CO}_{3}\right]$. Os resultados indicaram um aumento no tamanho dos cristais com o aumento da temperatura e tempo de tratamento. ${ }^{7}$

O método do $\underline{\text { sal-óxido }}^{6,70}$ consiste na reação entre uma suspensão formada pelo óxido do metal divalente que é titulada com uma solução de um sal formado pelo ânion que se deseja intercalar e o cátion trivalente, mantendo-se o $\mathrm{pH}$ levemente ácido (entre 5 e 6) propiciando a hidrólise lenta do óxido do cátion bivalente. Apresenta excelentes resultados, porém algumas limitações o tornam restrito a poucas combinações de cátions e ânions, sendo impossível a síntese de HDL contendo carbonato, hidroxila ou carboxilatos intercalados por este método.

Na síntese hidrotérmica, os cátions di e trivalentes, na forma de seus óxidos, são suspensos em água e sobre essa suspensão é adicionada uma solução do ácido, cuja base conjugada é o ânion que se pretende intercalar. Essa reação é realizada sempre em altas pressões e temperaturas. Apesar de ser um método eficiente, é pouco utilizado, pois existem métodos mais simples com resultados semelhantes. Sua principal vantagem é evitar a presença de sais. ${ }^{26,39}$

Na $\underline{\text { hidrólise }} \underline{\text { induzida }}^{71}$, a síntese é realizada com uma solução do cátion que precipita em $\mathrm{pH}$ mais baixo (normalmente $\mathrm{M}^{\mathrm{III}}$ ) e elevando-se o $\mathrm{pH}$ até um valor pouco abaixo (0,2 unidades) daquele em que o outro cátion precipitaria formando hidróxido. Então, uma solução contendo o $\mathrm{M}^{\mathrm{II}}$ é adicionada. A hidrólise com incorporação do cátion $\mathrm{M}^{\mathrm{III}}$ à estrutura do hidróxido ocorre lentamente, provocando uma redução no $\mathrm{pH}$, que é corrigido pela adição de $\mathrm{NaOH}$ ou $\mathrm{KOH}$ até ficar constante. As principais desvantagens são: baixa organização estrutural dos materiais obtidos, longo tempo de síntese e a presença de impurezas.

No método de síntese eletroquímica, um eletrodo de níquel metálico (ou platina) é colocado em uma solução contendo nitrato de níquel e nitrato do metal trivalente. $\mathrm{O}$ 
nitrato é reduzido, formando hidroxila e precipitando o hidróxido duplo lamelar na superfície deste eletrodo. Os HDL assim obtidos não são de boa qualidade, principalmente quanto à organização estrutural, porém existe a possibilidade de aplicação posterior do eletrodo formado. ${ }^{72,73}$

No método sol-gel, ocorre a reação de uma solução alcoólica de etóxido de magnésio dissolvida em $\mathrm{HCl}$ com uma solução contendo tri-sec-butóxido de alumínio. A mistura é aquecida em refluxo e agitada até formação do gel. Os materiais preparados por este método têm tamanho de poro controlado e elevada área superficial específica, sendo o único método, diferente da coprecipitação, utilizado industrialmente para síntese de HDL, pois tem a vantagem de produzir materiais mais puros. ${ }^{18,74}$

\subsection{2) Métodos de Síntese Indireta}

A estrutura dos HDL, baseada no empilhamento de camadas positivamente carregadas intercaladas com ânions hidratados por atração eletrostática, torna favorável a difusão dos ânions. Essa característica tem sido amplamente utilizada na síntese de HDL, pela substituição do ânion interlamelar de um precursor previamente preparado. Tal substituição pode ser realizada de diferentes maneiras e envolve a capacidade do ânion para estabilizar a estrutura lamelar. Os métodos indiretos são particularmente úteis na intercalação de ânions que apresentam tendência a formar sais insolúveis ou complexar com os cátions di ou trivalente, ou ainda quando o ânion a ser intercalado não é estável na faixa de $\mathrm{pH}$ ideal para a precipitação do HDL. ${ }^{6,11,35}$ A equação geral que representa este equilíbrio é:

$$
\left[\mathrm{M}^{\mathrm{II}}-\mathrm{M}^{\mathrm{III}}-\mathrm{X}\right]+\mathrm{Y} \rightarrow\left[\mathrm{M}^{\mathrm{II}}-\mathrm{M}^{\mathrm{III}}-\mathrm{Y}\right]+\mathrm{X}
$$

Baseado na mobilidade do ânion interlamelar, através da competição entre o ânion a ser intercalado e aquele do precursor, o método de troca aniônica $\underline{\text { em }} \underline{\text { solução }}$ se utiliza de um HDL precursor (intercalado com ânions cloreto ou nitrato) que é suspenso em uma solução concentrada $\left(\geq 0,1 \mathrm{~mol} \mathrm{dm}^{-3}\right)$ do ânion de interesse. $O$ ânion substituinte deve apresentar maior capacidade de estabilização da lamela e estar em maior proporção que o ânion do material precursor, deslocando o equilíbrio no sentido da troca. A principal desvantagem é a baixa eficiência de troca e a existência de impurezas resultantes do ânion precursor. ${ }^{27}$ 
O método de troca aniônica $\underline{\text { em }} \underline{\text { meio }} \underline{\text { ácido }}$ é baseado no deslocamento de equilíbrio causado pela reação do ânion interlamelar com ácido. Para isto é necessário suspender o HDL precursor e adicionar sobre esta suspensão uma solução do ácido cuja base conjugada deseja-se intercalar. $\mathrm{O}$ pH da solução do ácido deve ser suficientemente baixo para protonar o ânion e substituí-lo, mas não para destruir a estrutura das lamelas, sendo que o precursor deve ter ânions suscetíveis a ataque ácido (carbonato ou carboxilato). Esse método é muito eficiente, entretanto o ataque ácido pode provocar destruição parcial das lamelas. ${ }^{75}$

A troca aniônica por regeneracão $\underline{\text { de }} \underline{\text { um }} \underline{\text { precursor }} \underline{\text { calcinado }}$ requer a preparação de um HDL contendo carbonato que deve submeter-se a um tratamento térmico (calcinação), em temperatura adequada (determinada por análise termogravimétrica), de modo a produzir um óxi-hidróxido. Os HDL do sistema [Mg-Al$\mathrm{CO}_{3}$ ] normalmente são calcinados à temperatura $773 \mathrm{~K}$ durante 4 horas. Outros ânions também poderiam ser empregados como o $\mathrm{Cl}^{-}$e o $\mathrm{NO}_{3}^{-}$, entretanto o uso do $\mathrm{CO}_{3}^{2-}$ é justificado pelo fato deste se decompor em temperaturas mais baixas e o gás resultante da decomposição não ser oxidante, como o gás $\mathrm{Cl}_{2}$ ou gás $\mathrm{NO}_{2}$. $\mathrm{O}$ processo ocorre devido à propriedade chamada "efeito memória" características de alguns HDL. ${ }^{29} \mathrm{O}$ oxi-hidróxido duplo obtido é então colocado em contato com uma solução do ânion a ser intercalado, normalmente em temperatura abaixo de $353 \mathrm{~K}$. A hidrólise deste óxido ocorre com regeneração da estrutura do HDL e intercalação do ânion. O processo é acompanhado por um aumento no $\mathrm{pH}$ que pode atingir valores superiores a 12 , que em muitos casos deve ser corrigido, para evitar a competição entre as hidroxilas e o ânion de interesse. Este método é particularmente útil na preparação de HDL intercalados com o ânions hidroxila, dificilmente obtidos em sua forma pura por outros métodos ${ }^{7}$, entretanto, está limitado aos HDL dos sistemas Mg-Al-HDL e Zn-Al-HDL únicos capazes de regenerar sua estrutura lamelar. ${ }^{29}$ Outro fator importante para que a troca seja realizada com sucesso é evitar o contato do material calcinado com o $\mathrm{CO}_{2}$ do ar, o que levaria à regeneração da estrutura com a intercalação de carbonato. ${ }^{11}$

Existe também um método de síntese indireta, que foi desenvolvido em nosso laboratório, a troca aniônica por substituicãa $\underline{\text { em }} \underline{\text { fase }} \underline{\text { dupla }}{ }^{67}$, que consiste na preparação de um HDL precursor intercalado com ânions de tensoativos sulfatados ou sulfonados $^{69}$, onde a troca do ânion intercalado pelo ânion de interesse ocorre através da adição de uma solução de um tensoativo catiônico em uma suspensão contendo: o HDL 
precursor, o ânion de interesse e uma fase orgânica. Ocorre a formação de um sal entre os tensoativos aniônicos e catiônicos, insolúvel em água e altamente solúvel na fase orgânica, para a qual é extraído, deslocando os ânions previamente intercalados do domínio interlamelar, permitindo a entrada do ânion de interesse, presente na fase aquosa, tornando a substituição rápida e eficiente. Os HDL assim obtidos apresentam alta organização estrutural e pureza de fase. ${ }^{66,76}$

\section{6) Modelos Gerais para o Estudo de Adsorção}

Na literatura são reportados vários modelos teóricos para a interação na interface sólido/líquido, tendo como objetivo a obtenção de parâmetros termodinâmicos, cinéticos e conformacionais. Esse processo é complexo e ainda não é completamente compreendido, pois informações detalhadas sobre estruturas e fases superficiais dos materiais adsorvidos são limitadas, tendo como principal fonte de dados os estudos de adsorção. ${ }^{77}$ Os modelos clássicos de Langmuir, BET, Freundlich, Temkin, embora simples, ainda são muito utilizados e servem como base para a concepção de modelos (teóricos ou não) mais detalhados, considerando sistemas reais.

Giles desenvolveu um estudo utilizando as isotermas típicas de adsorção, a fim de otimizar informações contidas nas mesmas, estudo esse muito utilizado como referência para o tratamento geral e classificação de isotermas de adsorção de solutos em soluções diluídas. ${ }^{78}$ Desenvolveu-se uma base teórica que relaciona o perfil característico das isotermas a parâmetros do solvente e influência da presença de um outro soluto, podendo auxiliar no tratamento teórico e na interpretação de isotermas. De acordo com essa classificação, as isotermas são divididas em quatro classes principais, em função de sua inclinação inicial, convenientemente chamadas de: S, L (Langmuir), H (high affinity), e C (constant partition), sendo cada uma dividida em vários subgrupos como mostrado na figura 1.6. 


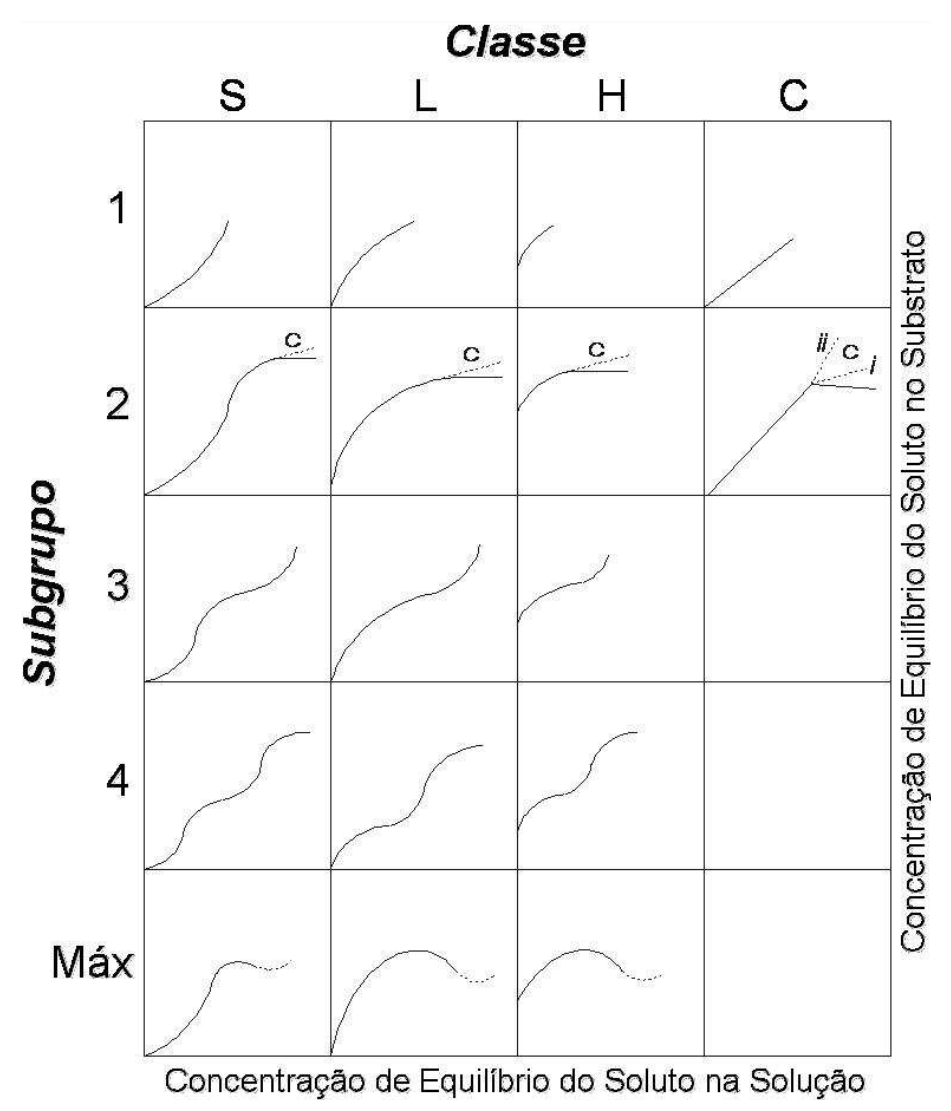

Figura 1.6: Sistema de classificação de isotermas proposto por Giles. ${ }^{78}$

De acordo com essa classificação, o perfil observado nas classes S, L e H pode ser explicado por diferenças na energia de ativação de dessorção dos solutos e do solvente, em magnitude relativa. A isoterma do tipo $S$ apresenta também uma dependência da concentração, implicando numa adsorção cooperativa, pelo aumento do número de sítios capazes de reter moléculas do adsorvato. A isoterma do tipo $\mathrm{H}$ é observada em casos especiais onde se tem uma alta afinidade entre adsorvente e adsorvato. A isoterma linear observada no tipo $\mathrm{C}$ ocorre em sistemas onde o adsorvente é microporoso e o adsorvato tem mais afinidade por ele do que pelo solvente, de modo que o adsorvato penetra nos microporos do adsorvente, levando à criação de novos sítios de adsorção. As curvas das outras classes $(\mathrm{S}, \mathrm{L}$ e H) também podem apresentar uma região linear acima da qual se esperaria o início do platô, representando condições semelhantes àquelas das curvas do tipo C. Finalmente, as isotermas da classe L são aquelas obtidas quando não são observados: a existência de microporos no adsorvente, adsorção cooperativa e uma alta afinidade entre adsorvato e adsorvente. ${ }^{79}$

As curvas do subgrupo 1 representam sistemas com a monocamada do adsorvato não saturada, provavelmente por dificuldades experimentais, como quando o Kps do adsorvato é atingido. No subgrupo 2, observa-se um patamar representando a saturação 
da monocamada. O subgrupo $2 \mathrm{c}$ indica microporosidade no adsorvente, sendo que na classe C, o segundo segmento da curva, nesse caso, pode ser horizontal, ou ter uma inclinação menor (ci) ou maior (cii) em relação ao primeiro segmento, de acordo com a natureza do sistema. Pode também representar uma modificação no empacotamento do adsorvato. ${ }^{80,81}$ Os aumentos subseqüentes (subgrupo 3) representam o desenvolvimento de uma segunda camada, que é saturada no subgrupo 4. Outros subgrupos, representando novas camadas, podem ser observados. Entretanto, esses casos seriam extremamente raros. Em casos conhecidos, uma curva que se classifica no subgrupo "max" (máximo) ocorre com soluções aquosas de um soluto que se associa em solução, tal como detergentes e certos tipos de tintas, provavelmente causado pela existência de traços de impurezas com alta atividade superficial. Nesse caso, com o aumento da concentração do adsorvato, na solução, alcança-se um ponto no qual as interações de van der Waals entre soluto-soluto ultrapassam as interações soluto-substrato de forma que parte do soluto é desorvido e incorporado em micelas solvatadas possivelmente incorporando alguma impureza de alta atividade superficial.

\section{7) O adsorvato - Ácido Cólico}

O ácido cólico é um dos quatro principais ácidos produzidos pela vesícula, também conhecidos como ácidos biliares. É uma substância branca e cristalina que tem propriedades detergentes similares aos sais de ácidos orgânicos de cadeia longa e promovem o transporte de lipídios através do meio aquoso. A estrutura molecular e as propriedades do ácido cólico são apresentadas respectivamente na figura 1.7 e na tabela 1.2.

Derivados do colesterol, como o ácido cólico, são moléculas anfifílicas que promovem importante papel na digestão de gorduras solúveis ingeridas na alimentação. Algumas doenças como a bradicardia (diminuição na freqüência cardíaca humana), a hipertonia (aumento anormal do tônus muscular e redução de sua capacidade de estiramento) e hemólise (enfraquecimento das hemácias que liberam hemoglobina no plasma) podem ser decorrentes de um aumento na quantidade de ácido cólico produzido pelo organismo humano. A adsorção de ácido cólico, nos casos onde o composto é produzido em excesso pelo organismo, reduz a quantidade de colesterol no sangue e conseqüentemente o risco de tais doenças. ${ }^{82}$ 

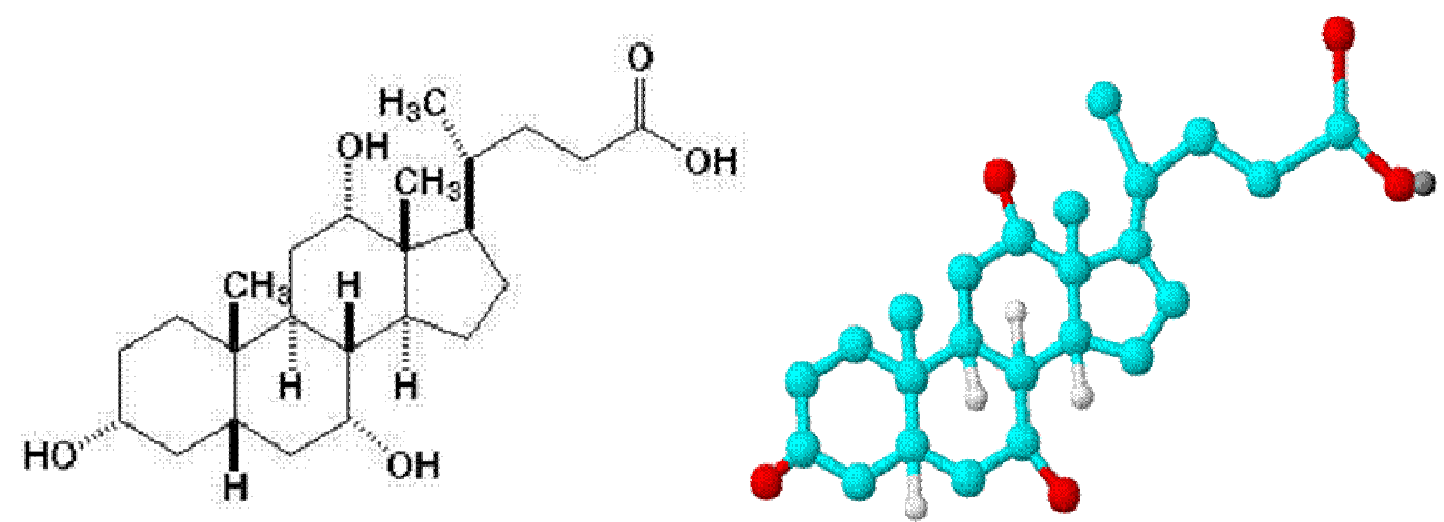

Figura 1.7. Representação da estrutura molecular do ácido cólico.

Tabela 1.2. Propriedades Físico-Químicas do Ácido Cólico

\begin{tabular}{c|c}
\hline Solubilidade & Álcool, acetona, éter, clorofórmio e aminoácidos \\
\hline Ponto de Fusão & $198^{\circ} \mathrm{C}$ (anidro) \\
\hline pKa & 5,08 \\
\hline
\end{tabular}




\section{Objetivos}

O objetivo geral deste trabalho foi o estudo da adsorção e sorção do ânion colato, a partir de soluções aquosas, em hidróxidos duplos lamelares de magnésio e alumínio.

Os objetivos específicos consistiram em:

i) Preparar e caracterizar o hidróxido duplo lamelar de magnésio e alumínio contendo carbonato assim como o produto de sua calcinação, que foram utilizados como adsorvente ou sorvente para o colato;

ii) Estudar a adsorção e a sorção de colato em função do tempo, ou seja, realizar um estudo cinético da adsorção do colato levando em conta efeitos como temperatura, $\mathrm{pH}$ e força iônica do meio;

iii) Estudar o efeito de parâmetros como temperatura, $\mathrm{pH}$ e força iônica do meio, na adsorção do colato no HDL, monitorando a variação do potencial eletrocinético em função da quantidade adsorvida;

iv) Estudar a sorção deste composto no HDL calcinado, com controle de temperatura;

v) Realizar um tratamento estatístico dos dados obtidos, visando quantificar a influência de cada variável no processo de adsorção. 


\section{Parte Experimental}

\section{1) Materiais}

Todos os reagentes empregados na execução deste trabalho apresentavam grau de pureza analítica e assim sendo, foram utilizados sem purificação prévia. Uma listagem completa, contendo nome, fórmula molecular, marca e grau de pureza dos reagentes utilizados é apresentada no apêndice $\boldsymbol{A}$. Reagentes higroscópicos como os nitratos dos cátions magnésio e alumínio foram previamente secos sob vácuo em presença de sílica gel ativada. Toda água utilizada neste trabalho foi destilada e sempre que necessário utilizou-se água deionizada através do sistema de purificação "Millipore MilliQ ${ }^{\circledR}$ “. Para os experimentos de adsorção/sorção, optou-se pelo uso do colato de sódio (Acros Organics, 99\%) no preparo das soluções. O colato de sódio é mais solúvel que o ácido cólico, além de ter um custo um pouco menor.

\section{2) Preparação do $\mathrm{HDL} \mathrm{MgAlCO}_{3}$, o adsorvente}

O HDL utilizado como adsorvente foi preparado pelo método de precipitação a $\mathrm{pH}$ variável (decrescente) ${ }^{39}$. O material foi preparado em quantidade suficiente para ser utilizado durante todo o projeto (aproximadamente 200g), garantindo assim a homogeineidade do material adsorvente, de forma que os resultados pudessem ser correlacionados.

Para isto utilizou-se duas soluções. A solução 1, que consistiu em 2,0 mol de $\mathrm{Mg}\left(\mathrm{NO}_{3}\right)_{2} \cdot 6 \mathrm{H}_{2} \mathrm{O}$ e $1,0 \mathrm{~mol}$ de $\mathrm{Al}\left(\mathrm{NO}_{3}\right)_{3} \cdot 9 \mathrm{H}_{2} \mathrm{O}$ dissolvidos em $1,4 \mathrm{dm}^{3}$ de água deionizada $\left(\right.$ MilliQ $^{\circledR}$ ); e a solução 2 que constituiu em 7,0 mol de $\mathrm{NaOH}$ (17\% excesso) e 2,0 mol de $\mathrm{Na}_{2} \mathrm{CO}_{3}$ (300\% de excesso do ânion), dissolvidos em 2,0 $\mathrm{dm}^{3}$ de água deionizada.

A solução 1 foi adicionada lentamente à solução 2 (por aproximadamente 8 horas), sob vigorosa e constante agitação, em temperatura sempre inferior a $303 \mathrm{~K}$. Ao final da adição mediu-se o pH, obtendo-se em um valor próximo de 13.

O material proveniente deste tipo de coprecipitação normalmente apresenta uma baixa organização estrutural. Desse modo, é recomendado que a suspensão viscosa obtida seja submetida a um tratamento hidrotérmico (neste caso, durante 18 horas à 
$343 \mathrm{~K}$ e pressão ambiente) para uma melhor cristalização do material obtido. Feito isso, a suspensão foi resfriada até a temperatura ambiente ( $298 \mathrm{~K})$ e o sólido foi lavado, através de sucessivos procedimentos de filtração a vácuo e re-suspensão em água destilada, até que o sobrenadante apresentasse um valor constante de $\mathrm{pH}$ (próximo de 7,3), sendo que a última lavagem foi feita com água MilliQ ${ }^{\circledR}$. O sólido assim obtido foi seco em dessecador sob vácuo, em presença de sílica gel ativado e então triturado manualmente a pó e estocando para caracterização e posterior utilização.

Todas as medidas de $\mathrm{pH}$ aqui referidas, assim como aquelas que serão mencionadas posteriormente, foram realizadas utilizando um potenciômetro “Analyser pH 300" associado a um eletrodo de vidro combinado.

\section{3) Tratamento Térmico - Calcinação}

Nos experimentos para avaliar a capacidade de remoção por sorção (adsorção e intercalação simultâneas por regeneração), o HDL foi tratado termicamente (calcinado) para remover o ânion inicialemente intercalado $\left(\mathrm{CO}_{3}{ }^{2-}\right)$ e obter o óxido-hidróxido misto de $\mathrm{Mg}$ e Al utilizado como sorvente. Realizou-se a calcinação do material em um forno de cerâmica "EDGCON-5P" com atmosfera de oxigênio White Martins de pureza $>99,9 \%$ (fluxo de $150 \mathrm{~cm}^{3} \cdot \mathrm{min}^{-1}$ ) a $773 \mathrm{~K}$ durante 4 horas, sendo em seguida resfriado até temperatura ambiente em dessecador sob vácuo em presença de sílica gel ativada. $\mathrm{O}$ material obtido desta calcinação também foi submetido às técnicas de caracterização. A temperatura ideal de calcinação foi determinada através de análise termogravimétrica acoplada à análise térmica diferencial.

\section{4) Caracterização dos materiais obtidos}

\subsection{1) Difração de Raios-X no Pó}

As análises por difração de raios X no pó (DRXP) dos sólidos obtidos foram realizadas em um difratômetro de raios X modelo "Siemens D 5005", que utiliza fonte de cobre e monocromador de grafite, selecionando a radiação $\mathrm{K} \alpha_{1}$ do $\mathrm{Cu}$ com comprimento de onda de 1,5406 ̊. Foi aplicada uma diferença de potencial de $40 \mathrm{kV}$, 
resultando em corrente de $40 \mathrm{~mA}$. Os difratogramas foram coletados em uma faixa de ângulo $(2 \theta)$ de 2 a $70^{\circ}$ a uma velocidade de $0,02^{\circ} \mathrm{s}^{-1}$. 6,7

\subsection{2) Análise Termogravimétrica / Térmica Diferencial}

As análises termogravimétrica e térmica diferencial (ATG/ATD) simultâneas foram realizadas em uma microbalança térmica "SDT 2960 Simultaneous TGA-DTA", acoplada ao microcomputador (analisador) "Thermal Analyst 2100", ambos da "TA Instruments", que permitem a realização simultânea das análises termogravimétrica e térmica diferencial. As análises foram realizadas com uma taxa de aquecimento de $10 \mathrm{~K} \mathrm{~min}^{-1}$, com um fluxo de ar sintético superseco (White Martins, $80 \% \mathrm{~N}_{2}, 20 \% \mathrm{O}_{2}$, $>99,997 \%$ ) de $100 \mathrm{~cm}^{3} \mathrm{~min}^{-1}$, utilizando uma faixa de aquecimento desde a temperatura ambiente até $1173 \mathrm{~K}$. A quantidade de amostra utilizada foi de aproximadamente $10 \mathrm{mg}$ e as medidas foram feitas contra um padrão de alumina. ${ }^{46,83}$

\subsection{3) Espectroscopia na Região do Infravermelho}

As análises por espectroscopia na região do infravermelho (IV-TF) foram realizadas em um espectrofotômetro "ABB Bomem MB 100”, em pastilhas de $\mathrm{KBr}$ (soluções sólidas de 2,5\% da amostra em $\mathrm{KBr}$ ) com 60 varreduras por espectro, na região espectral de 4000 a $400 \mathrm{~cm}^{-1}$.

\subsection{4) Espectrofotometria de Absorção Atômica}

A quantidade de cátions metálicos $\mathrm{M}^{\mathrm{II}}$ (magnésio) presente no HDL preparado foi determinada através de espectrofotometria de absorção atômica (AA), utilizando-se um espectrofotômetro de absorção atômica "VARIAN AA-175", com lâmpada específica para magnésio e chama de acetileno-ar. O padrão utilizado foi o óxido de magnésio, que após pesagem e conseqüentes diluições (ambas em balança analítica com precisão de \pm $0,01 \mathrm{mg}$ ) apresentou uma concentração final de 1000 ppm.

Para preparar as amostras inicialmente tomou-se $400 \mathrm{mg}$ do HDL, que foi dissolvido em ácido clorídrico (10\%) e diluído a $50 \mathrm{~cm}^{3}$ em água deionizada. Para leitura das absorbâncias a solução contendo o HDL dissolvido sofreu várias diluições 
sucessivas, até apresentar uma concentração compatível com o limite de detecção do aparelho.

\subsection{5) Espectrofotometria na Região do Ultravioleta-Visível}

A quantidade de cátions metálicos $\mathrm{M}^{\mathrm{III}}$ (alumínio) presente no HDL preparado foi determinada através de espectrofotometria na região do ultravioleta-visível (UV-Vis) utilizando um espectrofotômetro de absorção no ultravioleta-visível "Hewlett Packard HP 8453 UV-Vis".

As amostras para a quantificação do alumínio foram feitas a partir da mesma amostra empregada na determinação de magnésio, adicionando $0,1 \mathrm{~cm}^{3}$ de uma solução contendo hidrato de morina e álcool acidificado $\left(\mathrm{H}_{2} \mathrm{SO}_{4}\right) \mathrm{em} 0,1 \mathrm{~cm}^{3}$ da solução contendo o HDL dissolvido. A solução resultante foi então diluída, com água deionizada, para um volume de $25 \mathrm{~cm}^{3}$ e medida a absorbância da solução $(\lambda=418 \mathrm{~nm})$. Os dados de absorbância das amostras foram convertidos em concentração através da curva-padrão adequada, obtida a partir de diluições sucessivas de um padrão primário de alumínio. ${ }^{84}$

\subsection{6) Área Superficial Específica}

A área superficial específica (ASE) foi determinada através da isoterma BET, obtida a partir de experimentos de adsorção de nitrogênio. Para essas medidas foi utilizado um “Quantachrome NOVA 1200”.

As amostras foram previamente secas sob vácuo em presença de sílica gel ativada. A degaseificação da amostra ocorreu a $340 \mathrm{~K}$ e os experimentos foram realizados a partir da adsorção de nitrogênio no seu ponto de ebulição (a 77,35 K em banho de nitrogênio líquido), utilizando-se cerca de $100 \mathrm{mg}$ de amostra. As medidas foram realizadas, adicionando-se, no interior do porta-amostra, volumes conhecidos de nitrogênio gasoso e medindo-se a pressão, em cada caso, após se atingir o equilíbrio.

\subsection{7) Microscopia Eletrônica de Varredura}

A morfologia do adsorvente obtido foi verificada pela técnica de microscopia eletrônica de varredura (MEV), pela micrografia gerada do contraste topográfico observado através de um microscópio eletrônico, “LEO 440 - Scanning Electronic 
Microscope". As amostras foram suportadas no porta-amostra pela dispersão do pó sobre uma camada de verniz e submetidas ao jateamento com ouro, utilizando para isso um "Bal - Tec MED 020 - Coating System”. Esta cobertura é necessária, pois o HDL não apresenta condutividade suficiente para a geração de boas imagens.

\subsection{8) Potencial Eletrocinético e Potencial de Carga Zero}

Quando uma partícula sólida carregada como a de um HDL é colocada em solução e uma diferença de potencial é aplicada, a partícula se movimenta na solução carregando contra íons e, evidentemente, terá moléculas de solvente compondo um plano de cisalhamento. Esse plano de cisalhamento constituído por partículacarregada/contra-íons/solvente tem um potencial que pode ser medido facilmente através de eletroforese, ou seja, determinando-se a velocidade da partícula sob a influência de um campo elétrico aplicado. Esse potencial de cisalhamento é, por definição, o potencial eletrocinético ou potencial zeta $(\zeta)$. Para se produzir um campo elétrico uniforme, utiliza-se uma célula cilíndrica, longa e fina. A velocidade da partícula através da célula é medida por observação microscópica óptica direta ou pelo uso de técnicas de espalhamento de luz laser por efeito Doppler, segundo o qual a luz espalhada a partir de uma partícula em movimento, sofre um deslocamento da freqüência (desde que a freqüência da luz utilizada seja alta comparada com a freqüência do deslocamento). Assim, o deslocamento pode ser determinado utilizandose um par de feixes de laser mutuamente coerentes, a partir de uma única fonte e seguindo caminhos de comprimentos similares, arranjados de forma a se cruzarem; a luz espalhada na região (ponto) do cruzamento dos feixes é, portanto, detectada. A mobilidade eletroforética pode então ser calculada pela razão entre a velocidade da partícula e a força do campo aplicado. A partir da mobilidade eletroforética pode-se determinar o potencial eletrocinético, visto que o mesmo é diretamente proporcional a ela.

O potencial de carga zero (PZC - Point of Zero Charge) de uma partícula em suspensão pode ser interpretado como a condição na qual a partícula apresenta uma densidade de carga superficial igual a zero, ou seja, partícula não apresenta mobilidade frente a um campo elétrico. Esta análise é de extrema importância, uma vez que o HDL (partícula carregada), será utilizado como adsorvente. Esse potencial eletrocinético nulo é também interpretado como uma carga superficial "líquida" igual a zero, dessa forma, 
o conceito de PZC pode ser monitorado não apenas em função da variação do $\mathrm{pH}$, mas também em função da presença de outros eletrólitos.

O PZC foi determinado utilizando suspensões do HDL em água deionizada na mesma razão massa/volume que a utilizada nos experimentos de adsorção. Estas suspensões tiveram o $\mathrm{pH}$ ajustado em valores diferentes, sendo então submetidas a medidas de potencial eletrocinético, utilizando um "Zetasizer 3000 HSa" da Malvern Instruments.

As medidas de potencial eletrocinético das amostras provenientes dos experimentos de adsorção foram realizadas da seguinte forma: a suspensão, formada pelo HDL e a solução de colato nas condições estudadas, permaneceu em repouso até que as partículas maiores fossem decantadas ( 10 minutos) e a suspensão resultante foi submetida à análise na mesma temperatura em que o experimento foi realizado. As medidas foram realizadas com amostras em duplicata, sendo que os valores obtidos em cada análise são valores médios correspondentes a três leituras individuais.

\section{5) Quantificação dos Ânions Colato}

A quantificação dos ânions colato foi feita por meio de cromatografia líquida de alta performance (HPLC). As condições cromatográficas utilizadas foram: coluna cromatográfica C18 RP-ODS (250 mm X 4,6 mm X $5 \mathrm{~mm}$ ) com detector de índice de refração (RID) acoplado. A fase móvel era constituída de 69,6\% (\%v/v) de metanol; 17,4\% de acetonitrila; $12,99 \%$ de água e $0,01 \%$ de ácido fórmico. A taxa de eluição pela coluna foi de $1,4 \mathrm{~mL} \min ^{-1} .85$

\section{6) Estudo da adsorção e sorção dos ânions colato em $\mathrm{MgAlCO}_{3}-\mathrm{HDL}$ em função do tempo}

Os experimentos consistiram na adição de $400 \mathrm{~cm}^{3}$ de uma solução de concentração inicial de colato $\left(\mathrm{C}_{0}=5 \times 10^{-3} \mathrm{~mol} \mathrm{~L}^{-1}\right)$ sobre uma massa constante do sólido (3200 mg do HDL preparado) previamente seco a vácuo, com vigorosa agitação, em uma cela fechada, de forma a evitar evaporação da água e o contato com $\mathrm{CO}_{2}$ da atmosfera, que era mantida à temperatura constante através de circulação de água de um banho termostatizado através de uma camisa de vidro, que envolvia a cela. Alíquotas 
de $25 \mathrm{~cm}^{3}$ foram retiradas, em tempos pré-estabelecidos, mantendo sempre o sistema à temperatura constante. As alíquotas retiradas foram centrifugadas, para que o material sólido fosse separado e seco e as soluções sobrenadantes fossem analisadas para a quantificação de colato pelo método apropriado. $\mathrm{O}$ pH das soluções sobrenadantes foi medido. Adotou-se o mesmo procedimento utilizando o HDL calcinado.

Nestes experimentos, foram utilizadas duas temperaturas diferentes, de $298 \mathrm{~K}$ e de $323 \mathrm{~K}$, sendo que na temperatura de $298 \mathrm{~K}$ foram empregados dois valores diferentes de força iônica, sem e com a adição de $0,1 \mathrm{~mol} \mathrm{dm}^{-3} \mathrm{de} \mathrm{NaCl}$ e dois valores diferentes de $\mathrm{pH}$, iguais a 7 e 10 , na solução de colato.

\section{7) Adsorção e Sorção}

Os experimentos de adsorção e sorção do colato foram realizados utilizado o método batelada. O material sólido proveniente dos experimentos de adsorção foi submetido às análises de DRXP e IV-TF. A suspensão HDL/solução de colato foi submetida a medidas de potencial eletrocinético. O sobrenadante obtido foi submetido a medidas de pH e à quantificação do colato em solução.

\subsection{1) Determinação das isotermas de adsorção / sorção}

Os experimentos constituíram na adição de uma massa constante de HDL (200 $\mathrm{mg}$ ) previamente seco à vácuo em 16 erlenmeyers com capacidade de aproximadamente $125 \mathrm{~cm}^{3}$. A cada um foram adicionados $25 \mathrm{~cm}^{3}$ das soluções contendo diferentes quantidades de colato nas condições de $\mathrm{pH}$ e força iônica desejadas, submetendo-os à sonicação para diminuir e homogeneizar o tamanho das partículas. Todas as soluções de colato foram preparadas em água deionizada (Milli-Q), bem como suas diluições. Quando necessário, o $\mathrm{pH}$ foi ajustado com $\mathrm{HCl} / \mathrm{NaOH}$. As variações de força iônica foram obtidas através da adição de $\mathrm{NaCl}$.

As amostras permaneceram em um banho termostatizado tipo Dubnoff (Marconi) à temperatura controlada sob agitação constante, por cerca de 72 horas, para garantir o equilíbrio. Após esse período, dividiu-se cada amostra em duas porções: uma parte que foi centrifugada por 10 minutos em uma centrífuga Eppendorf 5403, tornando possível a separação e análise para quantificação do colato presente no sobrenadante e 
caracterização do resíduo (sólido); a outra porção foi mantida em suspensão para as medidas de potencial eletrocinético.

As concentrações iniciais e finais de colato em solução foram determinadas por cromatografia líquida de alta perfomance (HPLC), como citada no item 3.5. Os resultados obtidos foram comparados com os de uma curva de calibração preparada nas mesmas condições do experimento.

Os experimentos foram realizados nas seguintes condições:

\section{$\underline{\text { Adsorção (com HDL sem calcinar) }}$}

1. $\mathrm{pH} 7 ; 298 \mathrm{~K}$; sem adição de $\mathrm{NaCl}$

2. $\mathrm{pH} 7 ; 323 \mathrm{~K}$; sem adição de $\mathrm{NaCl}$

3. pH 7; 298K; com adição de $\mathrm{NaCl}$

4. $\mathrm{pH} 7 ; 323 \mathrm{~K}$; com adição de $\mathrm{NaCl}$

5. $\mathrm{pH} 10 ; 298 \mathrm{~K}$; sem adição de $\mathrm{NaCl}$

6. pH 10; 323K; sem adição de $\mathrm{NaCl}$

7. pH 10; 298K; com adição de $\mathrm{NaCl}$

8. pH 10; 323K; com adição de $\mathrm{NaCl}$

9. $\mathrm{pH} 7 ; 288 \mathrm{~K}$; sem adição de $\mathrm{NaCl}$

10. pH 7; 288K; com adição de $\mathrm{NaCl}$

\section{$\underline{\text { Sorção (com HDL calcinado) }}$}

1. $\mathrm{pH} 7 ; 298 \mathrm{~K}$; sem adição de $\mathrm{NaCl}$

2. $\mathrm{pH} 7 ; 323 \mathrm{~K}$; sem adição de $\mathrm{NaCl}$

3. $\mathrm{pH} 7 ; 288 \mathrm{~K}$; sem adição de $\mathrm{NaCl}$

\section{8) Forma de Tratamento de Dados}

Os dados obtidos através de difração de raios $\mathrm{X}$ no pó permitiram determinar se o composto é lamelar, pela repetição dos picos basais, obtendo-se os espaçamentos basais através da equação de Bragg. ${ }^{6,11,86}$

$$
\mathrm{n} \lambda=2 \mathrm{~d}_{\mathrm{hkl}} \cdot \operatorname{sen} \theta
$$


onde $n$ é a ordem de "reflexão" do pico, $\lambda$ é o comprimento de onda dos raios X utilizado na análise, $\boldsymbol{d}_{\boldsymbol{h} \boldsymbol{k} l}$ é o espaçamento basal para o conjunto de planos hkl e $\theta$ o ângulo de Bragg, determinado pelo pico de difração. Estes cálculos foram realizados com o auxílio do programa computacional "Diffrac Plus Basic 1.70”, específico para o equipamento de raios X utilizado (seção 3.4.1). A partir do valor de $d$ assim calculado, descontando-se o valor da espessura da lamela, que para HDL deste sistema é de 4,8 , obtem-se o valor da distância entre as lamelas.

Outra informação obtida a partir dos dados obtidos por DRXP foi a determinação do tamanho médio de partículas do HDL no sólido precursor e do sólido adsorvido em alguns pontos das isotermas obtidas. O método de Scherrer utilizado ${ }^{87}$, baseia-se no fato de que cristalitos pequenos $(<2000 \AA)$ causam um alargamento do pico de difração de raios X. Portanto, utilizando-se como padrão interno um material que apresenta seguramente um tamanho médio de partículas acima de $2000 \AA$ (normalmente $\mathrm{KCl}$ ou $\mathrm{NaCl}$ ) e picos de difração próximos ao do material a ser analisado, pode-se obter o tamanho de partículas do material através da equação

$$
t=\frac{0,9 \lambda}{\mathrm{B} \cos \theta_{\mathrm{B}}}
$$

onde $\boldsymbol{t}$ é a espessura da partícula, $\lambda$ é o comprimento de onda dos raios $\mathrm{X}$ utilizados na análise, $\boldsymbol{B}$ é a diferença entre a largura à meia altura dos picos da amostra e do padrão e $\boldsymbol{\theta}_{\mathbf{B}}$ é o ângulo de Bragg, determinado pelo pico da amostra. $\mathrm{O}$ valor de $\boldsymbol{B}$ é obtido pela relação

$$
B^{2}=B_{A m}^{2}-B_{P d}^{2}
$$

onde $\boldsymbol{B}_{A \boldsymbol{m}}$ e $\boldsymbol{B}_{\boldsymbol{P d}}$ representam, a largura à meia altura dos picos da amostra e do padrão respectivamente. Um exemplo deste cálculo, realizado para o adsorvente $\mathrm{Mg}-\mathrm{Al}-\mathrm{CO}_{3}$ HDL, é apresentado na figura 3.1. 


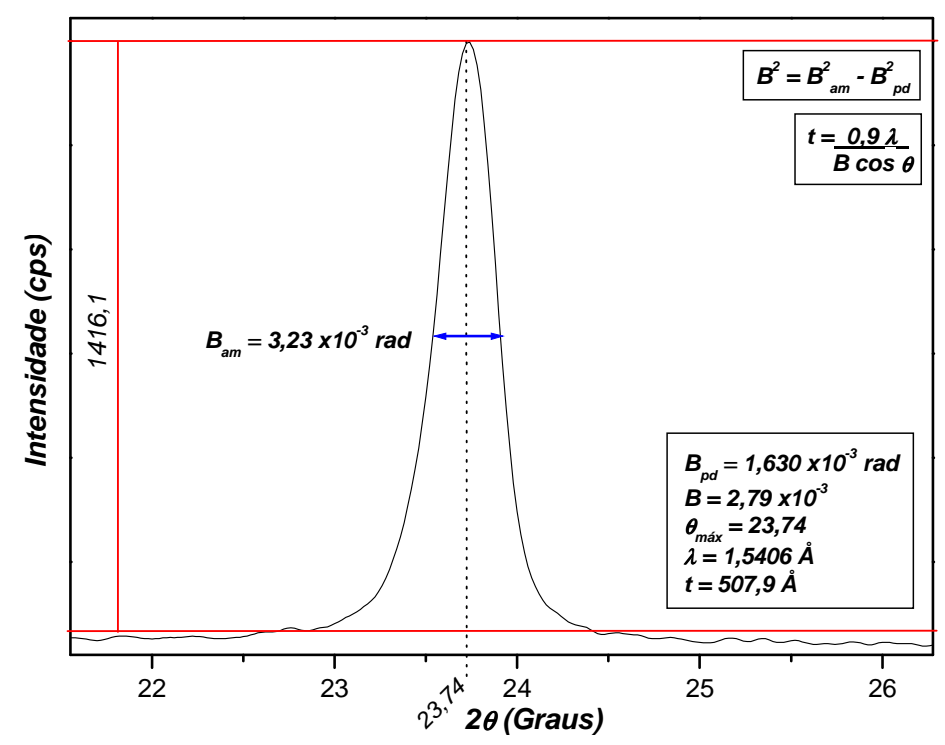

Figura. 3.1: Exemplo para o cálculo do tamanho de partículas do HDL por DRXP: $\mathrm{Mg}-\mathrm{Al}-\mathrm{CO}_{3}-\mathrm{HDL}$ utilizando $\mathrm{KCl}$ como padrão interno.

A determinação das etapas de decomposição dos HDL foi realizada pela comparação da taxa de decomposição ao longo da curva de análise termogravimétrica (ATG). Esta diferença na taxa de decomposição pode ser claramente observada pela curva da primeira derivada da curva de ATG (DTG). A definição de máximos e mínimos na curva derivada foi então utilizada para determinar os limites das etapas de decomposição. Assim os pontos de máximo representam as velocidades máximas de decomposição, sendo que o os mínimos nas curvas derivadas indicam o início e término dos processos que levam a perda de massa. ${ }^{35,39}$

A curva de ATD identifica a ocorrência de processos endotérmicos e exotérmicos através da medida da variação de temperatura da amostra em relação a um padrão, no caso alumina, em função da variação de temperatura do forno. Estes processos podem estar associados ou não à decomposição térmica do material e ainda indicar quando ocorrem reações de combustão, quando picos altamente exotérmicos são observados em experimentos realizados em fluxo de gás contendo oxigênio, enquanto que os mesmo são menos intensos em atmosfera inerte. Através da avaliação da quantidade de água perdida é possível determinar o grau de hidratação do composto.

A análise das propriedades texturais como ASE e MEV do material preparado em sua forma original e calcinado, foi realizada conforme descrito nas Seções 3.4.6. e 3.4.7. 
Através das análises por IV-TF é possível se obter informações sobre a estrutura e composição do material, inclusive detectar a presença de quantidades discretas de espécies como carbonato e nitrato.

Os espectros IV-TF foram utilizados aqui para avaliar e confirmar a presença ou não de espécies orgânicas (ânions colato) e inorgânicas (carbonato e/ou nitrato) nas amostras, através da identificação das bandas de absorção relacionadas a grupos característicos.

Os dados obtidos nos experimentos descritos na Seção 3.7.1 foram convertidos em quantidade de colato adsorvida, através do cálculo da diferença entre as concentrações iniciais e após o equilíbrio de adsorção. As isotermas são apresentadas em gráficos contendo no eixo das abscissas a concentração (em mol.dm ${ }^{-3}$ ) do colato em solução após o equilíbrio de adsorção e no eixo das ordenadas, a quantidade adsorvida (em mmol de colato por grama de HDL). As concentrações iniciais e finais foram obtidas conforme descrito na Seção 3.5 .

\section{9) Tratamento Estatístico dos Dados}

Os resultados obtidos nos experimentos de adsorção foram tratados utilizando-se da análise multivariacional. O planejamento de experimentos, além de ser aplicável a qualquer tipo de processo, é uma ferramenta que permite o estudo de diversas variáveis simultâneas e proporciona a modelagem matemática empírica do processo estudado. A análise multivariacional pode levar à otimização do processo analisado, além de quantificar a contribuição de cada variável ao processo.

Para que esta de análise possa ser aplicada, devem-se introduzir alguns conceitos básicos de planejamento de experimentos. As variáveis independentes, ou variáveis de entrada, são denominadas fatores. As variáveis dependentes, ou variáveis de saída, são denominadas respostas. Os valores físicos dos fatores que são ajustados no processo são chamados de níveis, e são geralmente divididos em nível alto e baixo, determinados pelo experimentador. Para a obtenção de respostas conclusivas, deve se garantir a aleatorização dos experimentos propostos. ${ }^{88,89}$

Os fatores pré-determinados nos experimentos de adsorção foram temperatura, pH inicial da solução de colato e presença ou ausência de $\mathrm{NaCl}$ às soluções de colato 
(alteração da força iônica do meio). Cada fator foi dividido em dois níveis, como mostrado na tabela 3.1

Tabela 3.1. Níveis dos fatores para os experimentos de adsorção.

\begin{tabular}{c|c|c}
\hline Fatores & Nível alto & Nível baixo \\
& + & - \\
\hline Temperatura (K) & 298 & 323 \\
\hline pH da solução de colato & 7,0 & 10,0 \\
\hline Presença de 0,1 mol.dm $^{-3}$ de $\mathrm{NaCl}$ & Sim & Não \\
\hline
\end{tabular}

Definidos os fatores e seus níveis, foi montada a matriz experimental. Usando a equação:

$$
n^{\circ} \text { de experimentos }=\mathbf{N}^{k}
$$

Onde:

N...quantidade de níveis

k...quantidade de fatores

Logo, para o experimento estudado foram necessários 8 experimentos $\left(2^{3}\right)$, realizados de maneira randômica.

A tabela 3.2 mostra a matriz experimental para os experimentos de adsorção.

Tabela 3.2. Matriz experimental para os experimentos de adsorção de colato em $\mathrm{MgAlCO}_{3}-\mathrm{HDL}$.

\begin{tabular}{c|c|c|c|c}
\hline Experimento & Temperatura & pH & Força lônica & Resultados \\
\hline 1 & & & & \\
\hline 2 & + & + & + & $\mathbf{y}_{1}$ \\
\hline 3 & - & + & + & $\mathbf{y}_{2}$ \\
\hline 4 & + & - & + & $\mathbf{y}_{3}$ \\
\hline $\mathbf{5}$ & - & - & + & $\mathbf{y}_{4}$ \\
\hline 6 & + & + & - & $\mathbf{y}_{5}$ \\
\hline 7 & - & + & - & $\mathbf{y}_{6}$ \\
\hline 8 & + & - & - & $\mathbf{y}_{7}$ \\
\hline
\end{tabular}


Finalmente, puderam ser calculados os efeitos de cada variável no processo de adsorção. Os efeitos podem ser interpretados como as influências exercidas pelos fatores sobre a variável resposta. Os efeitos podem ser classificados como principais (efeitos simples), ou efeitos de $2^{\mathrm{a}}$ ordem (efeitos combinados).

As equações 3.1, 3.2 e 3.3 foram utilizadas para o cálculo dos efeitos principais, seguindo-se como exemplo a matriz experimental mostrada na tabela 3.2.

$$
\begin{aligned}
& \mathbf{E P}_{(\mathbf{T})}=\left(\mathrm{y}_{1}+\mathrm{y}_{3}+\mathrm{y}_{5}+\mathrm{y}_{7}\right) / 4-\left(\mathrm{y}_{2}+\mathrm{y}_{4}+\mathrm{y}_{6}+\mathrm{y}_{8}\right) / 4 \\
& \mathbf{E P}_{(\mathbf{p H})}=\left(\mathrm{y}_{1}+\mathrm{y}_{2}+\mathrm{y}_{5}+\mathrm{y}_{6}\right) / 4-\left(\mathrm{y}_{3}+\mathrm{y}_{4}+\mathrm{y}_{7}+\mathrm{y}_{8}\right) / 4 \\
& \mathbf{E P}_{(\mathbf{F I})}=\left(\mathrm{y}_{1}+\mathrm{y}_{2}+\mathrm{y}_{3}+\mathrm{y}_{4}\right) / 4-\left(\mathrm{y}_{5}+\mathrm{y}_{6}+\mathrm{y}_{7}+\mathrm{y}_{8}\right) / 4
\end{aligned}
$$

As equações 3.4, 3.5 e 3.6 foram utilizadas para o cálculo dos efeitos combinados, seguindo-se também como exemplo a matriz experimental (tabela 3.2)

$$
\begin{aligned}
& \mathbf{E P}_{(\mathbf{T} / \mathbf{p H})}=\left(\mathrm{y}_{1}+\mathrm{y}_{4}+\mathrm{y}_{5}+\mathrm{y}_{8}\right) / 4-\left(\mathrm{y}_{2}+\mathrm{y}_{3}+\mathrm{y}_{6}+\mathrm{y}_{7}\right) / 4 \\
& \mathbf{E P}_{(\mathbf{p H} / \mathbf{F I})}=\left(\mathrm{y}_{1}+\mathrm{y}_{2}+\mathrm{y}_{7}+\mathrm{y}_{8}\right) / 4-\left(\mathrm{y}_{3}+\mathrm{y}_{4}+\mathrm{y}_{5}+\mathrm{y}_{6}\right) / 4 \\
& \mathbf{E P}_{(\mathbf{F I} / \mathbf{T})}=\left(\mathrm{y}_{1}+\mathrm{y}_{3}+\mathrm{y}_{6}+\mathrm{y}_{8}\right) / 4-\left(\mathrm{y}_{2}+\mathrm{y}_{4}+\mathrm{y}_{5}+\mathrm{y}_{7}\right) / 4
\end{aligned}
$$




\section{Resultados e Discussão}

\section{1) Preparação e caracterização do adsorvente $\mathrm{MgAlCO}_{3}-\mathrm{HDL}$}

O hidróxido duplo lamelar de magnésio e alumínio contendo o ânion inorgânico carbonato foi preparado pelo método da precipitação a $\mathrm{pH}$ variável, já descrito na seção 3.2, alcançando um pH final próximo de 13 , na solução da suspensão obtida.

A figura 4.1a mostra o difratograma obtido para o material preparado sem calcinar. A análise por difração de raios-X no pó (DRXP) apresentou picos basais característicos, confirmando a natureza lamelar do material. As distâncias interlamelares foram calculadas utilizando-se a equação de Bragg. O espaçamento basal obtido pela média dos valores de $\theta$ dos picos basais no difratograma (003 e 006) foi de 7,58 $\AA$, que concorda com o valor reportado na literatura para este tipo de material. ${ }^{7} \mathrm{O}$ tamanho médio dos cristalitos calculado foi de 501,6 Å. Nota-se, pela intensidade e largura dos picos que o material é bem ordenado.

A figura $4.1 b$ mostra o difratograma de raios-X no pó obtido para o material após tratamento térmico (calcinação), indicando que o sólido resultante não apresenta mais a estrutura lamelar organizada do HDL. Os picos mostrados são referentes ao óxido misto.
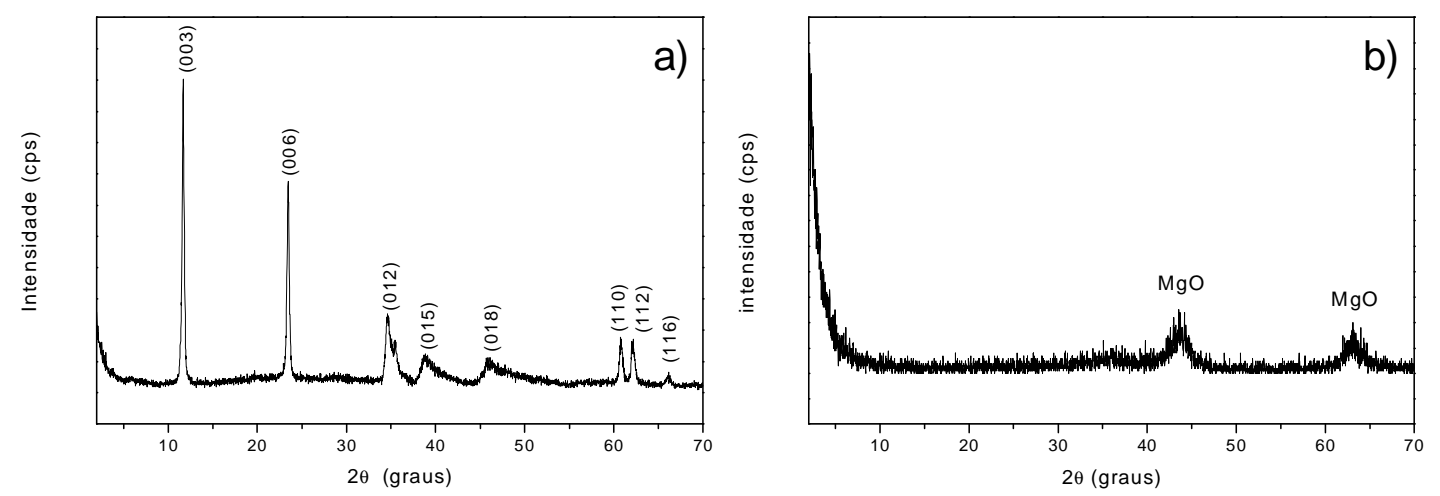

Figura 4.1. a) Difratograma de raios $\mathrm{X}$ no pó (DRXP) para: a) o $\mathrm{MgAlCO}_{3}$-HDL após tratamento hidrotérmico; b) para o $\mathrm{MgAlCO}_{3}-\mathrm{HDL}$ após tratamento térmico (calcinação).

As curvas de decomposição térmica, obtidas por análise termogravimétrica acoplada à análise térmica diferencial (ATG/ATD) são mostradas na figura 4.2. 
Por meio da análise termogravimétrica, podemos identificar três faixas distintas de decomposição do material utilizado. A primeira faixa, entre a temperatura ambiente até aproximadamente $500 \mathrm{~K}$, corresponde à eliminação de água adsorvida e água de solvatação dos ânions na estrutura cristalina do material, correspondendo a $15 \%$ da massa do HDL. A segunda faixa, entre 500 e 700K, corresponde à desidroxilação e a decomposição do carbonato intercalado, representado outros $30 \%$ de perda de massa. Acima de 700K, a perda de massa corresponde à formação do óxido misto e o colapso da estrutura lamelar.

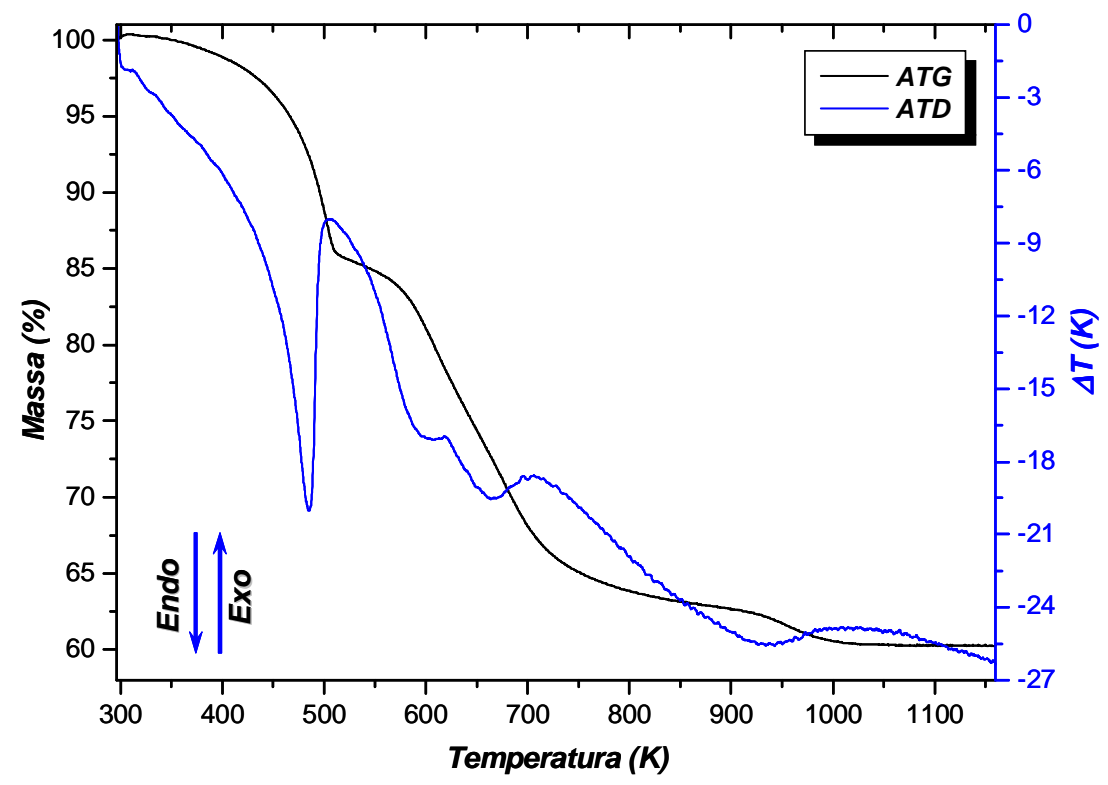

Figura 4.2. Curvas de TA e DTA para o $\mathrm{MgAlCO}_{3}$-HDL após o tratamento hidrotérmico.

A figura 4.3 mostra a análise por espectroscopia na região do infravermelho (IVTF) para o HDL sem calcinar $(\underline{a})$ e para o mesmo após a calcinação $(b)$. Para o material sem calcinar observa-se uma banda larga na faixa de $3450 \mathrm{~cm}^{-1}$ que é atribuída ao estiramento do grupo $\mathrm{OH}$ das moléculas de água de hidratação, cristalização e grupos hidroxilas das lamelas, comuns a todos os HDL. A banda de absorção na região próxima de $1590 \mathrm{~cm}^{-1}$ é atribuída à deformação angular das moléculas de água. $\mathrm{Na}$ região de $1400 \mathrm{~cm}^{-1}$ tem-se a banda referente ao estiramento $\mathrm{C}-\mathrm{O}$ do carbonato intercalado. As bandas na região entre 920 e $430 \mathrm{~cm}^{-1}$ são referentes aos estiramentos das ligações M-O e O-M-O $\left(\mathrm{M}=\mathrm{Mg}^{2+}\right.$ ou $\left.\mathrm{Al}^{3+}\right)$ nas lamelas dos HDL. Em $(b)$ são mostradas diferenças significativas para o material calcinado. As bandas observadas na 
faixa de $3400 \mathrm{~cm}^{-1}$ e em $1400 \mathrm{~cm}^{-1}$ são de menor intensidade. Isso se deve, respectivamente, à perda de água de adsorção e de intercalação e perda de carbonato. ${ }^{90}$

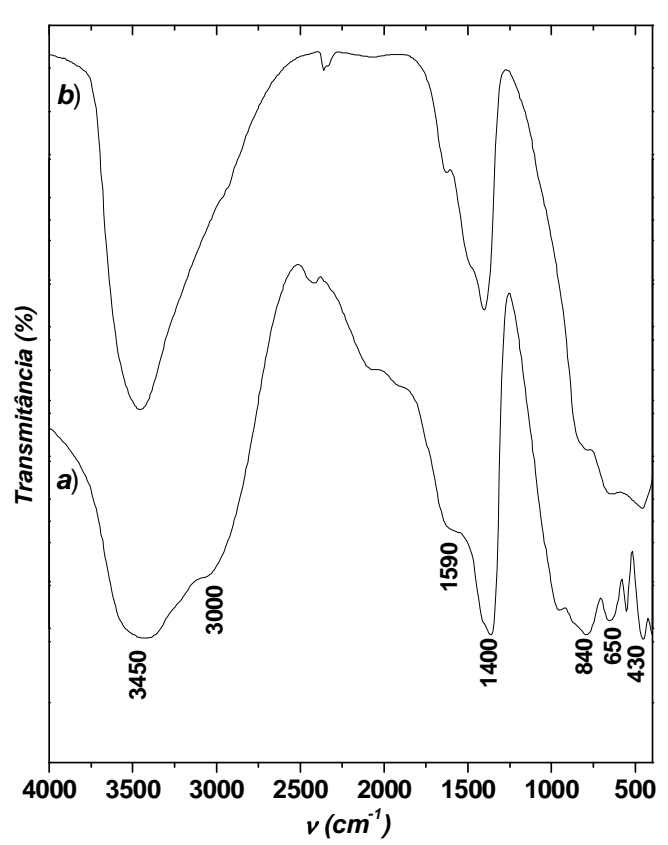

Figura 4.3. Espectros IV-TF para o $\mathrm{MgAlCO}_{3}-\mathrm{HDL}$ : $a$ )após tratamento hidrotérmico; $b)$ calcinado.

Através das quantidades de $\mathrm{Mg}$ e $\mathrm{Al}$, determinadas por espectroscopia de absorção atômica e espectroscopia na região do ultravioleta-visível respectivamente, determinou-se uma razão $\mathrm{M}^{\mathrm{II}}: \mathrm{M}^{\mathrm{III}}$ de 2,56:1 para o material submetido a tratamento hidrotérmico. Esta razão é de extrema importância, pois especifica a densidade de carga do HDL, um dos fatores que devem ser levados em conta para o entendimento do processo de adsorção. As análises foram realizadas em triplicata, de modo que a razão obtida é resultado de valores médios.

As propriedades texturais do HDL preparado foram avaliadas conforme descrito na seção 3.4.6, através de isotermas de adsorção-desorção de nitrogênio, mostradas na figura 4.4, para o material calcinado e não-calcinado. Nos dois casos, a histerese da curva indica uma morfologia de mesoporos ${ }^{91}$. No caso dos HDL sem calcinar, estes são formados pelos agregados do material, enquanto para o material calcinado estes mesoporos são formados durante a calcinação. 

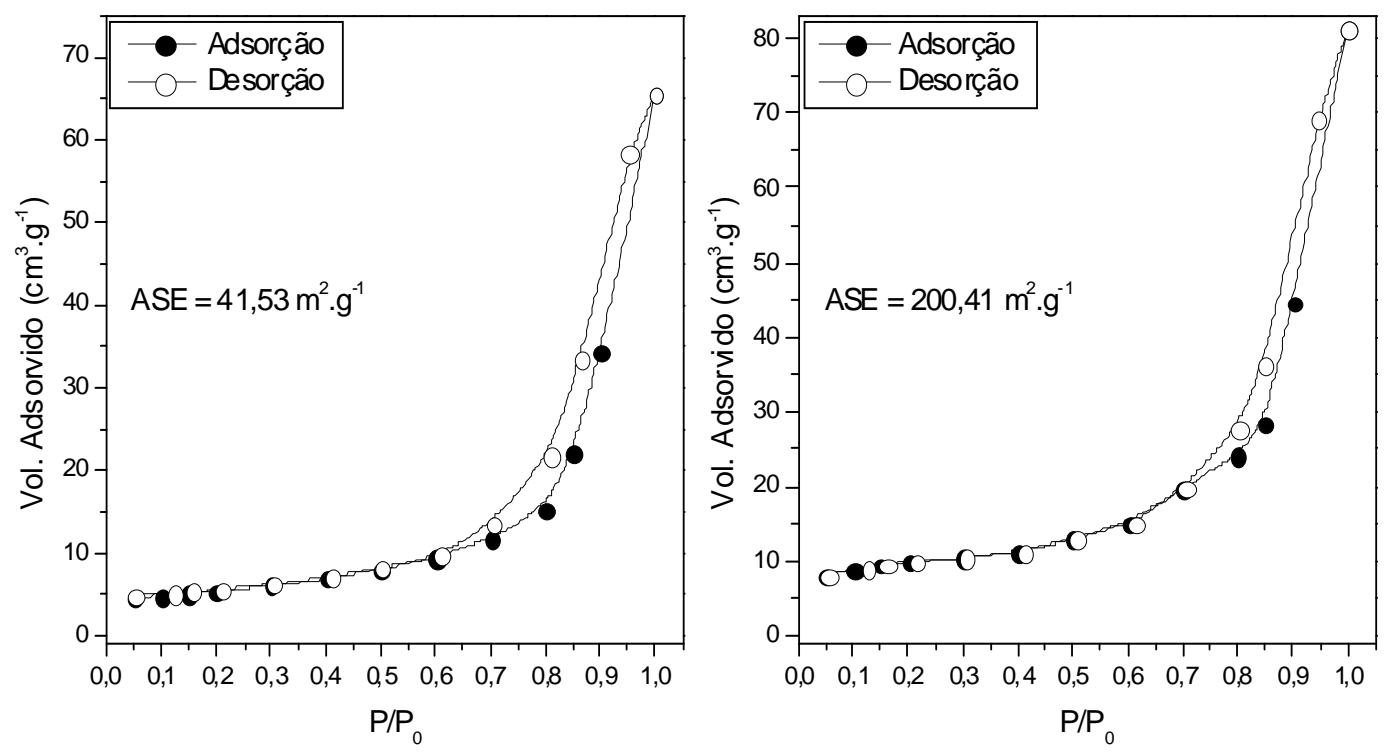

Figura 4.4. Isotermas BET para o MgAlCO3-HDL: $a$ ) após o $\mathrm{TH} ; b$ ) calcinado.

Sabendo que um dos objetivos desse trabalho é avaliar a variação da adsorção do colato em função do $\mathrm{pH}$, outro método de caracterização usado no material foi a determinação do ponto de carga zero do HDL. O PZC foi determinado, conforme descrito na seção 3.4.8, para o material preparado. A variação do potencial eletrocinético em função do $\mathrm{pH}$ é mostrado na figura 4.5, indicando o PZC em um valor de $\mathrm{pH}$ de 11,46 .

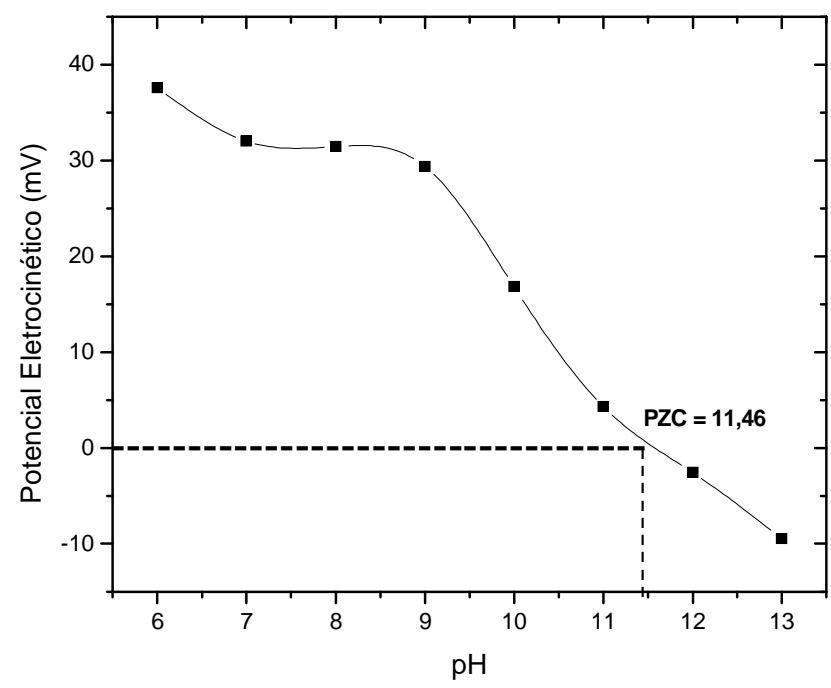

Figura 4.5. Variação do Potencial Eletrocinético em função do pH, para suspensões do HDL em água.

A figura 4.6 mostra as imagens de microscopia eletrônica de varredura (MEV), em diferentes magnificações, obtidas para o HDL preparado e para o produto de 
calcinação do mesmo. No caso do HDL original, observa-se uma superfície irregular, pouco porosa e a existência de alguns aglomerados. Já no material calcinado, destaca-se um grande aumento na porosidade da superfície.
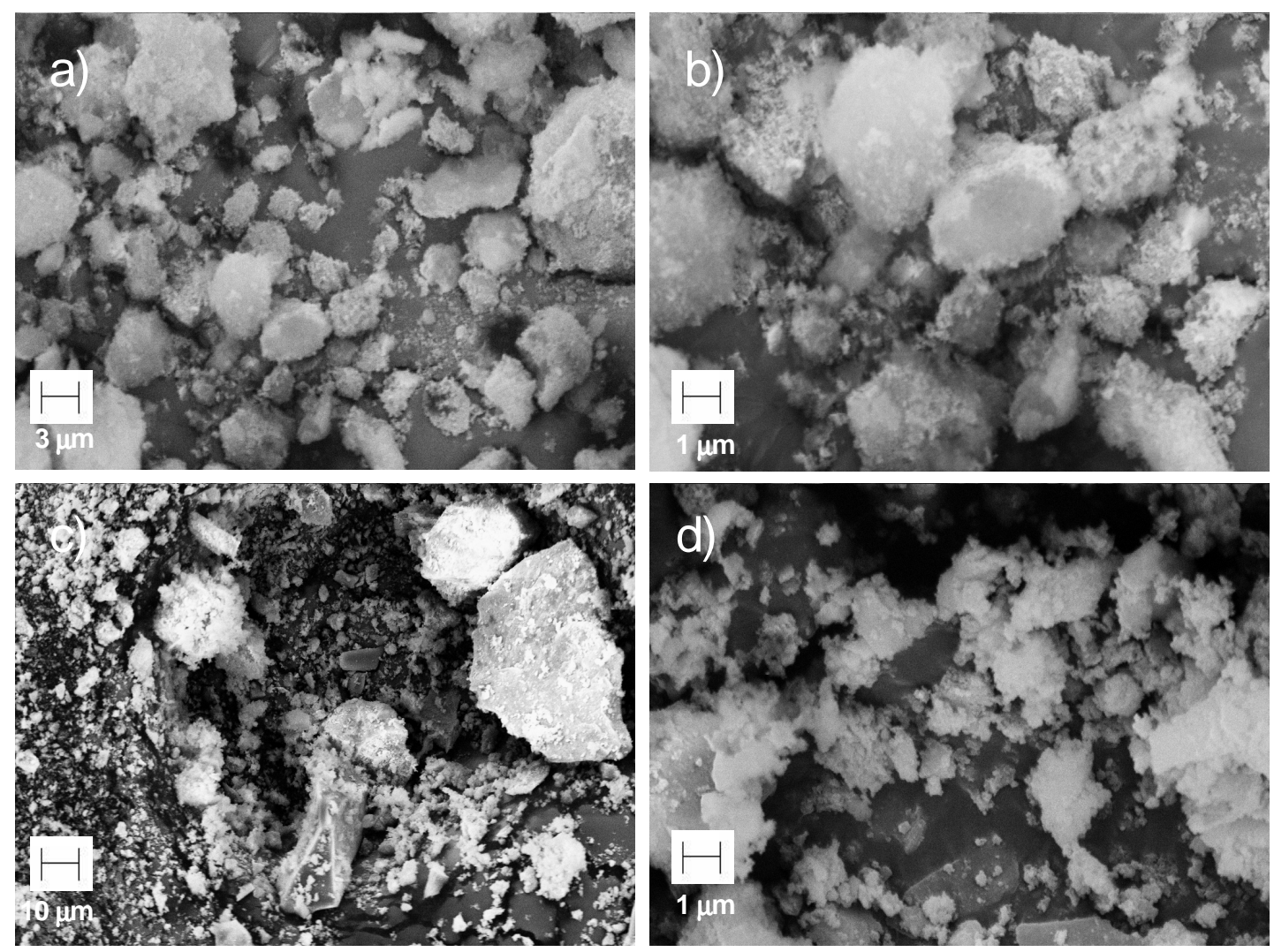

Figura 4.6. Imagens de $\mathrm{MEV}$ para o $\mathrm{MgAlCO}_{3}$-HDL. a) não calcinado (5.000 x); b) não calcinado $(10.000 \mathrm{x})$; c) calcinado $(1.000 \mathrm{x})$; d) calcinado $(10.000 \mathrm{x})$

\section{2) Estudo da adsorção de ânions colato em $\mathrm{MgAlCO}_{3}-\mathrm{HDL}$ em função do tempo - estudo cinético}

A partir do estudo da adsorção (para o HDL original) e sorção (para o HDL calcinado) em função do tempo, foi possível determinar o tempo necessário para se atingir o equilíbrio nos dois tipos de processos. Realizaram-se experimentos variando-se os seguintes parâmeteros: temperatura (298 e 323 K), pH da solução inicial de colato (7,0 e 10,0) e presença ou ausência de 0,1 mol.dm ${ }^{-3}$ de $\mathrm{NaCl}$ às soluções (aumento da força iônica do meio). Foram também medidos os valores de $\mathrm{pH}$ finais, no sobrenadante 
de cada alíquota. A variação do valor da concentração de equilíbrio em função do tempo passa a ser praticamente nula após 72 horas. Os perfis das curvas obtidas são semelhantes para todas as condições. (figura 4.7)
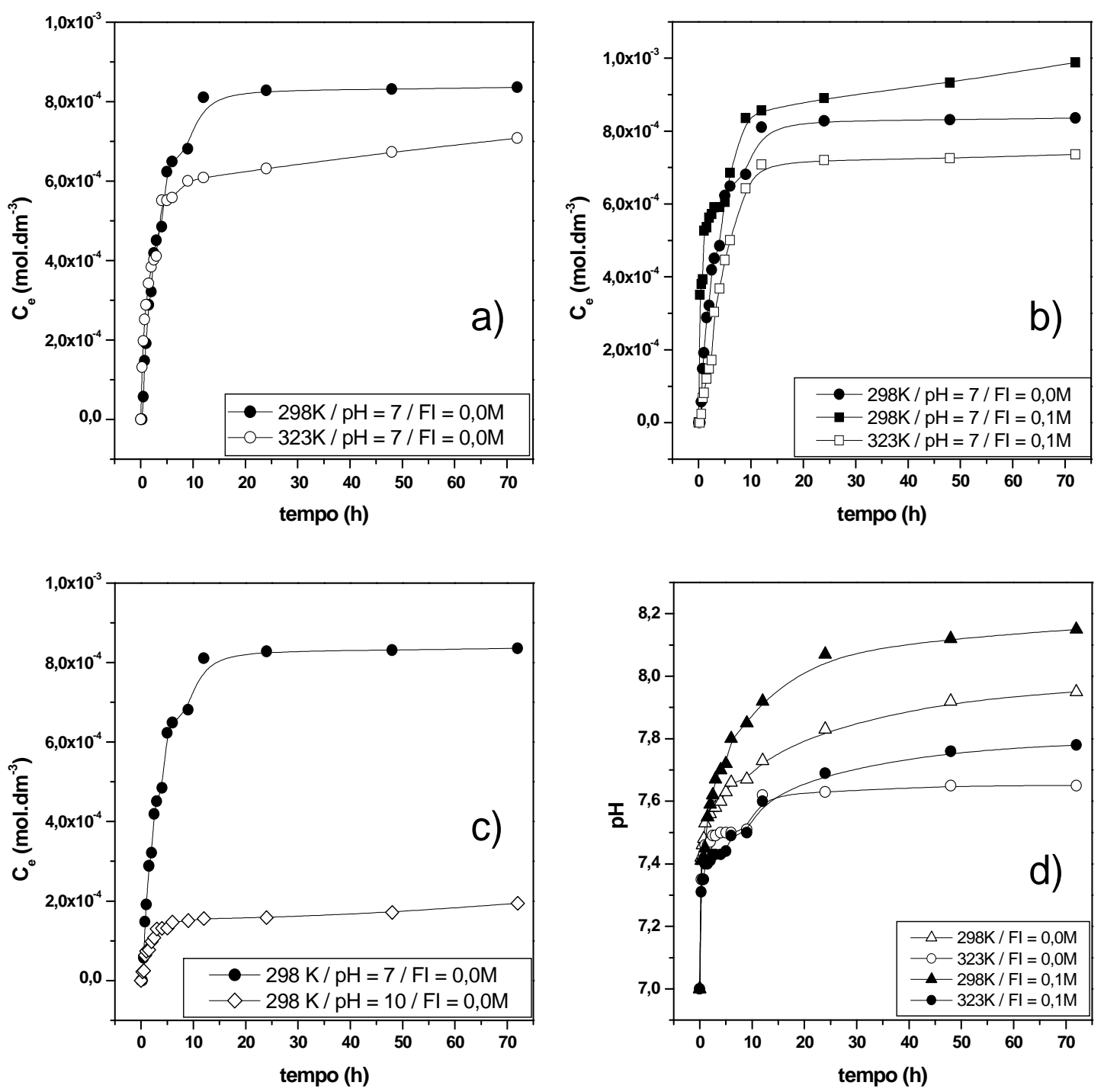

Figura 4.7. Curvas de adsorção de ânions colato em $\mathrm{MgAlCO}_{3}-\mathrm{HDL}$ em função do tempo em diferentes condições. a) em diferentes temperaturas (298 e 323K); b) na presença e na ausência de $\mathrm{NaCl}$ no meio; c) em diferentes valores de pH das soluções iniciais de colato (7,0 e 10,0). Curva de evolução temporal do pH do sobrenadante d), após a adsorção, em diversas condições.

Para o HDL original, a condição experimental que resultou em uma melhor eficiência de adsorção foi aquela com temperatura de adsorção de $298 \mathrm{~K}$, com pH da solução de colato com valor ajustado para 7,0 e com a adição de 0,1 mol.dm ${ }^{-3}$ de $\mathrm{NaCl}$. 
Além disso, todas as curvas indicam uma tendência ao início de saturação dos sítios do adsorvente nos últimos pontos das isotermas.

Comparando as curvas, verifica-se que o aumento da temperatura de 298 para $323 \mathrm{~K}$ levou a um desfavorecimento da quantidade adsorvida de colato. Este efeito pode ser visto na figura $4.7 a$. $\mathrm{O}$ aumento da temperatura causa uma diminuição na adsorção porque resulta numa maior influência da componente entrópica da variação de energia livre do sistema (dada por $\Delta \mathrm{G}=\Delta \mathrm{H}-\mathrm{T} \Delta \mathrm{S}$ ). Entretanto, a adsorção de colato na superfície do HDL resulta numa maior organização do sistema, ou seja, uma diminuição da entropia $(\Delta S<0)$, representando uma diminuição no valor negativo de energia livre, governada pelo fator entálpico $(\Delta \mathrm{H})$, de modo que a adsorção ocorre acompanhada da liberação de calor. Quando a temperatura é maior, a componente entrópica (T $\Delta S)$ é aumentada, diminuindo a importância da componente entálpica no valor da energia livre do sistema para o processo espontâneo $(\Delta \mathrm{G}<0)$. Assim, a organização de agregados mais compactos ou com um número maior de moléculas de colato no HDL, leva a uma diminuição da eficiência da adsorção em temperaturas mais altas.

Como demonstrado na figura $4.7 \mathrm{~b}$, o aumento da força iônica do sistema, provocado pela adição de $\mathrm{NaCl}$, resultou em um considerável aumento na quantidade adsorvida de colato, na faixa de concentração avaliada. Foi também observada formação de um patamar de adsorção. A adição de $\mathrm{NaCl}$, com conseqüente aumento de força iônica do meio, ajuda a diminuir as forças repulsivas existentes entre os grupos polares do colato, permitindo a formação de agregado mais compacto, aumentando a adsorção do composto em HDL.

Em condições de $\mathrm{pH}$ mais elevado, a quantidade de colato adsorvido é menor uma vez que ocorre uma diminuição da carga da superfície do HDL em função da interação desta com íons hidroxilas $\left(\mathrm{OH}^{-}\right)$da solução. Essa diminuição da quantidade adsorvida fica evidenciada na figura $4.7 c$.

Nos experimentos onde o pH inicial das soluções de colato foi 7 , houve uma pequena dissolução do HDL e conseqüente liberação de hidroxilas para a solução, fato esse que eleva o pH do meio após a adsorção. Contudo, a quantidade de $\mathrm{OH}^{-}$liberada pela dissolução do HDL é pequena e não interfere significativamente no processo de adsorção. Após a adsorção, os valores de pH atingiram valores entre 7,6 e 8,2. Esse efeito pode ser visto claramente na figura $4.7 d$. Por outro lado, quando o valor inicial do pH é igual a 10, a dissolução do HDL foi praticamente nula. 
As taxas de extração foram calculadas medindo a diferença entre a concentração inicial da solução de colato $\left(\mathrm{C}_{0}=5 \times 10^{-3} \mathrm{~mol} . \mathrm{L}^{-1}\right)$ e a concentração obtida após 72 horas (concentração de equilíbrio). A tabela 4.1 indica os valores de taxa de extração para a adsorção do colato em $\mathrm{MgAlCO}_{3}-\mathrm{HDL}$, em diversas condições diferentes.

Tabela 4.1. Taxas de extração de colato pelo HDL original.

\begin{tabular}{cccc}
\hline $\begin{array}{c}\text { Temperatura } \\
(\mathbf{K})\end{array}$ & $\mathbf{0 , 1} \mathbf{M}(\mathbf{N a C l})$ & $\mathbf{p H}$ & $\begin{array}{c}\text { Taxas de } \\
\text { Extração (\%) }\end{array}$ \\
\hline 298 & Sim & 7,0 & 19,8 \\
298 & Não & 7,0 & 16,8 \\
323 & Sim & 7,0 & 14,7 \\
323 & Não & 7,0 & 14,1 \\
298 & Não & 10,0 & 3,9 \\
\hline
\end{tabular}

Na figura 4.8, são apresentados os difratogramas de raios-X obtidos para o HDL original e o HDL com colato adsorvido após 72 horas em contato com as soluções, em diferentes condições.

Os resultados mostram que não há diferenças significativas em relação aos picos basais que caracterizam o $\mathrm{MgAlCO}_{3}-\mathrm{HDL}$, ou seja, não foi observada alteração no espaçamento basal do HDL. 


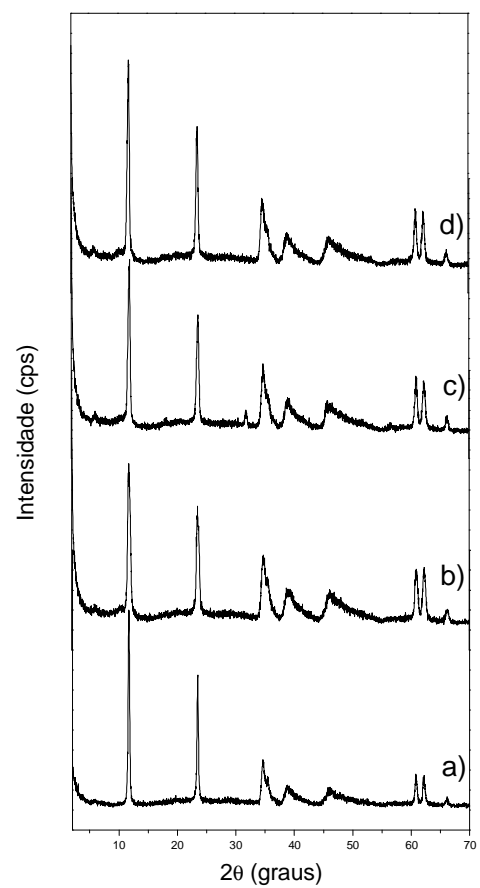

Figura 4.8. DRXP para o HDL original em diversas condições. a) puro; b) adsorvido com colato a $298 \mathrm{~K} \mathrm{em} \mathrm{pH} 10$; c) adsorvido a $323 \mathrm{~K} \mathrm{em} \mathrm{pH} \mathrm{7;} \mathrm{d)} \mathrm{adsorvido} \mathrm{a} 298 \mathrm{~K} \mathrm{em}$ pH 7 com adição de $\mathrm{NaCl}$.

$\mathrm{O}$ espectro de infravermelho para o $\mathrm{MgAlCO}_{3}$ - $\mathrm{HDL}$ com colato adsorvido após 72 horas em contato com as soluções, em diferentes condições, é mostrado na figura 4.9. Esse espectro apresenta uma larga banda na região próxima a $3400 \mathrm{~cm}^{-1}$, atribuída à água de hidratação e às hidroxilas (das lamelas). As bandas localizadas entre 2750-3000 $\mathrm{cm}^{-1}$ podem estar associadas às ligações de hidrogênio existentes entre os dímeros de ânions colato intercalados no domínio interlamelar.

As bandas localizadas na região próxima a $1500 \mathrm{~cm}^{-1}$ comprovam a presença do composto carboxílico no material. Nos compostos em que existem ligações de hidrogênio intermoleculares entre ácidos carboxílicos, a banda $\mathrm{C}=\mathrm{O}$ aparece na região de $1700 \mathrm{~cm}^{-1}$. Observam-se também bandas largas na região de 1400 a $920 \mathrm{~cm}^{-1}$, devidos à deformação da ligação O-H. ${ }^{92}$ 


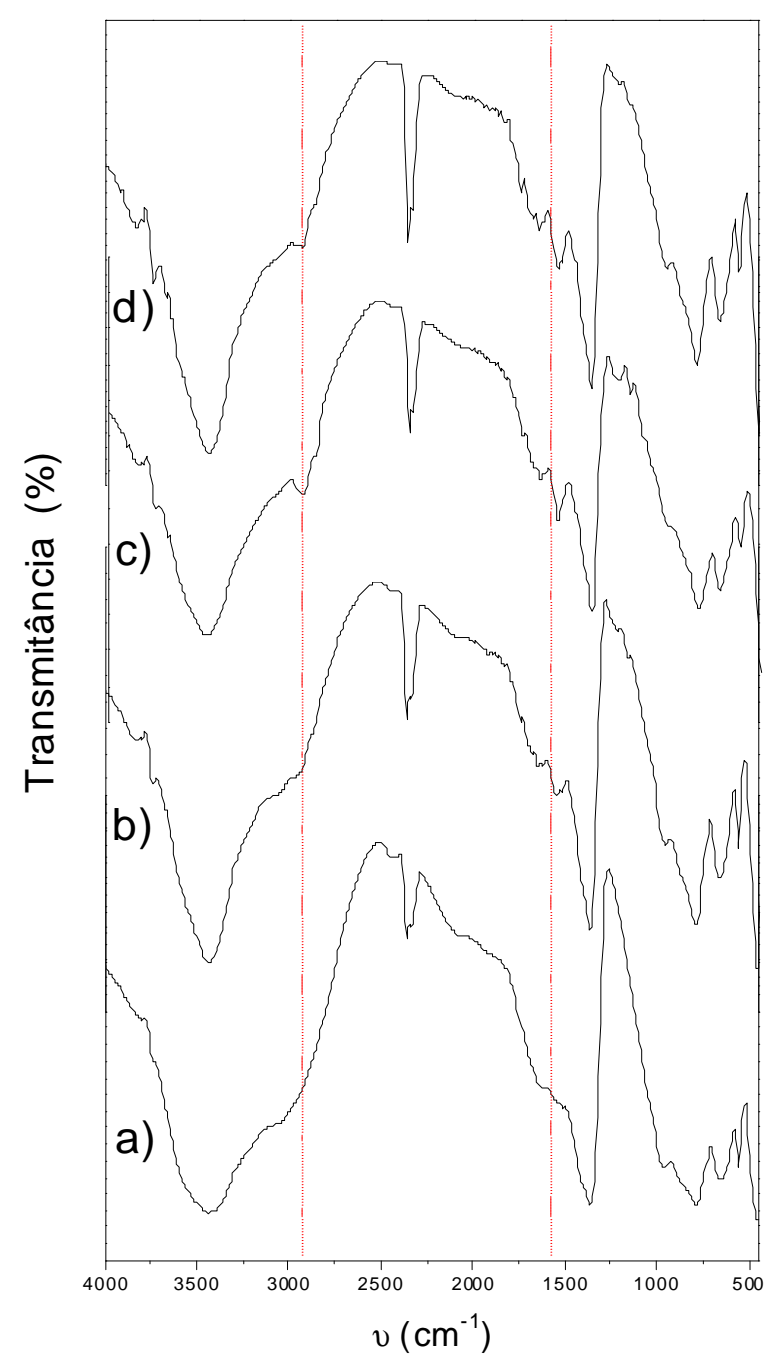

Figura 4.9. Espectro na região do infravermelho para o HDL original. $a$ ) puro; $b$ ) adsorvido com colato a $298 \mathrm{~K} \mathrm{em} \mathrm{pH} \mathrm{10;} \mathrm{c)} \mathrm{adsorvido} \mathrm{a} 323 \mathrm{~K} \mathrm{em} \mathrm{pH} \mathrm{7;} \mathrm{d)} \mathrm{adsorvido} \mathrm{a}$ $298 \mathrm{~K}$ em $\mathrm{pH} 7$ com adição de $\mathrm{NaCl}$.

O tamanho médio dos cristalitos foi determinado pelo método de Scherrer, como explicado na seção 3.8, para os sólidos correspondentes aos últimos pontos de cada curva mostradas na figura 4.7. Os valores obtidos são mostrados na tabela 4.2. Os valores de tamanho médio de cristalitos é sempre maior para os sólidos adsorvidos, quando comparados com o do HDL puro. 
Tabela 4.2. Tamanho médio dos cristalitos para o HDL adsorvido com colato (estudo

\begin{tabular}{cc}
\multicolumn{2}{c}{ cinético) } \\
\hline Amostra & Tamanho (Å) \\
\hline HDL puro & 433,5 \\
298K; pH 10; FI 0,0M & 454,6 \\
323K; pH 7; FI 0,0M & 481,9 \\
323K; pH 7; FI 0,1M & 482,6 \\
298K; pH 7; FI 0,0M & 495,6 \\
298K; pH 7; Fl 0,1M & 496,2
\end{tabular}

Adotou-se o mesmo procedimento de estudo cinético para o HDL calcinado. Para isso, quantidade suficiente de adsorvente foi colocado em um cadinho de porcelana em um forno e levado à temperatura de $873 \mathrm{~K}$, durante 6 horas, em atmosfera de oxigênio. As condições experimentais de adsorção foram as mesmas usadas para o HDL original. Após a calcinação, esse material foi devidamente armazenado de forma a evitar o contato com $\mathrm{CO}_{2}$ presente na atmosfera. Para a sorção no material calcinado, a única variável foi a temperatura, pois as outras variáveis são de difícil controle para esse tipo de material.

Para o HDL calcinado, a condição experimental que leva a melhor eficiência de remoção de íons é aquela com temperatura de adsorção de 298 K. Novamente, o aumento da temperatura desfavorece a adsorção de colato, como já discutido. Mais uma vez, as curvas indicam uma tendência ao início da saturação dos sítios do adsorvente nos últimos pontos das isotermas. Nota-se, entretanto, que a região de saturação é atingida mais rapidamente (aproximadamente 4 horas) para estas condições. A figura 4.10 mostra uma comparação entre as curvas de adsorção de colato pelo HDL original e de sorção pelo HDL calcinado, em diferentes temperaturas. 


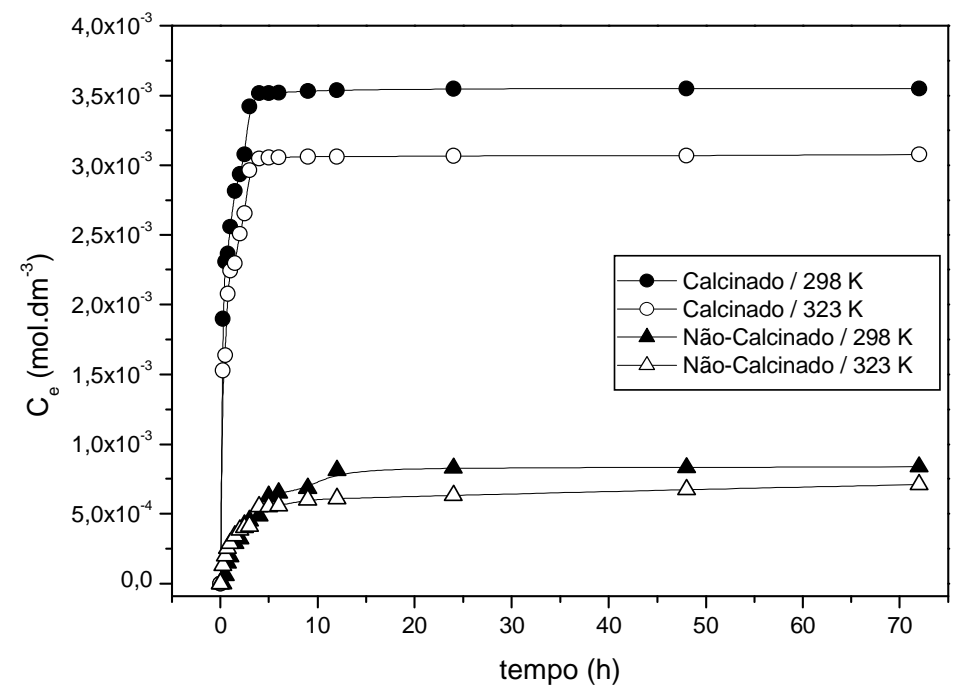

Figura 4.10. Curvas de adsorção e de sorção de colato em $\mathrm{MgAlCO}_{3}$ - $\mathrm{HDL}$ ou no material calcinado, em função do tempo em diferentes condições de temperatura.

Comparação entre as taxas de remoção de íons pelo HDL original e calcinado.

A tabela 4.3 mostra as taxas de extração de colato pelo HDL calcinado nas condições experimentais utilizadas. As eficiências de sorção são maiores do que as eficiências de adsorção. Isso pode ser explicado por dois fatores: (i) Durante o processo de sorção, ocorrem ambos os processos de adsorção e intercalação devido a regeneração do precursor calcinado (também conhecido com "efeito memória"); (ii) o valor de área superficial específica do HDL calcinado é aproximadamente cinco vezes maior do que do material não-calcinado, resultando assim em taxas de extração maiores.

Tabela 4.3. Taxas de extração de colato pelo HDL calcinado.

\begin{tabular}{cc}
\hline Temperatura (K) & $\begin{array}{c}\text { Taxas de Extração } \\
\text { (\%) }\end{array}$ \\
\hline 298 & 71,1 \\
323 & 61,4 \\
\hline
\end{tabular}

Na figura 4.11, são apresentados os difratogramas de raios-X obtidos para o HDL calcinado e o HDL calcinado com colato adsorvido após 72 horas em contato com as soluções, em diferentes condições.

Os difratogramas mostram a reconstrução das lamelas do HDL calcinado quando colocado em contato com as soluções de colato, entretanto com um valor de 
espaçamento basal similar à intercalação de íons hidroxila. $\mathrm{O}$ oxi-hidróxido obtido após a calcinação do HDL é hidrolisado, regenerando a estrutura do HDL. Nota-se o surgimento de dois discretos picos em $2 \theta$ igual a 7,5 e 16,3 $3^{\circ}$ Comparando com o difratograma obtido para o colato de sódio puro, mostrado na figura 4.12, observa-se a existência de dois picos com o mesmo valor de $2 \theta$. Assim, concluímos que devido à grande quantidade de colato sorvido pelo HDL calcinado, cristais podem ter se formado na superfície do HDL, sendo detectados por meio de difração de raios-X.

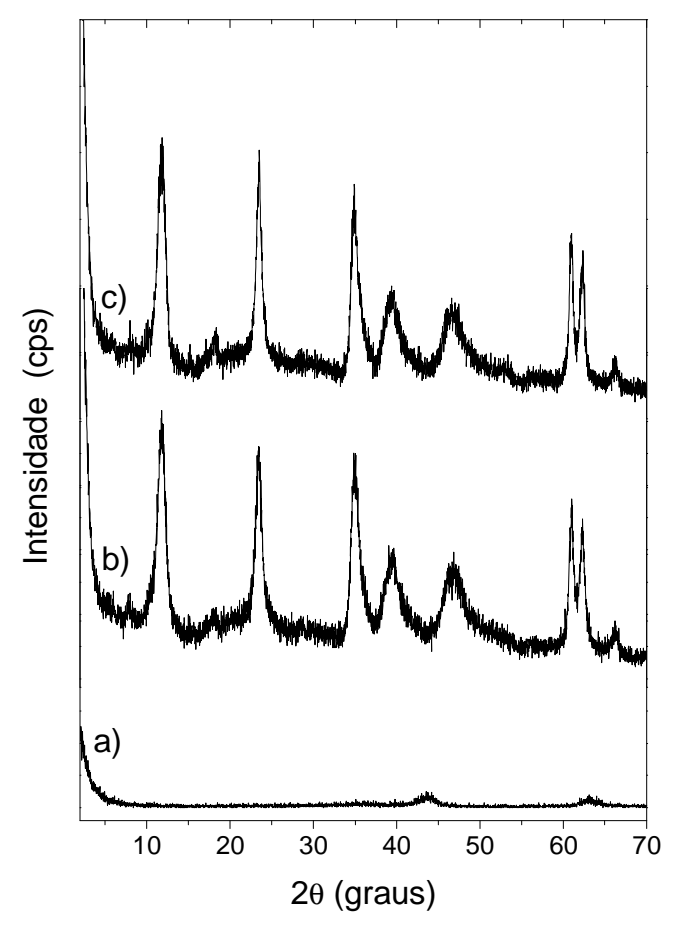

Figura 4.11. DRXP para o HDL calcinado em diversas condições. a) puro; $b$ ) adsorvido a $323 \mathrm{~K}$; c) adsorvido a $298 \mathrm{~K}$. 


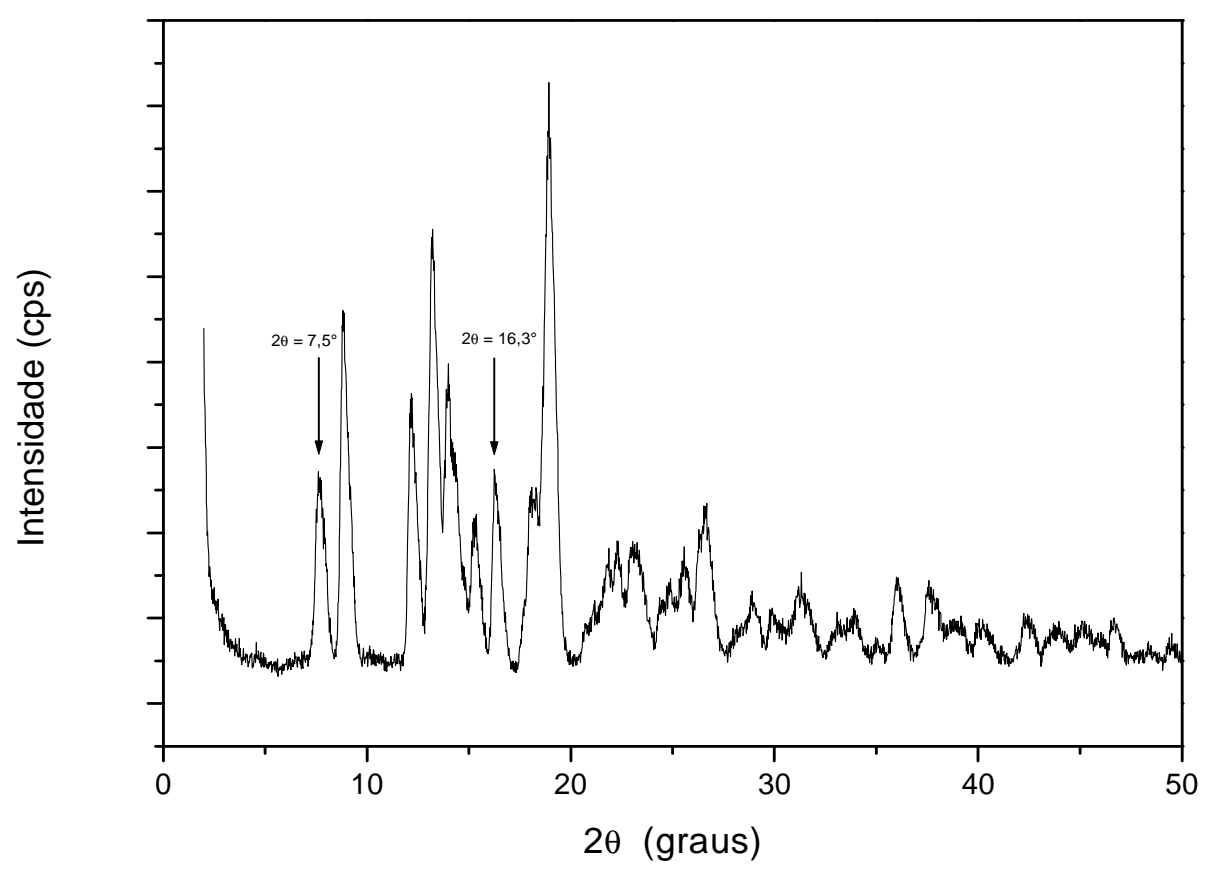

Figura 4.12. DRXP para o colato de sódio puro.

\section{3) Adsorção dos ânions colato em $\mathrm{MgAlCO}_{3}-\mathrm{HDL}$}

Os resultados obtidos do estudo da adsorção do colato no HDL sem calcinar são mostrados na forma de isotermas de adsorção e discutidos, detalhadamente, para cada variável estudada.

Foram escolhidas três variáveis para serem estudadas no processo de adsorção utilizando-se o HDL não calcinado (já citadas: temperatura, pH inicial das soluções de colato e força iônica do meio). Cada variável foi dividida em duas condições, e foram realizadas todas as combinações possíveis entre essas condições, totalizando oito experimentos. As duas condições das variáveis escolhidas foram: temperatura (298K e $323 \mathrm{~K}$ ); força iônica (presença ou ausência de $0,1 \mathrm{M}$ de $\mathrm{NaCl}$ às soluções de colato) e pH inicial da solução de colato $(7,0$ e 10,0$)$. 


\subsection{1) Influência da temperatura e do $\mathrm{pH}$}

O efeito da adsorção do colato foi avaliado em dois valores de $\mathrm{pH}$, já que o adsorvente apresenta valores diferentes de potencial eletrocinético, dependendo do $\mathrm{pH}$ de meio. Os resultados obtidos são mostrados na figura 4.13.
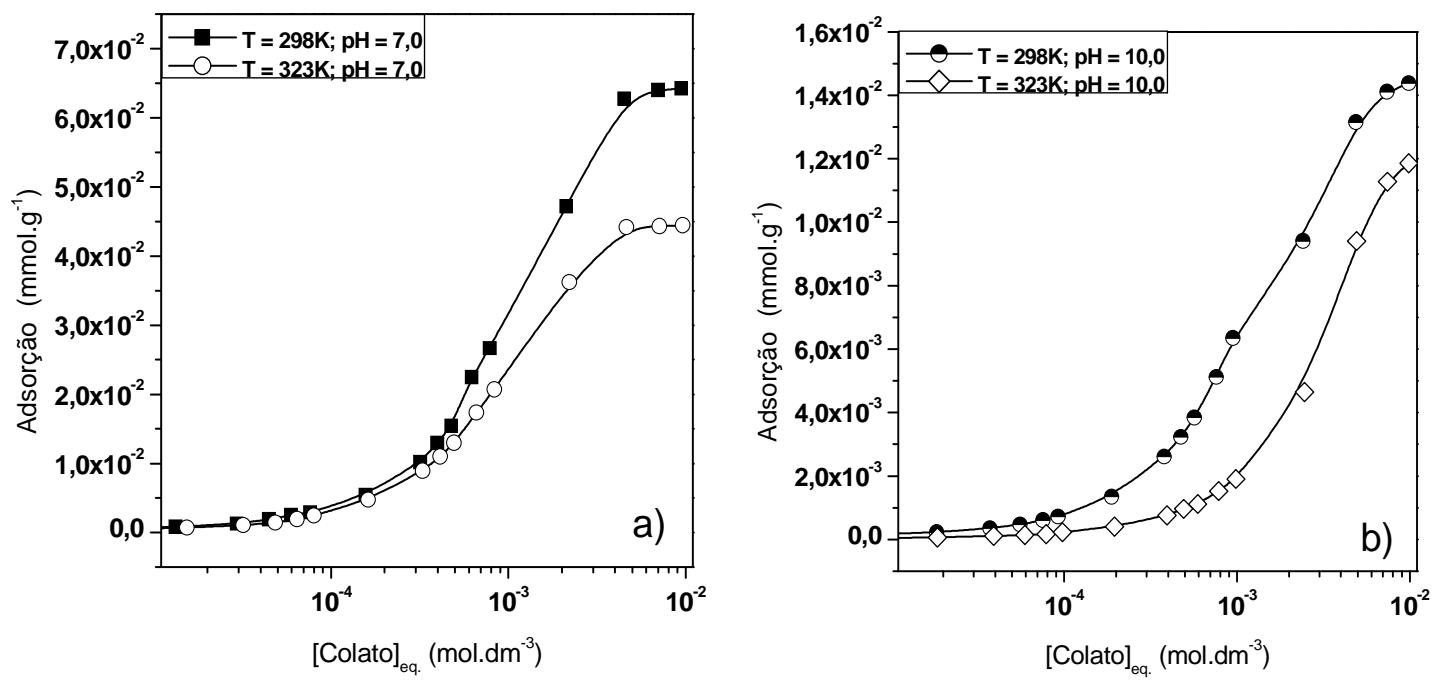

Figura 4.13. Isotermas de adsorção de colato em HDL, a 298 e 323 K. a) pH 7,0; b) pH $10,0$.

De acordo com a classificação proposta por Giles ${ }^{78,79}$, as isotermas da figura 4.12 são do tipo $\mathrm{S}$, indicando que a isoterma apresenta uma dependência da concentração, implicando numa adsorção cooperativa, pelo aumento do número de sítios capazes de reter moléculas de adsorvato. Em ambas as condições de $\mathrm{pH}$, as isotermas se encaixam no subgrupo 2, característica nos casos de saturação da monocamada. Nota-se, pelos gráficos, que as isotermas a pH 7 atingem um patamar de adsorção, que poderia ser interpretado com a saturação dos sítios de adsorção disponíveis. Nas isotermas a pH 10, apesar dos patamares ainda não estarem bem definidos, os perfis das isotermas indicam uma tendência ao início da formação destes.

Comparando os gráficos, é possível notar que o aumento da temperatura causou uma visível redução na quantidade máxima adsorvida, sendo esta diferenciação mais pronunciada em concentrações de equilíbrio mais altas. Esse comportamento está de acordo com o explicado na seção 4.2. Novamente, o aumento na temperatura torna mais difícil a formação de uma organização ou agregado mais compacto na superfície do 
HDL. Essas características têm sido reportadas para vários sistemas de adsorção de tensoativos em óxidos minerais e em HDL.

Pelos gráficos, também fica evidenciado que o aumento do $\mathrm{pH}$ de 7,0 para 10,0 causou uma redução na quantidade máxima adsorvida. A menor capacidade de adsorção em $\mathrm{pH}$ mais alto deve-se à mudança provocada no potencial superficial do adsorvente pela maior concentração de íons hidroxila em solução. Como já demonstrado, o potencial eletrocinético do HDL preparado sofre uma variação, em função do $\mathrm{pH}$, de aproximadamente $16 \mathrm{mV}(36 \mathrm{mV}$ em pH 7 a $16 \mathrm{mV}$ em pH 10). Considerando que as interações responsáveis pela adsorção na superfície do HDL são predominantemente de origem eletrostática, ou seja, dependem das cargas presentes na superfície do HDL e do ânion em solução, a diferença na capacidade de adsorção é justificada.

As curvas de variação de potencial eletrocinético em função da temperatura e do pH para estas isotermas são mostradas na figura 4.14.
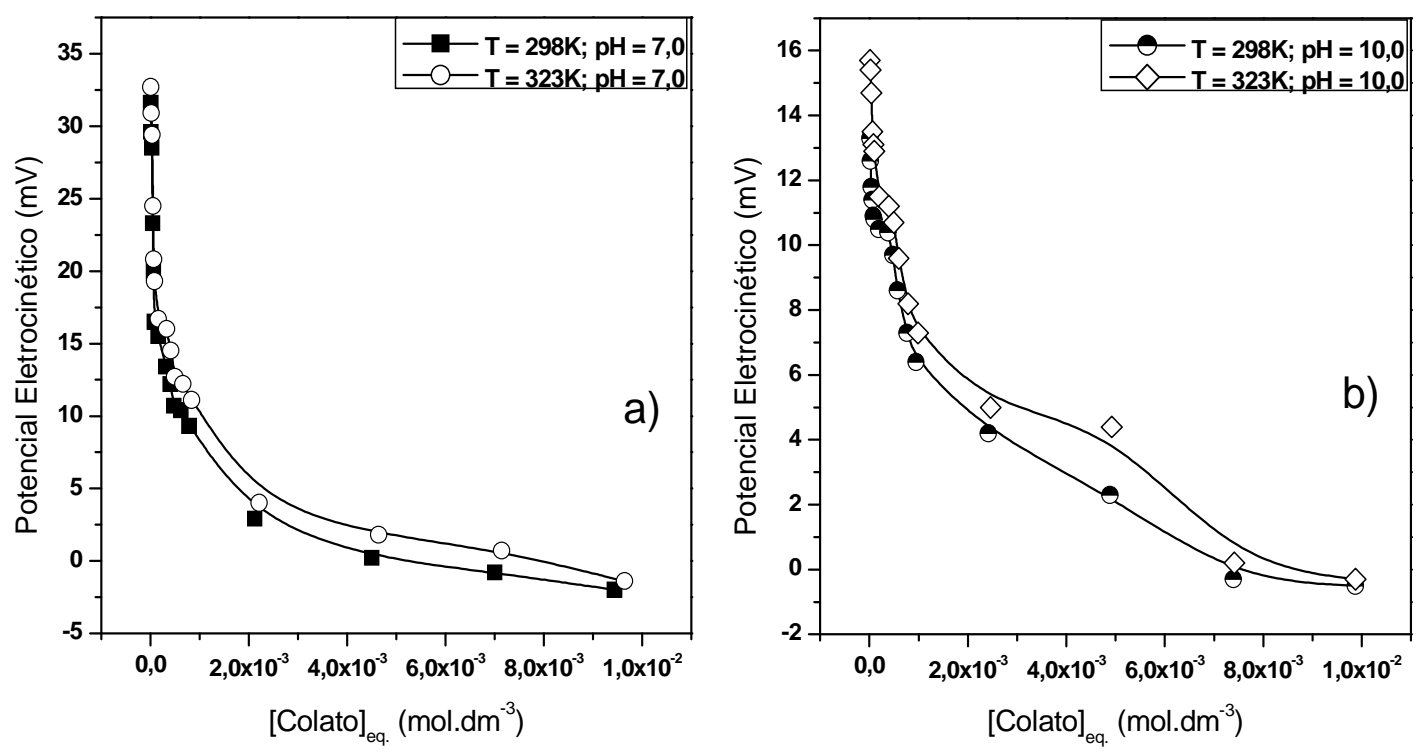

Figura 4.14. Potecial eletrocinético em função da adsorção de colato em HDL, a 298 e 323 K. a) pH 7; b) pH 10.

Os perfis das curvas de potencial eletrocinético relativos à adsorção do colato no HDL, em cada valor de $\mathrm{pH}$, são bastante semelhantes. Em $\mathrm{pH} 7$, as duas curvas começam em valores pouco acima de $31 \mathrm{mV}$ que decrescem com o aumento da concentração de colato, até o ponto em que as duas curvas convergem a valores próximos a zero. No segundo caso, em pH 10, as duas curvas começam em valores próximos a $15 \mathrm{mV}$ decrescendo também até valores próximos a zero. Em ambos os casos, os perfis estão de acordo com o observado em suas respectivas isotermas. Os 
valores próximos a zero nos pontos de maior quantidade adsorvida confirmam a proposta de saturação dos sítios adsorventes disponíveis.

Foram realizadas medidas de $\mathrm{pH}$ em cada uma das soluções de sobrenadante obtidas após o contato com o adsorvente. A figura 4.15 mostra a variação do $\mathrm{pH}$ com a concentração.
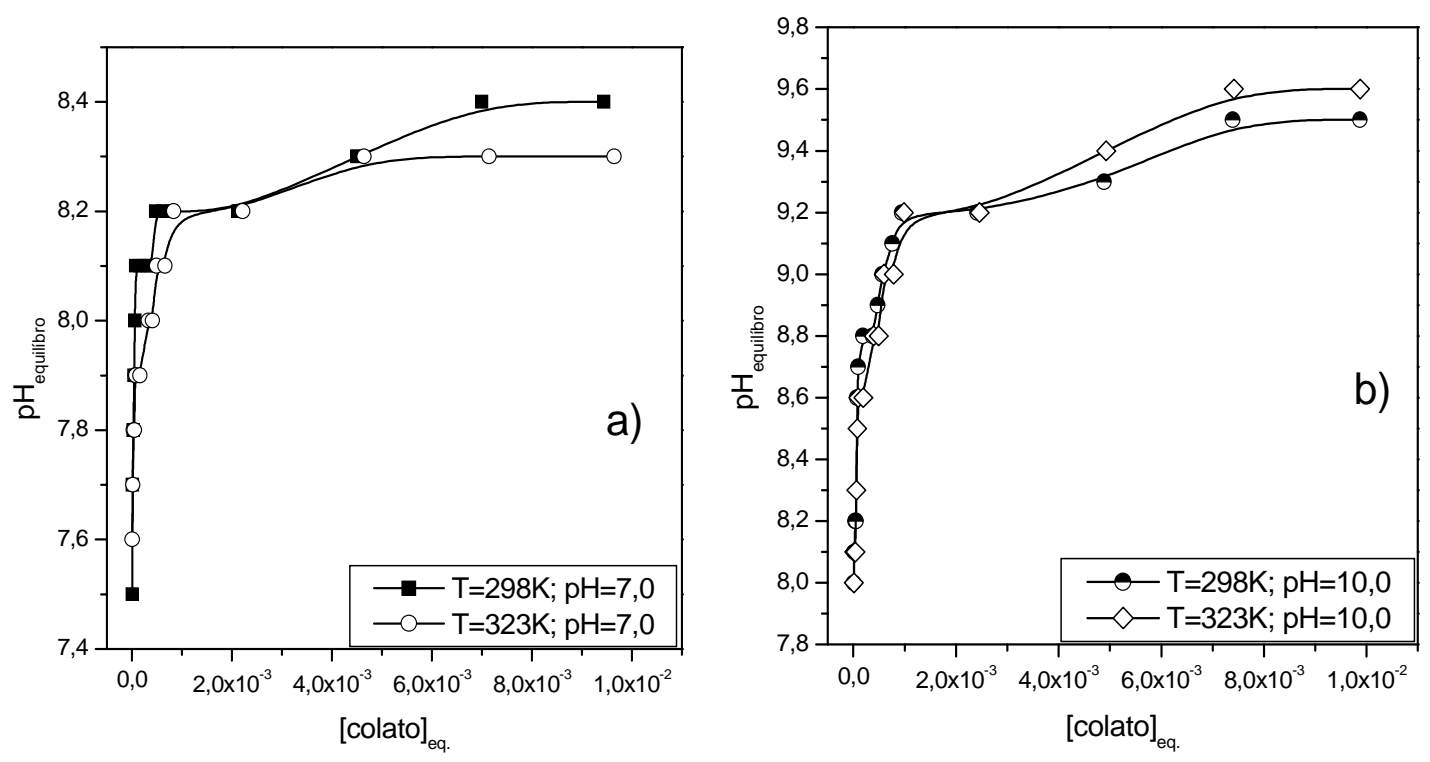

Figura 4.15. Variação do pH do sobrenadante em função da adsorção de colato em HDL, a 298 e 323K. a) pH 7; b) pH 10.

Os gráficos mostram dois comportamentos distintos para os materiais estudados. No primeiro caso, nos experimentos preparados em $\mathrm{pH}$, após o equilíbrio, o $\mathrm{pH}$ observado foi maior que o inicial, começando em valores de 7,45 e 7,6 (298 e $323 \mathrm{~K}$ ), sendo incrementado gradualmente até tornar-se constante em valores de aproximadamente 8,3 e 8,4 (à 298 e à $323 \mathrm{~K}$ respectivamente). Isso ocorre porque em pH 7, uma pequena quantidade do HDL pode ser solubilizada, liberando hidroxilas para a solução, promovendo um discreto incremento no $\mathrm{pH}$ da solução, conforme a adsorção inicia-se em baixas concentrações de colato. Quando o $\mathrm{pH}$ atinge um determinado valor, o equilíbrio é atingido e o mesmo permanece constante.

No segundo caso, nos experimentos realizados em $\mathrm{pH} 10$ observou-se nas menores concentrações um valor de $\mathrm{pH}$ menor do que o inicial $(8,0$ e 8,1 à 298 e à $323 \mathrm{~K}$ respectivamente), que foi aumentado gradualmente até convergir, nas duas temperaturas, para o valor próximo do inicial $(\sim 10,0)$. Esse comportamento pode ser explicado pelo fato de que em pH 10, a concentração de íons $\mathrm{OH}^{-}$em solução é grande 
o suficiente para promover uma competição com a adsorção do colato pelos sítios de adsorção do HDL, em baixas concentrações do colato (primeiros pontos da curva). Quando a concentração de colato aumenta, o equilíbrio de adsorção é deslocado favorecendo a adsorção do mesmo, fazendo com que a diminuição do pH seja cada vez menor, até que a concentração do colato seja suficientemente alta para manter o pH da solução constante.

Os sólidos adsorvidos correspondentes a alguns pontos da região do patamar nas isotermas mostradas na figura 4.13 foram submetidos à análise por difração de raios $\mathrm{X}$ no pó. Os difratogramas foram comparados com o obtido para o adsorvente puro (figura 4.16).

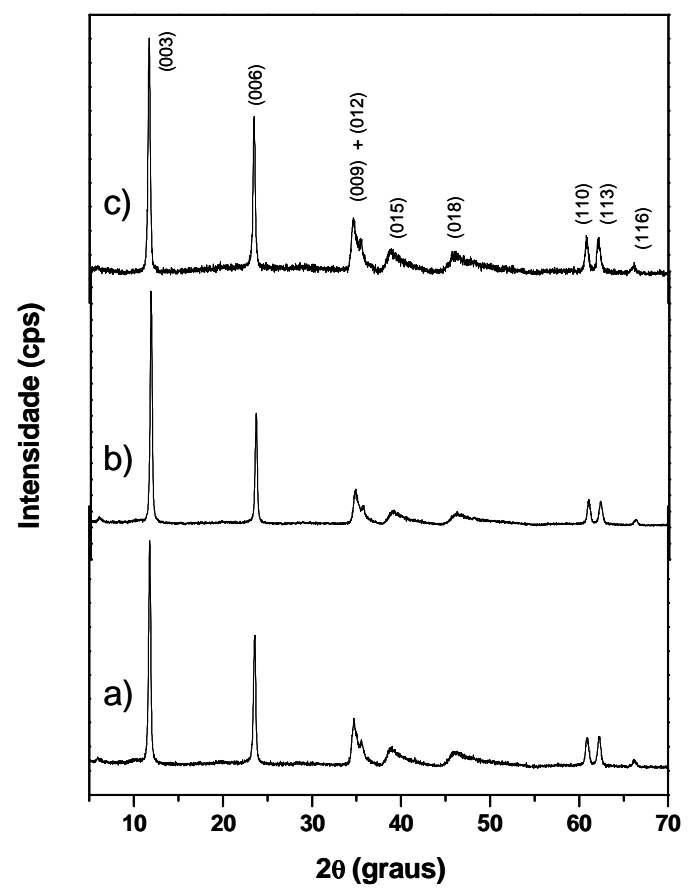

Figura 4.16. DRXP para o HDL adsorvido com colato em diferentes condições. a) puro; $b$ ) adsorvido a $323 \mathrm{~K} \mathrm{a} \mathrm{pH} \mathrm{7;} \mathrm{c)} \mathrm{adsorvido} \mathrm{a} 298 \mathrm{~K}$ a pH 7.

Os difratogramas indicam que não ocorreu substituição do ânion interlamelar $\mathrm{CO}_{3}{ }^{2-}$ pelo colato na forma aniônica, visto que não foi observada alteração no espaçamento basal do HDL. Em todas as amostras, o valor de $d=7,59 \AA$ permanece constante, indicando que ocorre adsorção de colato apenas na superfície. Os valores obtidos para o tamanho médio dos cristalitos, para os sólidos correspondentes aos últimos pontos nas isotermas de adsorção, são mostrados na tabela 4.4. Estes resultados 
estão de acordo com o observado nas isotermas: os valores de tamanho médio de cristalitos são sempre maiores para os sólidos adsorvidos.

Tabela 4.4. Tamanho médio dos cristalitos para o HDL adsorvido com colato variando o $\mathrm{pH}$ e a temperatura.

\begin{tabular}{cc}
\hline Amostra & Tamanho (Å) \\
\hline HDL puro & 433,5 \\
323K; pH 10 & 454,7 \\
298K; pH 10 & 459,8 \\
323K; pH 7 & 482,7 \\
298K; pH 7 & 495,4
\end{tabular}

As mesmas amostras analisadas por DRXP foram submetidas à análise por IVTF, e os espectros são mostrados na figura 4.17.

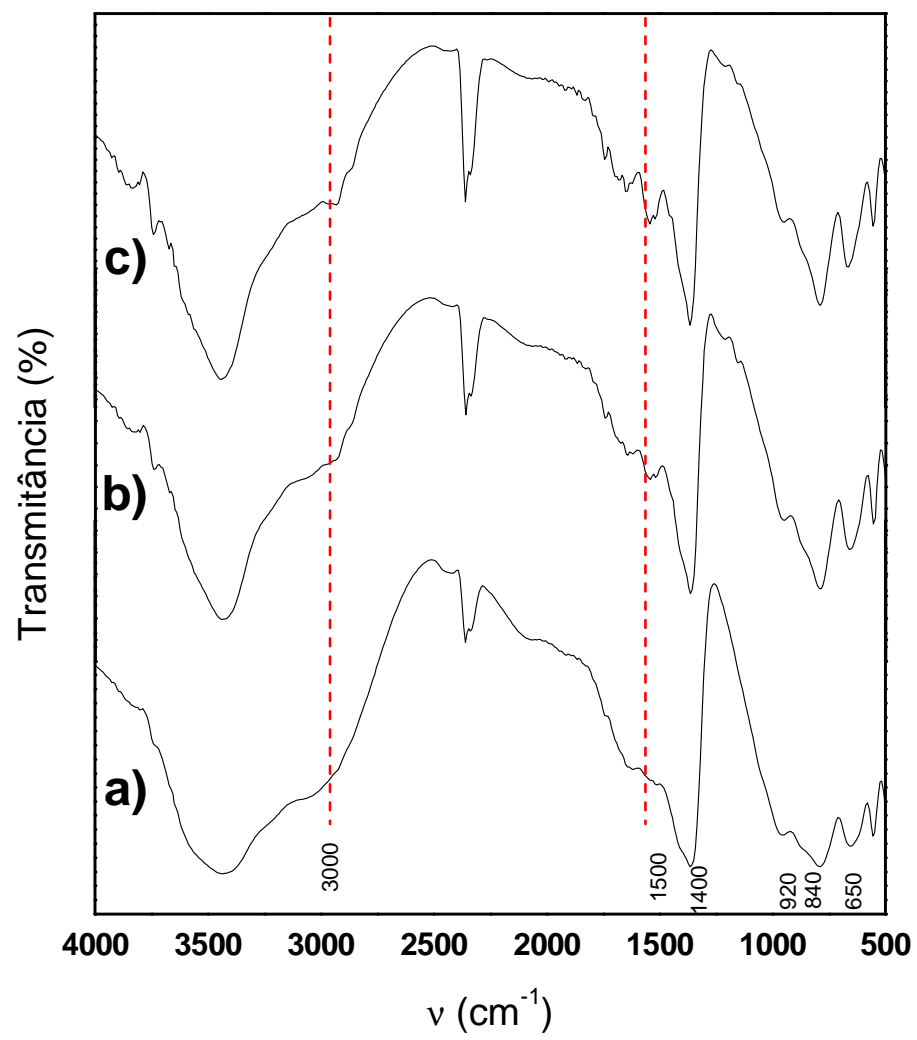

Figura 4.17. Espectros na região do infravermelho para o HDL adsorvido com colato em diferentes condições. a) puro; b) adsorvido a $323 \mathrm{~K} \mathrm{a} \mathrm{pH} \mathrm{7;} \mathrm{c)} \mathrm{adsorvido} \mathrm{a} 298 \mathrm{~K} \mathrm{a}$ $\mathrm{pH} 7$. 
Os espectros obtidos para o material adsorvido apresentam perfil diferente daquele obtido para o HDL puro. A presença de bandas características na região próxima a $3400 \mathrm{~cm}^{-1}$, são atribuídas à água de hidratação e às hidroxilas (das lamelas). As bandas localizadas entre $2750-3000 \mathrm{~cm}^{-1}$ estão associadas às ligações de hidrogênio existentes entre os dímeros de ânions colato intercalados no domínio interlamelar.

As bandas localizadas na região próxima a $1500 \mathrm{~cm}^{-1}$ comprovam a presença de composto carboxílico no material. Nos compostos em que existem ligações de hidrogênio intermoleculares entre ácidos carboxílicos, a banda $\mathrm{C}=\mathrm{O}$ aparece na região de $1700 \mathrm{~cm}^{-1}$.

A tabela 4.5 mostra a adsorção máxima obtida em diferentes condições, assim como a eficiência de adsorção no último ponto de cada isoterma. Considera-se como "eficiência" a porcentagem de massa do adsorvato adsorvida na região do platô, em relação à quantidade de adsorvente utilizada. Os cálculos foram realizados utilizando a quantidade de colato inicial como sendo a máxima disponível para ser adsorvida (100\%), considerando-se a influência da temperatura e do pH inicial das soluções de colato.

Tabela 4.5. Dados sobre a quantidade máxima adsorvida pelo HDL não-calcinado, em diversas condições, considerando-se a influência da temperatura e do $\mathrm{pH}$.

\begin{tabular}{ccccc}
\hline $\begin{array}{c}\text { Temperatura } \\
\text { (K) }\end{array}$ & $\mathbf{p H}$ & $\mathbf{0 , 1} \mathbf{~ M ~ ( N a C l ) ~}$ & $\begin{array}{c}\text { Adsorção } \\
\text { Máxima } \\
\left(\mathbf{m m o l}^{-1} \mathbf{)}\right)\end{array}$ & Eficiência (\%) \\
\hline 298 & 7,0 & Não & $6,424 \times 10^{-2}$ & 5,561 \\
323 & 7,0 & Não & $4,444 \times 10^{-2}$ & 3,555 \\
298 & 10,0 & Não & $1,438 \times 10^{-2}$ & 1,152 \\
323 & 10,0 & Não & $1,186 \times 10^{-2}$ & 0,951
\end{tabular}

Os dados da tabela confirmam que o aumento da temperatura diminui a adsorção de colato. $\mathrm{O}$ aumento do $\mathrm{pH}$ inicial das soluções de colato também prejudica sensivelmente a adsorção máxima e, conseqüentemente, a eficiência de adsorção. 


\subsection{2) Influência da Força Iônica e do pH}

O efeito da alteração da força iônica causado pela adição de um sal $(\mathrm{NaCl})$ na adsorção do colato foi avaliado também em dois valores diferentes de $\mathrm{pH}$ e mantendo-se a temperatura constante a $298 \mathrm{~K}$ As isotermas são apresentadas na figura 4.18.
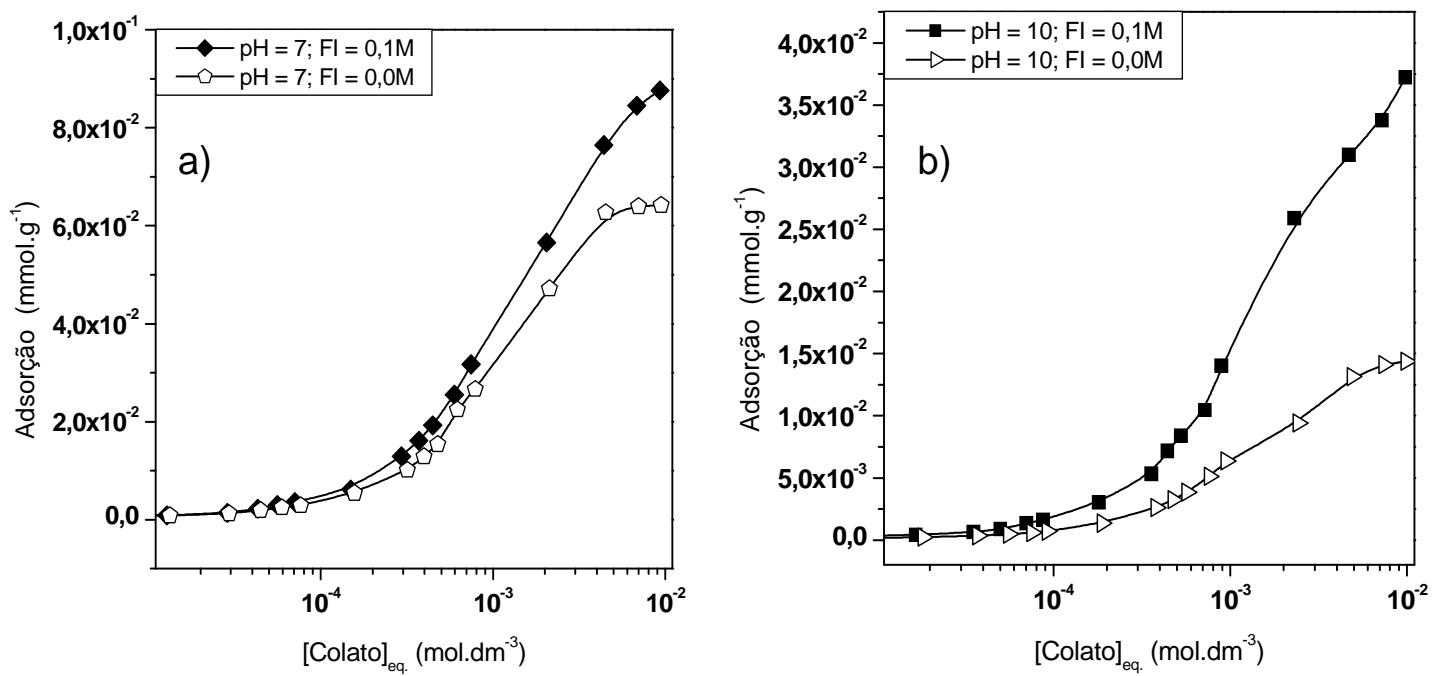

Figura 4.18. Isotermas de adsorção de colato em HDL, a 298 K com e sem adição de $\mathrm{NaCl} a) \mathrm{pH} 7,0 ; b) \mathrm{pH} 10,0$.

Em ambos os casos, as isotermas obtidas em força iônica maior podem ser classificadas como pertencentes à classe S, subgrupo 1 , de acordo com Giles, ${ }^{78,79}$ indicando sistemas com a monocamada do adsorvato não saturada. Isso explica a não formação de um patamar bem definido nessas condições experimentais. As isotermas sem alteração da força iônica já foram discutidas em 4.3.1.

Em ambos os valores de $\mathrm{pH}$, as isotermas obtidas com aumento da força iônica do meio apresentaram uma capacidade de adsorção maior do que a obtida sem a adição de $\mathrm{NaCl}$. Esse efeito já foi discutido no estudo cinético em 4.2.

As curvas de variação do potencial eletrocinético em função da força iônica e do pH para estas isotermas são mostradas na figura 4.19. 

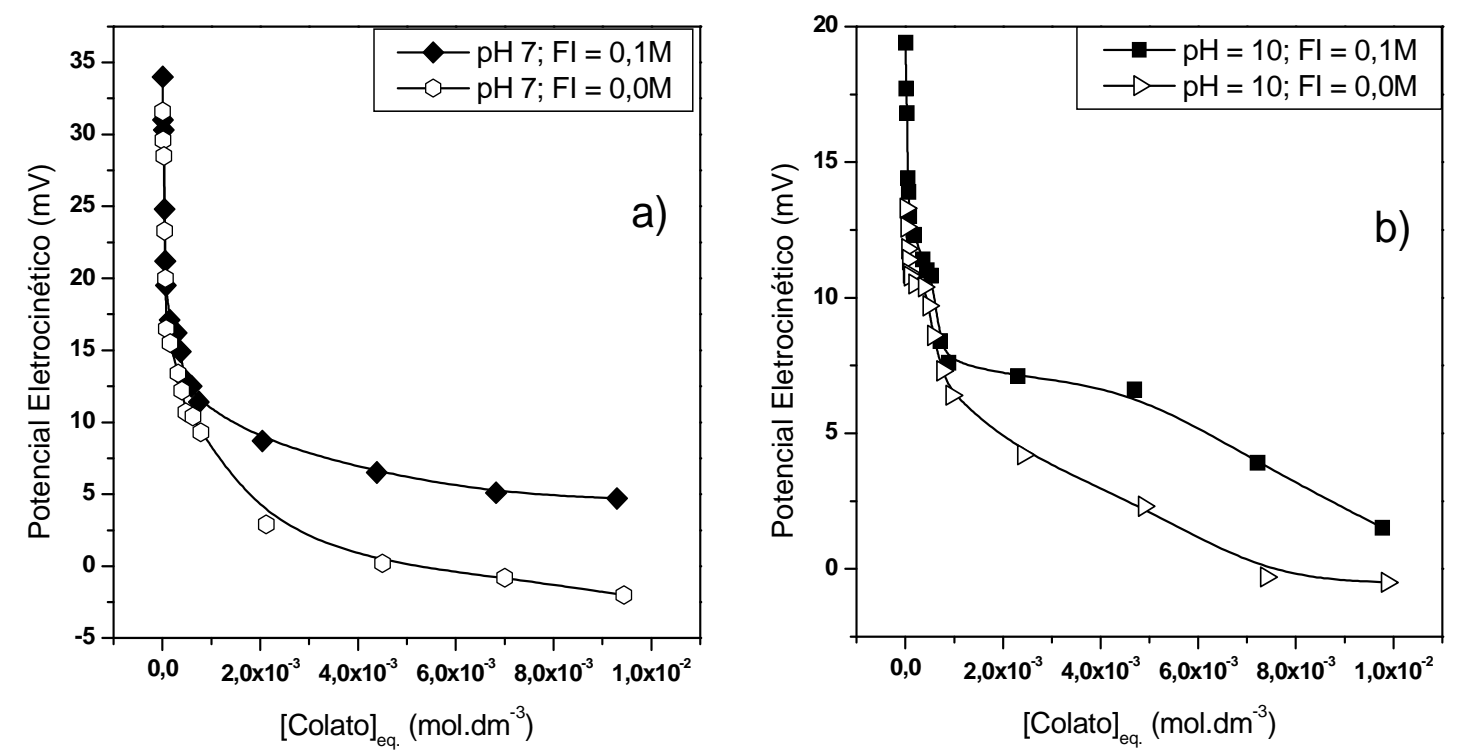

Figura 4.19. Potencial Eletrocinético em função da adsorção de colato em HDL, a 298 K com e sem adição de $\mathrm{NaCl}$. a) pH 7; b) pH 10.

As curvas do potencial eletrocinético relativo à adsorção de colato no HDL apresentam perfis semelhantes. Em pH 7, as curvas começam em valores próximos a 34 e $32 \mathrm{mV}$, decrescendo, com o aumento da concentração de colato até valores próximos de 5 e $-2 \mathrm{mV}$, respectivamente para as isotermas com e sem adição de $\mathrm{NaCl}$. Em pH 10, as curvas começam em valores próximos de 19 e $13 \mathrm{mV}$ e decrescem até valores próximos 1,5 e $-0,5 \mathrm{mV}$, respectivamente.

Observa-se que o potencial eletrocinético medido é mais positivo para as suspensões obtidas em presença de $\mathrm{NaCl}$, embora a adsorção seja maior nestas condições. Esse fenômeno pode estar atribuído ao fato de que o sal promove um aumento no tamanho das partículas, devido à formação de agregados de tamanho significativamente maior. Esses agregados seriam grandes o suficiente para rapidamente decantar na suspensão, fazendo com que os resultados das medidas do potencial eletrocinético não levem em conta o potencial destas partículas e os valores observados sejam relativamente mais positivos do que os reais, quando a concentração de adsorvato é suficientemente alta. ${ }^{93}$

Mais uma vez, foram realizadas medidas de $\mathrm{pH}$ em cada uma das soluções de sobrenadante, obtidas após o contato com o adsorvente. A figura 4.20 mostra a variação do pH com a concentração. 

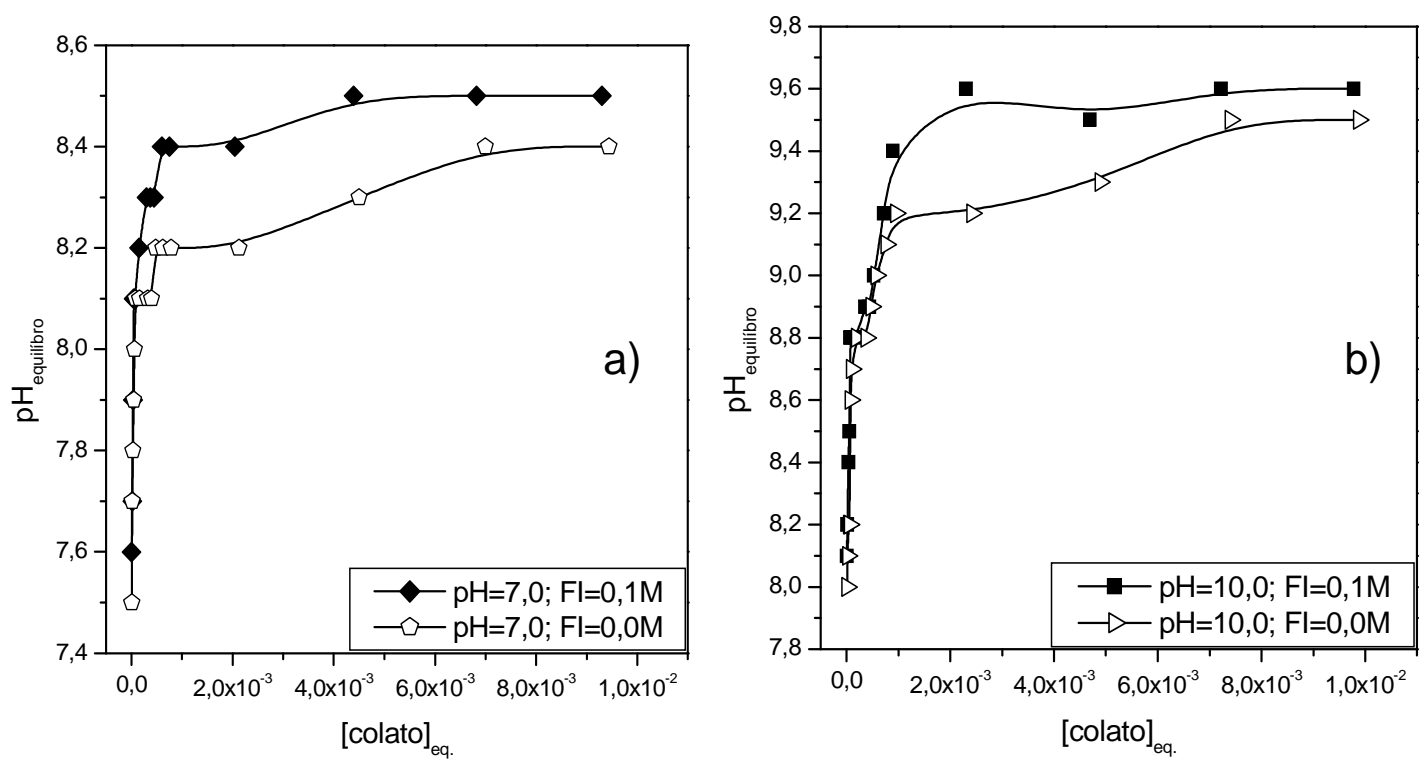

Figura 4.20. Variação do pH em função da adsorção de colato em HDL, com e sem adição de $0,1 \mathrm{M}$ de $\mathrm{NaCl}$ no meio. $a$ ) $\mathrm{pH} 7 ; b) \mathrm{pH} 10$.

Os gráficos mostram dois comportamentos distintos para os materiais estudados. Como já discutido em 4.3.1, nos experimentos preparados em $\mathrm{pH} 7$, após o equilíbrio, o $\mathrm{pH}$ observado foi maior que o inicial, começando em valores de 7,5 e 7,6 (0,0M de $\mathrm{NaCl}$ e $0,1 \mathrm{M}$ de $\mathrm{NaCl}$ ), sendo incrementado gradualmente até tornar-se constante em valores de aproximadamente 8,3 e 8,4. No segundo caso, nos experimentos realizados em pH 10 observou-se nas menores concentrações um valor de $\mathrm{pH}$ menor do que o inicial (8,0 e 8,1 com 0,0 e $0,1 \mathrm{M}$ de $\mathrm{NaCl}$, respectivamente), que foi aumentado gradualmente até convergir, nas duas temperaturas, ao valor próximo do inicial $(\sim 10,0)$.

Novamente, alguns pontos onde houve maior adsorção, foram submetidos à análise de raios-X. O resultado é mostrado na figura 4.21, indicando que não houve alteração no espaçamento basal do HDL e que a adsorção de colato ocorre apenas na superfície do material. O tamanho médio dos cristalitos para os sólidos correspondentes aos últimos pontos nas isotermas de adsorção é mostrado na tabela 4.6. Mais uma vez, os valores de tamanho médio de cristalitos são maiores para os sólidos adsorvidos. 


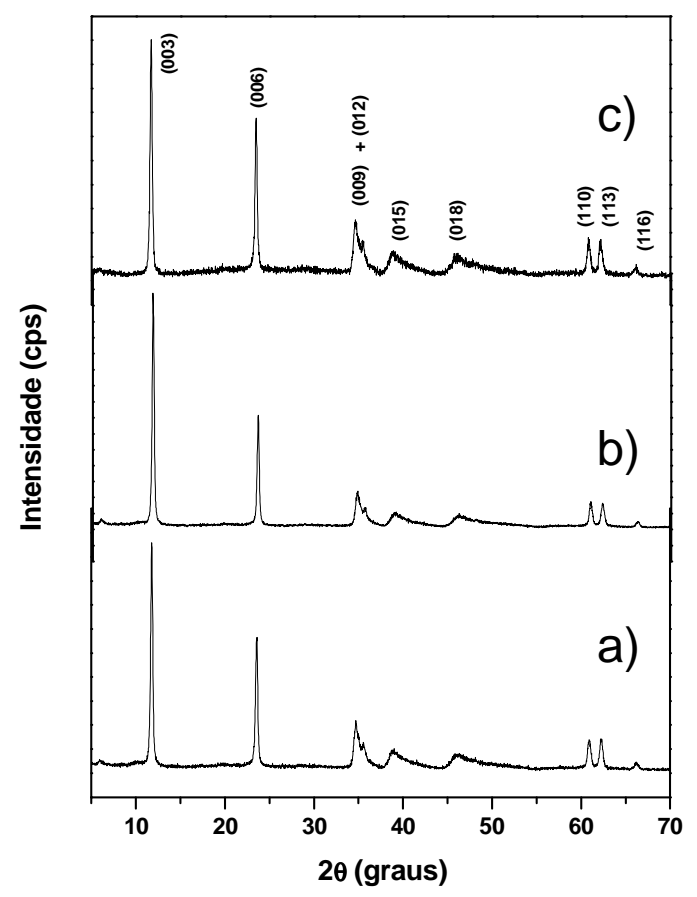

Figura 4.21. DRXP para o HDL adsorvido com colato em diferentes condições. $a$ ) puro; b) adsorvido a $298 \mathrm{~K}, \mathrm{pH} 10$; $c$ ) adsorvido a $298 \mathrm{~K}$ a pH 7.

Tabela 4.6. Tamanho médio dos cristalitos para o HDL adsorvido com colato variando a força iônica e o $\mathrm{pH}$.

\begin{tabular}{|c|c|}
\hline Amostra & Tamanho $(\AA)$ \\
\hline HDL puro & 433,5 \\
\hline $\mathrm{pH} 10 ; \mathrm{FI} 0,0 \mathrm{M}$ & 459,8 \\
\hline $\mathrm{pH} 10 ; \mathrm{FI} 0,1 \mathrm{M}$ & 477,1 \\
\hline pH 7; FI 0,0M & 495,4 \\
\hline $\mathrm{pH} 7 ; \mathrm{FI} 0,1 \mathrm{M}$ & 498,2 \\
\hline
\end{tabular}

As mesmas amostras analisadas por DRXP foram submetidas à análise por IVTF, e os espectros são mostrados na figura 4.22. 


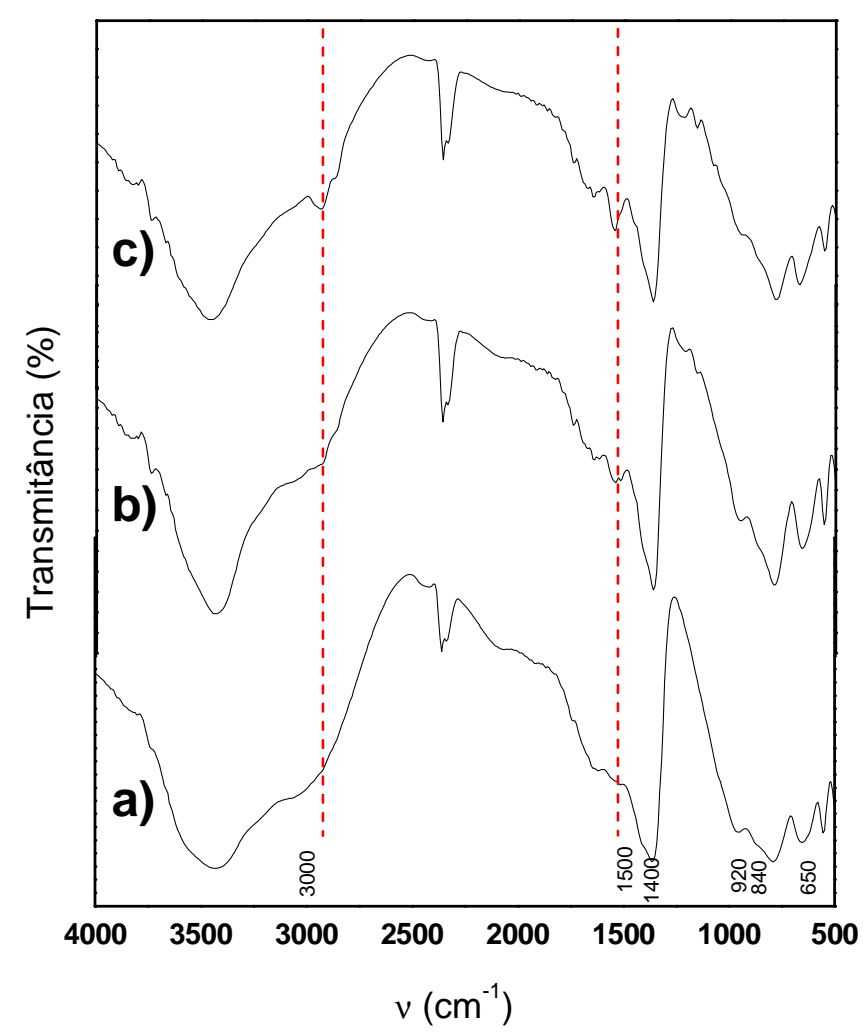

Figura 4.22. Espectros de IV-TF para o HDL adsorvido com colato em diferentes condições. $a$ ) puro; $b$ ) adsorvido a $298 \mathrm{~K} \mathrm{e} \mathrm{pH} \mathrm{10;} c$ ) adsorvido a $298 \mathrm{~K} \mathrm{e} \mathrm{pH} 7$.

Mais uma vez, os espectros obtidos para o material adsorvido apresentaram bandas diferentes quando comparadas ao HDL puro. Os espectros dos sólidos adsorvidos mostram bandas características já mencionadas em 4.3.1.

A tabela 4.7 mostra a adsorção máxima obtida em diferentes condições, considerando-se a influência da força iônica e do pH inicial das soluções de colato, assim como a eficiência da adsorção.

Tabela 4.7. Dados sobre a quantidade máxima adsorvida pelo HDL não-calcinado, em diversas condições, considerando-se a influência da temperatura e do pH .

\begin{tabular}{ccccc}
\hline $\mathbf{p H}$ & $\mathbf{0 , 1} \mathbf{M}(\mathbf{N a C l})$ & $\begin{array}{c}\text { Temperatura } \\
(\mathbf{K})\end{array}$ & $\begin{array}{c}\text { Adsorção } \\
\text { Máxima } \\
\left(\mathbf{m m o l . g}^{-1}\right)\end{array}$ & Eficiência (\%) \\
\hline 7,0 & Sim & 298 & $8,765 \times 10^{-2}$ & 7,010 \\
7,0 & Não & 298 & $6,424 \times 10^{-2}$ & 5,561 \\
10,0 & Sim & 298 & $3,723 \times 10^{-2}$ & 2,959 \\
10,0 & Não & 298 & $1,438 \times 10^{-2}$ & 1,152
\end{tabular}




\subsection{3) Influência da Temperatura e da Força Iônica}

O efeito da alteração da força iônica causado pela adição de um sal $(\mathrm{NaCl})$ na adsorção do colato foi avaliado também em dois valores diferentes de temperatura (298K e 323K) e mantendo-se, dessa vez, o pH inicial das soluções de colato no valor fixo de 7,0. As isotermas são apresentadas na figura 4.23.
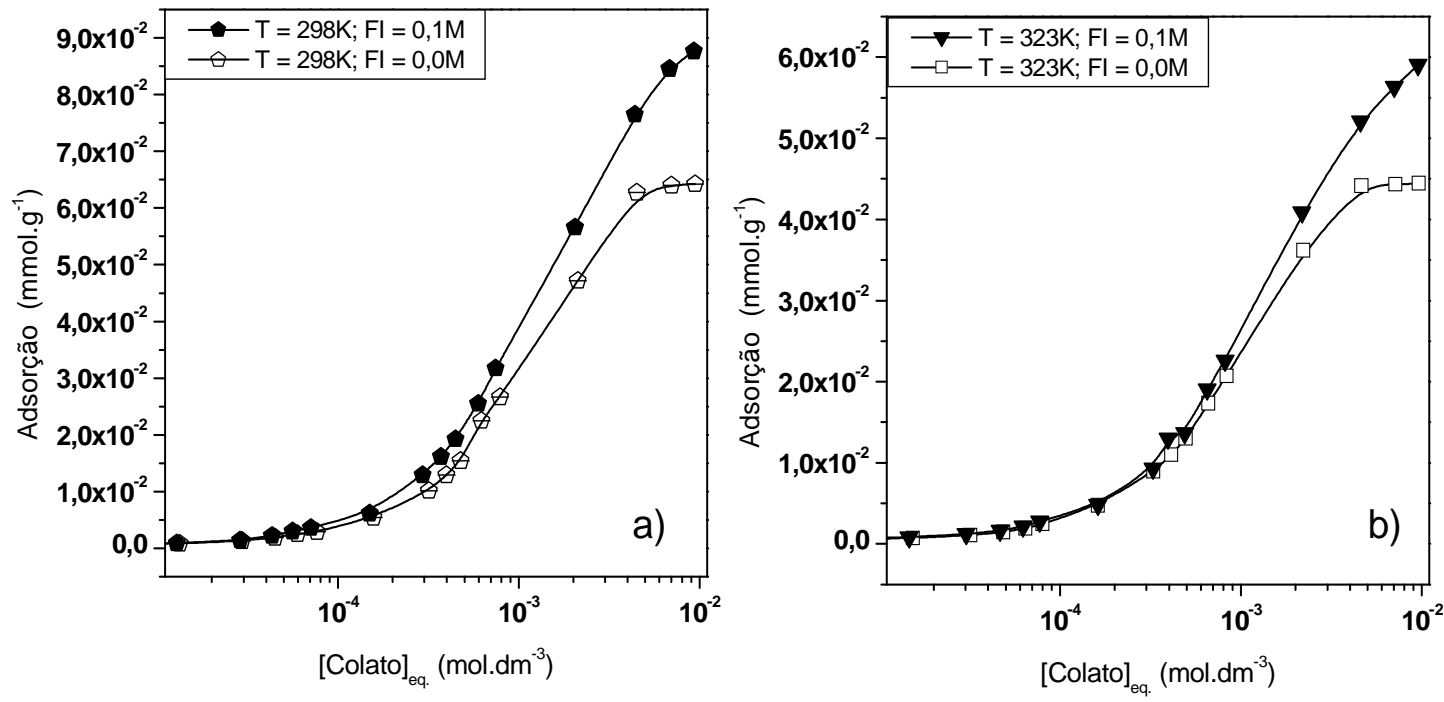

Figura 4.23. Isotermas de adsorção de colato em HDL, a pH 7,0 com e sem adição de NaCl. a) 298K; b) 323K.

Seguindo a classificação proposta por Giles, ${ }^{78,79}$ as isotermas obtidas em força iônica maior, em ambos os casos, podem ser classificadas na classe S, subgrupo 1, indicando sistemas com a monocamada do adsorvato não saturada. Novamente, não temos a formação de um patamar bem definido nessas condições experimentais.

Já as isotermas obtidas sem a adição de $0,1 \mathrm{M}$ de $\mathrm{NaCl}$ às soluções de colato se encaixam na classe $S$, subgrupo 2 da classificação de Giles, indicando que a isoterma apresenta uma dependência da concentração (adsorção cooperativa). Esse tipo de isoterma é característica nos casos onde ocorre a saturação da monocamada. É nítido, nas figuras das isotermas, que as curvas atingem um patamar de adsorção.

Em ambos os valores de $\mathrm{pH}$, as isotermas obtidas com aumento da força iônica do meio apresentaram uma capacidade de adsorção maior do que a obtida sem a adição de $\mathrm{NaCl}$. O aumento da temperatura causou novamente uma redução na quantidade máxima adsorvida. Esse efeito já foi discutido na seção 4.2. 
As curvas de variação do potencial eletrocinético em função da temperatura e da força iônica para estas isotermas são mostradas na figura 4.24.
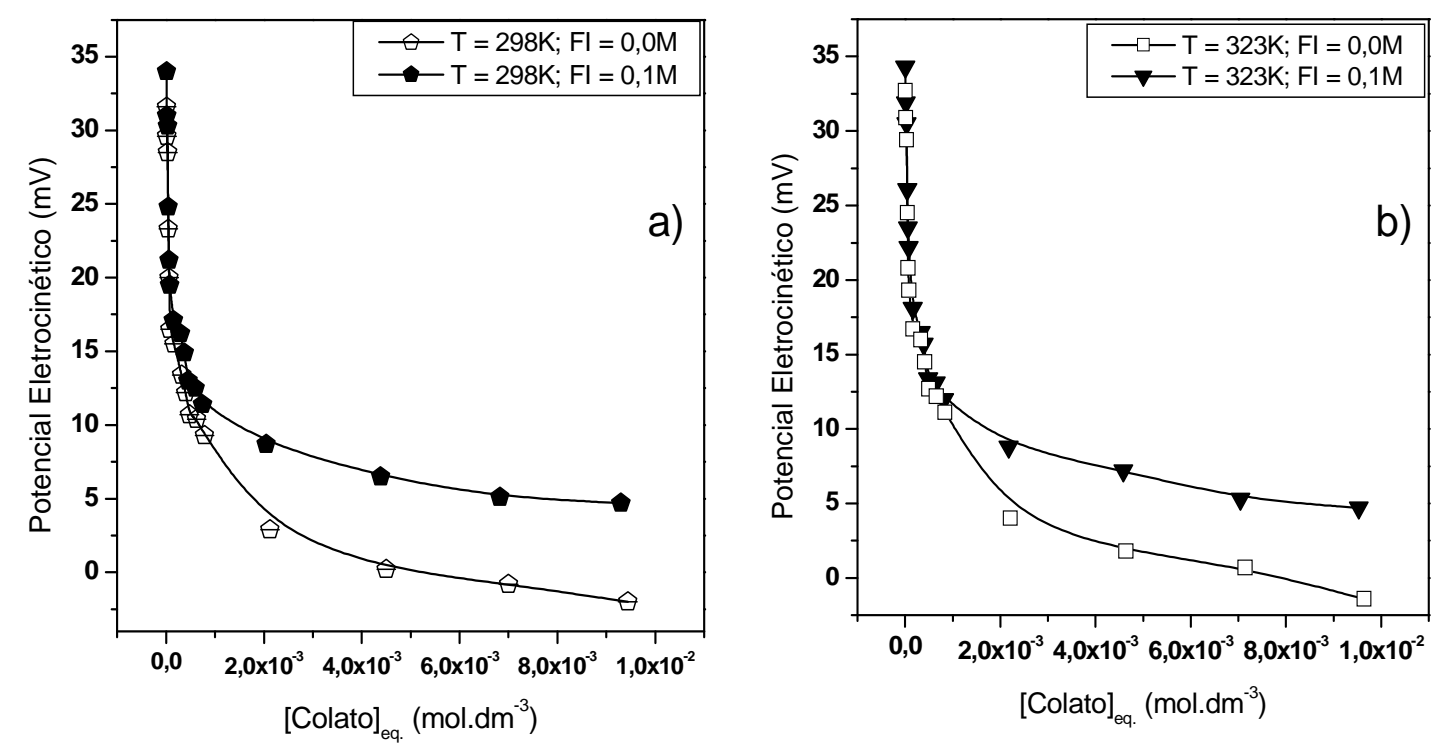

Figura 4.24. Potencial Eletrocinético em função da adsorção de colato em HDL, (pH inicial das soluções igual a 7,0) com e sem adição de $\mathrm{NaCl}$. a) 298K; b) 323K.

As curvas do potencial eletrocinético relativo à adsorção de colato no HDL, nestas condições, apresentam perfis semelhantes. Na temperatura de $298 \mathrm{~K}$, as curvas começam em valores próximos a 34 e $31 \mathrm{mV}$, decrescendo, com o aumento da concentração de colato até valores próximos de 4 para a isoterma com adição de $\mathrm{NaCl}$ e valores próximos a zero para a isoterma sem adição de $\mathrm{NaCl}$. $\mathrm{Na}$ temperatura de $393 \mathrm{~K}$, as curvas começam em valores próximos a $33 \mathrm{mV}$ e decrescem até valores próximos a 5,0 para a isoterma com adição de $0,1 \mathrm{M}$ de $\mathrm{NaCl}$ e para valores próximos de zero para a isoterma sem adição de $\mathrm{NaCl}$. Novamente, os valores de potencial eletrocinético obtidos para as isotermas com adição de $0,1 \mathrm{M}$ de $\mathrm{NaCl}$ são mais positivos, efeito já explicado na seção 4.3.2.

A figura 4.25 mostra a variação do $\mathrm{pH}$ com a concentração, das soluções de sobrenadante obtidas após o contato com o adsorvente. 

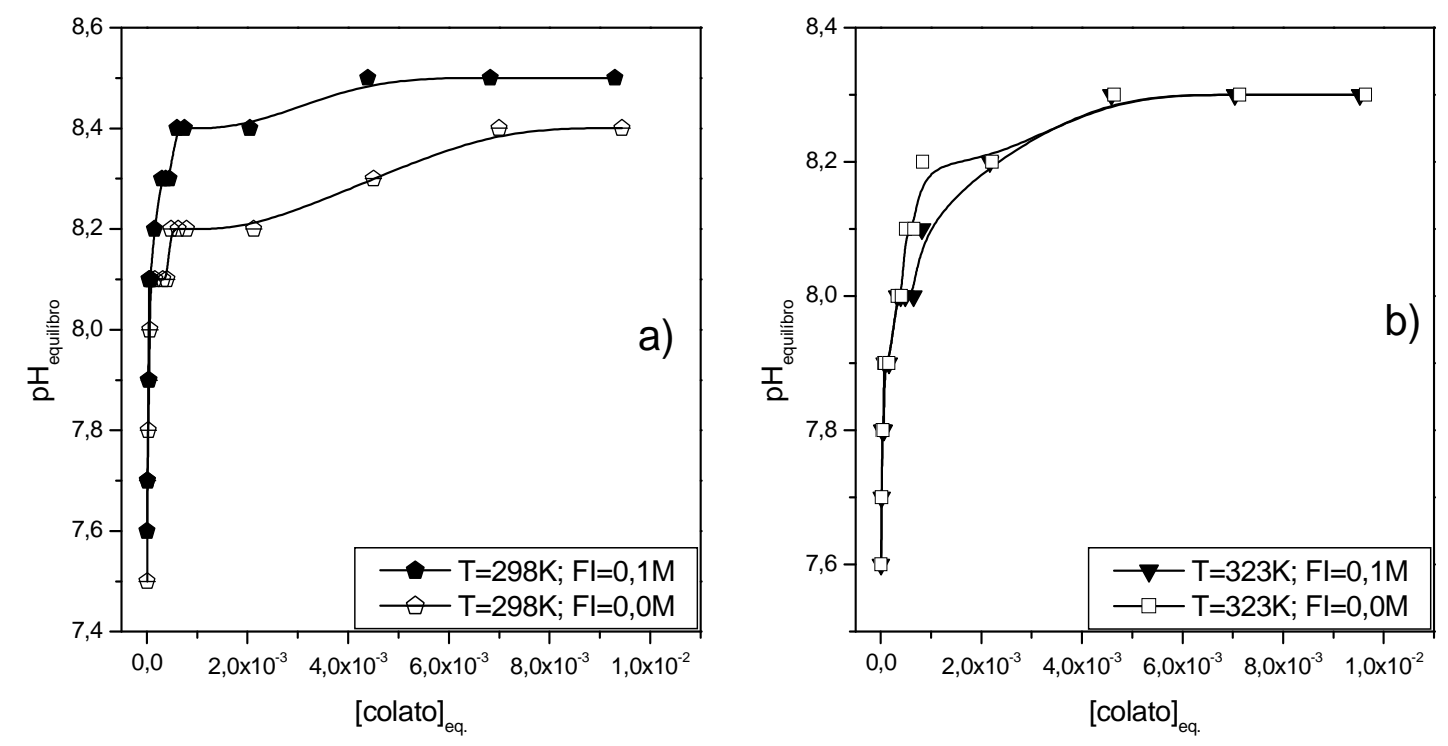

Figura 4.25. Variação do pH em função da adsorção de colato em HDL, com e sem adição de $0,1 \mathrm{M}$ de $\mathrm{NaCl}$ no meio. a) $298 \mathrm{~K}$; $b$ ) 323K.

Os resultados já discutidos em 4.3.1 e 4.3.2 se repetem. Nos experimentos preparados a 298K, após o equilíbrio, o pH observado foi maior que o inicial, começando em valores de 7,45 e 7,5 (0,0M de $\mathrm{NaCl}$ e $0,1 \mathrm{M}$ de $\mathrm{NaCl})$, sendo incrementado gradualmente até tornar-se constante em valores de aproximadamente 8,3 e 8,4 . No segundo caso, nos experimentos preparados a $323 \mathrm{~K}$, o pH observado também foi maior que o inicial, começando em valores iguais a 7,6 (em ambos os casos, com e sem adição de $0,1 \mathrm{M}$ de $\mathrm{NaCl}$ ), sofrendo um incremento até valores de aproximadamente 8,3 .

Os pontos na região do patamar nas isotermas onde houve maior adsorção foram submetidos à análise de raios-X. O resultado está apresentado na figura 4.26. Mais uma vez o espaçamento basal do HDL se manteve constante, indicando que a adsorção de colato ocorre apenas na superfície do material. O tamanho médio dos cristalitos para os sólidos correspondentes aos últimos pontos nas isotermas de adsorção é mostrado na tabela 4.8. Como já observado anteriormente, os valores de tamanho médio de cristalitos são maiores para os sólidos adsorvidos. 


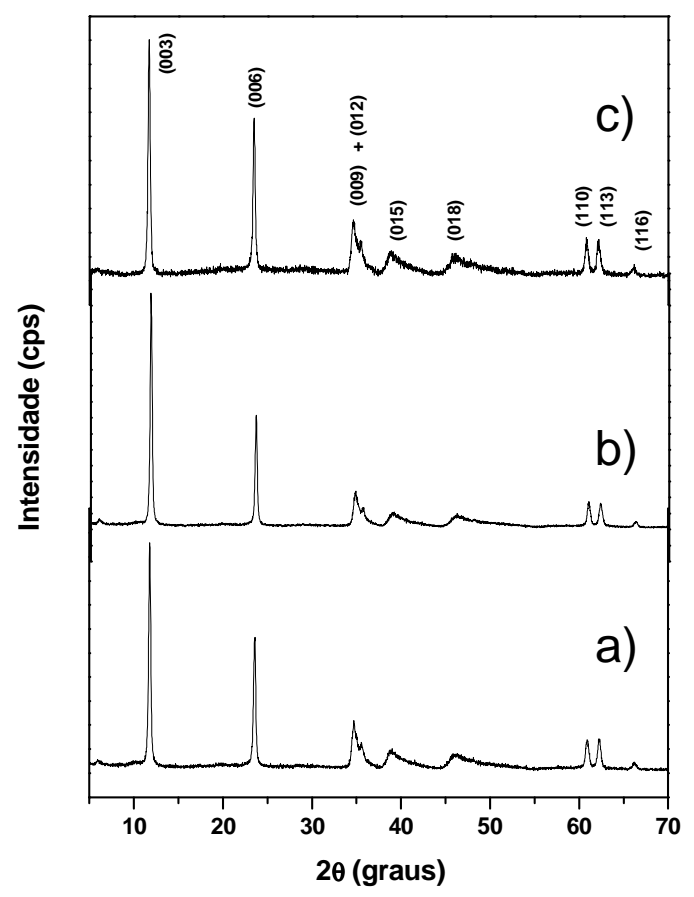

Figura 4.26. DRXP para o HDL adsorvido com colato em diferentes condições. a) puro; $b) 323 \mathrm{~K}$ e presença de $0,1 \mathrm{M}$ de $\mathrm{NaCl}$; $c$ ) $298 \mathrm{~K}$ e presença de $0,1 \mathrm{M}$ de $\mathrm{NaCl}$.

Tabela 4.8. Tamanho médio dos cristalitos para o HDL adsorvido com colato variando a temperatura e a força iônica do meio.

\begin{tabular}{|c|c|}
\hline Amostra & Tamanho $(\AA)$ \\
\hline HDL puro & 433,5 \\
\hline $323 \mathrm{~K} ; \mathrm{FI} 0,0 \mathrm{M}$ & 482,7 \\
\hline 323K; FI 0,1M & 485,2 \\
\hline 298K; FI 0,1M & 488,2 \\
\hline 298K; FI 0,0M & 495,4 \\
\hline
\end{tabular}

A tabela 4.9 mostra a adsorção máxima e a eficiência obtida em diferentes condições, considerando-se a influência da temperatura e da força iônica. 
Tabela 4.9. Dados sobre a quantidade máxima adsorvida pelo HDL não-calcinado, em diversas condições, considerando-se a influência da temperatura e da força iônica.

\begin{tabular}{ccccc}
\hline $\begin{array}{c}\text { Temperatura } \\
\text { (K) }\end{array}$ & $\mathbf{0 , 1} \mathbf{M}(\mathbf{N a C l})$ & $\mathbf{p H}$ & $\begin{array}{c}\text { Adsorção } \\
\text { Máxima } \\
\left(\mathbf{m m o l}^{-1} \mathbf{g}^{-1}\right.\end{array}$ & Eficiência (\%) \\
\hline 298 & Sim & 7,0 & $8,765 \times 10^{-2}$ & 7,010 \\
298 & Não & 7,0 & $6,424 \times 10^{-2}$ & 5,561 \\
323 & Sim & 7,0 & $5,904 \times 10^{-2}$ & 4,720 \\
323 & Não & 7,0 & $4,444 \times 10^{-2}$ & 3,555
\end{tabular}

\section{4) Comparação entre as isotermas}

Realizou-se também uma comparação geral entre todas as isotermas obtidas nos oito experimentos realizados na adsorção de colato usando-se o HDL não-calcinado. A figura 4.27 mostra esses resultados.

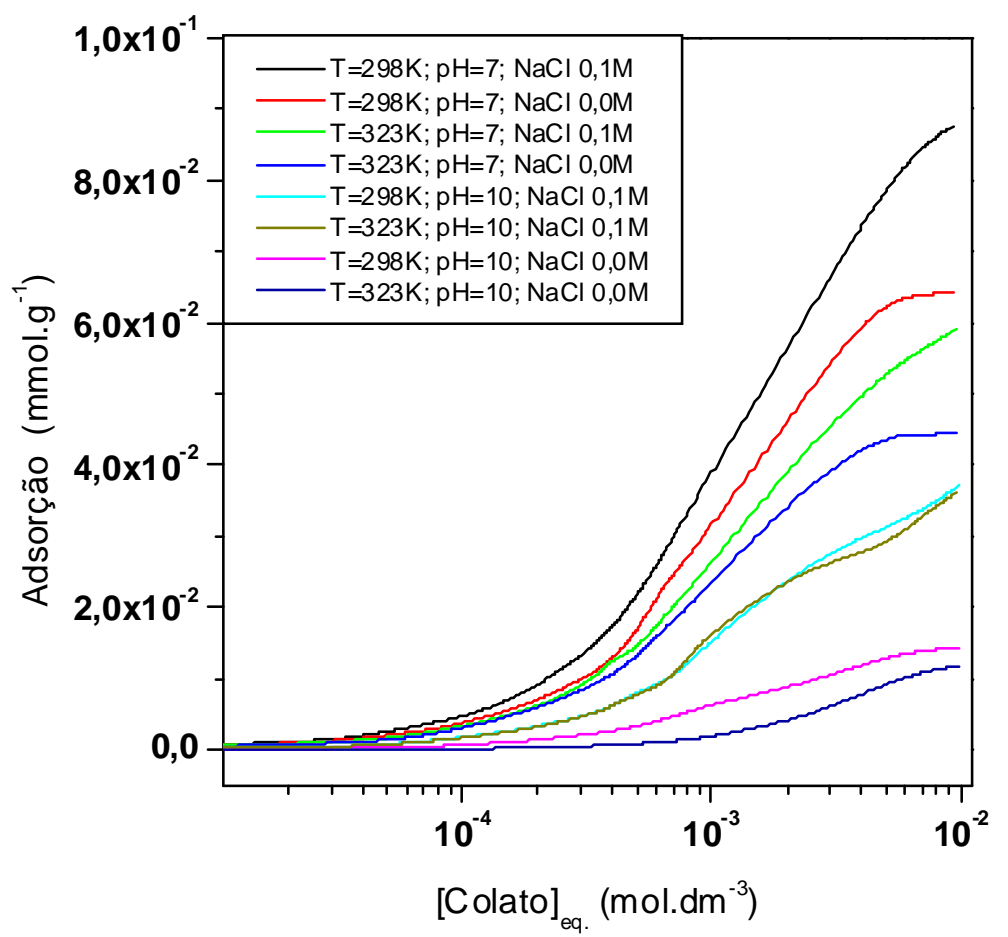

Figura 4.27. Isotermas relativas a adsorção de colato em $\mathrm{MgAlCO}_{3}-\mathrm{HDL}$, considerando todas as variáveis analisadas. 
Analisando as curvas da figura 4.27, nota-se a influência das diferentes condições no processo de adsorção, com a variação na concentração de colato em equilíbrio. Para concentrações de equilíbrio no intervalo entre 0 e aproximadamente $10^{-4}$ mol.dm ${ }^{-3}$, a adsorção sofre pouca influência das variáveis estudadas. A partir de $10^{-4}$ mol.dm ${ }^{-3}$, a adsorção à $298 \mathrm{~K}$ em pH 7 com a adição de 0,1 mol.dm ${ }^{-3}$ de $\mathrm{NaCl}$ passa a ser a condição em que a adsorção é mais eficiente.

Como pode ser observado no gráfico, para as demais condições, as capacidades de adsorção do material alternam suas posições, sendo em alguns casos bastante equivalentes entre si. Dessa forma, para uma possível aplicabilidade além da escala laboratorial, será necessário avaliar as condições do ambiente onde será realizada a extração e, partindo disso, optar pela condição que melhor se adapta ao processo.

Em todos os oito tipos de experimentos, a distância interlamelar do adsorvente foi mantida constante, em 7,59 $\AA$ (4,8 $\AA$ referentes ao tamanho da lamela do HDL e 2,8 Å referentes ao tamanho da molécula de carbonato), valor esse comprovado por todos os difratogramas de raios-x já discutidos nas seções anteriores. Não houve a substituição do ânion $\mathrm{CO}_{3}{ }^{2-}$ intercalado. Sendo assim, utilizando-se o software de simulação "ACD Chemsketch 4.0", foi proposto o esquema de adsorção proposto na figura 4.28. No esquema, as moléculas de colato são mostradas em contato apenas na superfície do HDL. O adsorvente mantém as moléculas de carbonato e água em seu domínio interlamelar. 


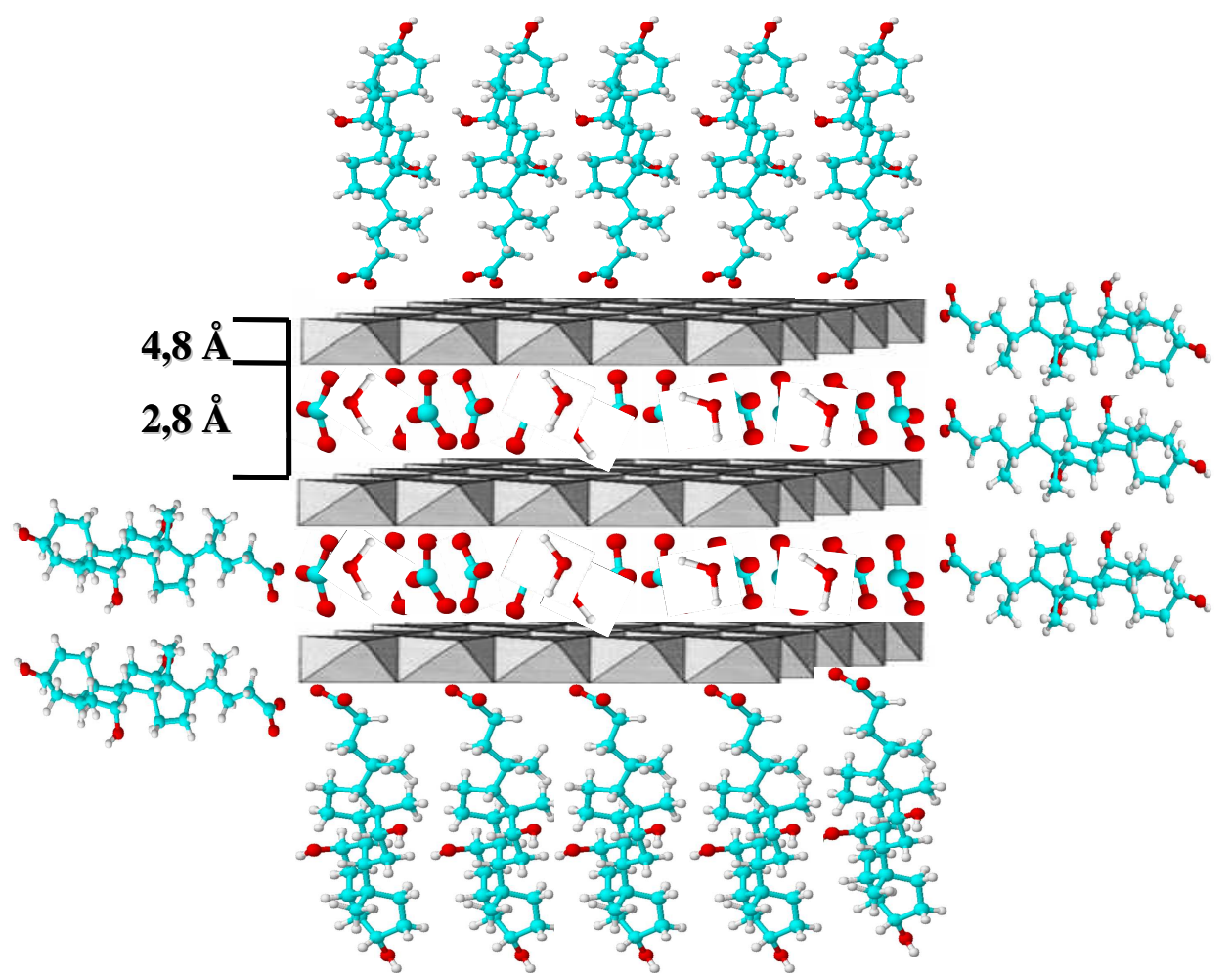

Figura 4.28. Esquema de Adsorção de Colato por Interações Eletrostáticas.

\section{5) Tratamento Estatístico dos Dados - Análise Multivariacional}

Como explicado na seção 3.9, os dados obtidos na realização dos experimentos de adsorção do ânion colato foram tratados utilizando-se de uma ferramenta estatística, conhecida como análise multivariacional. Assim sendo, foi possível quantificar numericamente a influência de cada variável estudada no processo, visando à otimização do mesmo.

Primeiramente, foram definidos os fatores e seus níveis e montada a sua matriz experimental (já discutidos em 3.9). A tabela 4.10 mostra essa matriz juntamente com as respostas obtidas dos experimentos realizados nas seções 4.3.1, 4.3.2 e 4.3.3. 
Tabela 4.10. Matriz experimental para os experimentos de adsorção de colato em $\mathrm{MgAlCO}_{3}-\mathrm{HDL}$ e suas variáveis respostas (adsorção máxima e eficiência de adsorção).

\begin{tabular}{|c|c|c|c|c|c|}
\hline Experimento & Temperatura & $\mathbf{p H}$ & $\begin{array}{l}\text { Força } \\
\text { Iônica }\end{array}$ & $\begin{array}{l}\text { Adsorção } \\
\text { Máxima } \\
\left(\text { mmol.g }^{-1}\right)\end{array}$ & $\begin{array}{c}\text { Eficiência } \\
(\%)\end{array}$ \\
\hline 1 & $298 K$ & 7 & $\begin{array}{l}\mathbf{0 , 1 M} \\
\mathrm{NaCl}\end{array}$ & $8,765 \times 10^{-2}$ & 7,010 \\
\hline 2 & $323 \mathrm{~K}$ & 7 & $\begin{array}{l}\mathbf{0 , 1 M} \\
\mathrm{NaCl}\end{array}$ & $5,904 \times 10^{-2}$ & 4,720 \\
\hline 3 & $298 \mathrm{~K}$ & 10 & $\begin{array}{l}0,1 \mathrm{M} \\
\mathrm{NaCl}\end{array}$ & $3,723 \times 10^{-2}$ & 2,959 \\
\hline 4 & $323 \mathrm{~K}$ & 10 & $\begin{array}{l}\mathbf{0 , 1 M} \\
\mathrm{NaCl}\end{array}$ & $3,626 \times 10^{-2}$ & 2,906 \\
\hline 5 & $298 K$ & 7 & $\begin{array}{l}\mathbf{0 , 0 M} \\
\mathrm{NaCl}\end{array}$ & $6,424 \times 10^{-2}$ & 5,561 \\
\hline 6 & $323 \mathrm{~K}$ & 7 & $\begin{array}{l}\mathbf{0 , 0 M} \\
\mathrm{NaCl}\end{array}$ & $4,444 \times 10^{-2}$ & 3,555 \\
\hline 7 & $298 \mathrm{~K}$ & 10 & $\begin{array}{l}\mathbf{0 , 0 M} \\
\mathrm{NaCl}\end{array}$ & $1,438 \times 10^{-2}$ & 1,152 \\
\hline 8 & $323 \mathrm{~K}$ & 10 & $\begin{array}{l}\mathbf{0 , 0 M} \\
\mathrm{NaCl}\end{array}$ & $1,186 \times 10^{-2}$ & 0,951 \\
\hline
\end{tabular}

\subsection{1) Cálculo dos efeitos principais (efeitos de primeira ordem)}

Utilizando-se as equações 3.1, 3.2. e 3.3 (seção 3.9), foram calculados os efeitos para cada uma das variáveis estudadas. Os efeitos, como já explicado, são as influências exercidas pelos fatores sobre a variável resposta. Os valores dos efeitos e sua porcentagem de influência no processo de adsorção do colato em $\mathrm{MgAlCO}_{3}$-HDL são mostrados na tabela 4.11. 
Tabela 4.11. Valores absolutos dos efeitos principais na adsorção de colato em $\mathrm{MgAlCO}_{3}-\mathrm{HDL}$ e sua influência (em \%) no processo, baseado em duas respostas (adsorção máxima e eficiência de adsorção).

\begin{tabular}{c|c|c|c|c}
\hline Variável & $\begin{array}{c}\text { Efeito da } \\
\text { adsorção } \\
\text { máxima } \\
\text { (valor absoluto) }\end{array}$ & $\begin{array}{c}\text { Influência no } \\
\text { processo } \\
(\boldsymbol{\%})\end{array}$ & $\begin{array}{c}\text { Efeito da } \\
\text { eficiência } \\
\text { (valor absoluto) }\end{array}$ & $\begin{array}{c}\text { Influência no } \\
\text { processo } \\
(\%)\end{array}$ \\
\hline Temperatura & $1,298 \times 10^{-2}$ & $\mathbf{1 7 , 7 3}$ & 1,138 & $\mathbf{1 9 , 1 4}$ \\
\hline pH & $3,891 \times 10^{-2}$ & $\mathbf{5 3 , 1 5}$ & 3,212 & $\mathbf{5 4 , 0 4}$ \\
\hline Força Iônica & $2,132 \times 10^{-2}$ & $\mathbf{2 9 , 1 2}$ & 1,594 & $\mathbf{2 6 , 8 2}$ \\
\hline$\sum$ & $7,321 \times 10^{-2}$ & $\mathbf{1 0 0}$ & 5,944 & $\mathbf{1 0 0}$ \\
\hline
\end{tabular}

Dentro da faixa avaliada, o pH inicial da solução de colato é a variável que mais influi no processo de adsorção (53,15 e 54,04\% considerando-se a resposta como adsorção máxima e eficiência no último ponto da isoterma, respectivamente). A alteração da força iônica do meio corresponde à segunda variável mais influente $(29,12$ e $26,82 \%$, respectivamente). Por fim, a temperatura é a variável menos influente nesse processo estudado (17,73 e 19,14\%, respectivamente). Todos os efeitos tiveram valores absolutos positivos, indicando que o melhor ajuste para a adsorção, na faixa avaliada, corresponde aos níveis ajustados como "positivos" na seção 3.9, O melhor ajuste das variáveis, confirmado pela análise multivariacional é: temperatura de $298 \mathrm{~K}$; $\mathrm{pH}$ inicial das soluções de colato ajustado para 7 e com a adição de $0,1 \mathrm{M}$ de $\mathrm{NaCl}$ ao meio.

\subsection{2) Cálculo dos efeitos combinados (efeitos de segunda ordem)}

Outra análise realizada foi o cálculo dos efeitos combinados do processo de adsorção estudado. Nesses novos cálculos, as variáveis são agrupadas em pares, e utilizando-se as equações 3.4, 3.5. e 3.6 (seção 3.9). Os efeitos combinados são apresentados na tabela 4.12 . 
Tabela 4.12. Valores absolutos dos efeitos combinados na adsorção de colato em $\mathrm{MgAlCO}_{3}-\mathrm{HDL}$ e sua influência (em \%) no processo baseado em duas respostas (adsorção máxima e eficiência de adsorção).

\begin{tabular}{c|c|c|c|c}
\hline $\begin{array}{c}\text { Variável } \\
\text { combinada }\end{array}$ & $\begin{array}{c}\text { Efeito da } \\
\text { adsorção } \\
\text { máxima } \\
\text { (valor absoluto) }\end{array}$ & $\begin{array}{c}\text { Influência no } \\
\text { processo } \\
(\%)\end{array}$ & $\begin{array}{c}\text { Efeito da } \\
\text { eficiência } \\
\text { (valor absoluto) }\end{array}$ & $\begin{array}{c}\text { Influência no } \\
\text { processo } \\
(\%)\end{array}$ \\
\hline $\begin{array}{c}\text { Temperatura } \\
\text { /pH }\end{array}$ & $1,123 \times 10^{-2}$ & $\mathbf{7 3 , 1 1}$ & 1,011 & $\mathbf{7 5 , 9 0}$ \\
\hline $\begin{array}{c}\text { pH/Força } \\
\text { Iônica }\end{array}$ & $0,231 \times 10^{-2}$ & $\mathbf{1 5 , 0 4}$ & 0,287 & $\mathbf{2 1 , 5 5}$ \\
\hline $\begin{array}{c}\text { Força Iônica/ } \\
\text { Temperatura }\end{array}$ & $0,182 \times 10^{-2}$ & $\mathbf{1 1 , 8 5}$ & 0,034 & $\mathbf{2 , 5 5}$ \\
\hline$\sum$ & $1,536 \times 10^{-2}$ & $\mathbf{1 0 0}$ & 1,332 & $\mathbf{1 0 0}$ \\
\hline
\end{tabular}

A análise de efeitos combinados apresenta resultados interessantes. Dentro da faixa avaliada, o efeito combinado que mais influencia no processo de adsorção dos ânions colato é o efeito combinado da temperatura e do pH inicial das soluções de colato. Esse efeito combinado é responsável por 73,11 e 75,90\% (considerando-se a resposta como adsorção máxima e eficiência no último ponto da isoterma, respectivamente). A segunda variável combinada mais influente é a combinação pH/força iônica responsável por 15,04 e 21,55\%, respectivamente para cada resposta obtida. Apesar de serem variáveis influentes quando analisadas separadamente, o efeito de uma variável "anula" o efeito positivo da outra. Em outras palavras, a influência "positiva" da adição de $0,1 \mathrm{M}$ de $\mathrm{NaCl}$ se contrapõe a influência "negativa" de valores de $\mathrm{pH}$ inicial das soluções de colato ajustados para 10. Esse efeito também é observado na combinação força iônica/temperatura, responsável por apenas 11,85 e 2,55\% de influência, respectivamente para cada resposta obtida.

Como demonstrado na análise multivariada, todas as variáveis escolhidas para o estudo de adsorção de ânions colato em $\mathrm{MgAlCO}_{3}-\mathrm{HDL}$ influem, em diferentes magnitudes, no processo. O próximo passo nesse trabalho foi melhorar essas condições experimentais, ampliando-se a faixa de avaliação de algumas variáveis e novamente, comparando-se os resultados obtidos. 


\section{6) Otimização do processo de adsorção - Experimentos a $288 \mathrm{~K}$}

Entre todas as variáveis estudadas, a temperatura exerce influência significativa nos estudos de adsorção, como já discutido. Na adsorção de colato por hidróxidos duplos lamelares de magnésio e alumínio, a influência da temperatura na faixa entre 298-323K é de aproximadamente $20 \%$. Quando combinado com o valor inicial do $\mathrm{pH}$ da solução de colato, o valor da influência chega a valores de aproximadamente $75 \%$, como visto na seção anterior. $O$ aumento da temperatura, nessa faixa, causou uma diminuição da quantidade adsorvida (seção 4.2). A temperatura é uma variável que pode ser facilmente controlada, apenas ajustando-se o banho termostatizado onde as amostras permaneceram em agitação. Assim sendo, foram escolhidas as duas condições onde as quantidades máximas adsorvidas foram maiores $(\mathrm{pH} 7 ; 298 \mathrm{~K}$; sem adição de $\mathrm{NaCl}$ e pH 7; 298K; com adição de $\mathrm{NaCl}$ ) e a temperatura foi alterada, dessa vez para 288K. Os resultados são mostrados nas isotermas da figura 4.29.
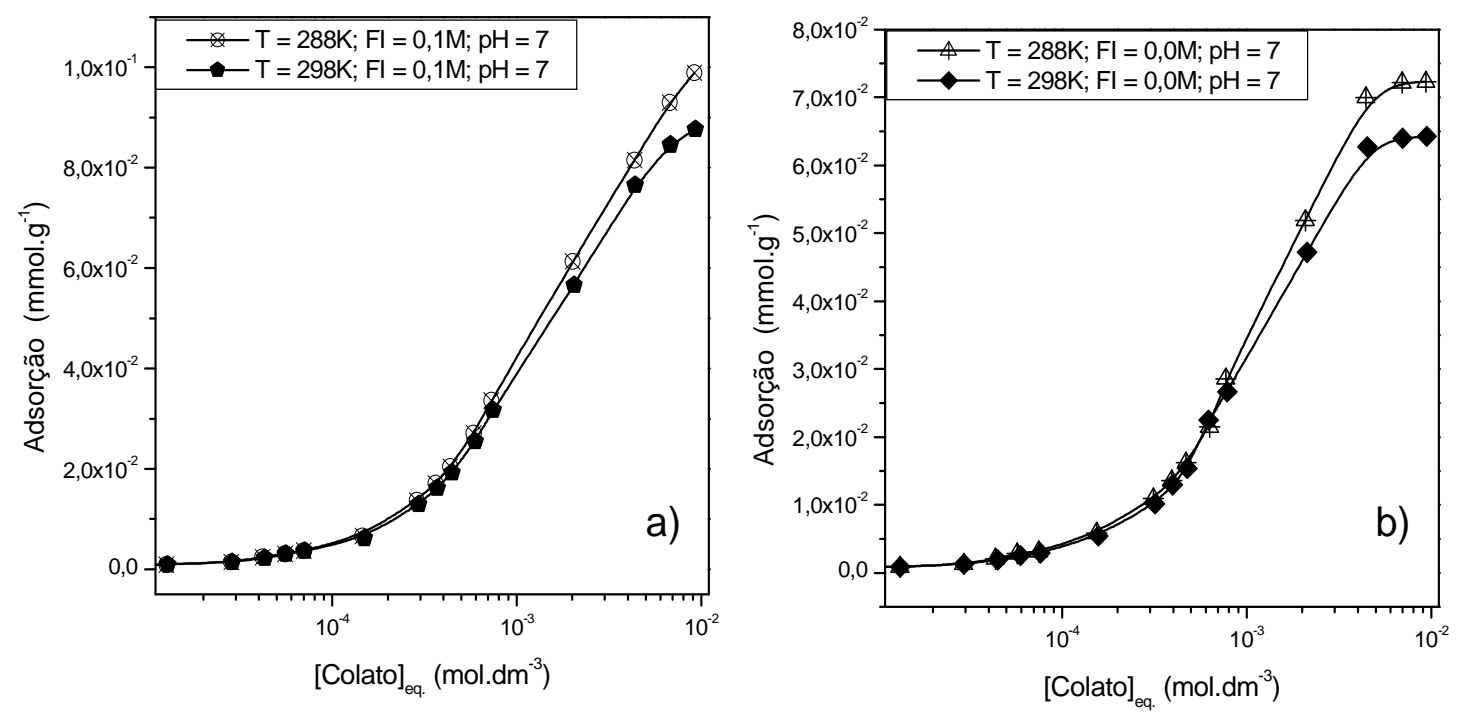

Figura 4.29. Comparação das isotermas de adsorção de colato a $288 \mathrm{~K}$ e $298 \mathrm{~K}$. a) pH 7 , com adição de $0,1 \mathrm{M}$ de $\mathrm{NaCl} ; b)$ pH 7 , sem adição de $\mathrm{NaCl}$.

Nos experimentos realizados a $288 \mathrm{~K}$, os perfis das curvas seguiram os mesmos padrões dos experimentos realizados a $298 \mathrm{~K}$. Pela classificação de Giles, ${ }^{78,79}$ as isotermas obtidas em força iônica maior, em ambos os casos, são classificadas na classe $\mathrm{S}$ subgrupo 1, indicando sistemas com a monocamada não saturada do adsorvato. Novamente, não há formação de patamar bem definido. 
As isotermas obtidas sem a adição de $0,1 \mathrm{M}$ de $\mathrm{NaCl}$ às soluções de colato se encaixam na classe $\mathrm{S}$ subgrupo 2 da classificação de Giles. Esse tipo de isoterma é característica nos casos onde ocorre a saturação da monocamada. As figuras das isotermas mostram que as curvas atingem um patamar de adsorção.

Em ambos os casos, a adsorção foi maior quando realizada a $288 \mathrm{~K}$. Esse fenômeno já foi explicado na seção 4.2. A tabela 4.13 mostra dados referentes à adsorção máxima e eficiência de adsorção, para os experimentos realizados a $288 \mathrm{~K}$.

Tabela 4.13. Dados sobre a quantidade máxima adsorvida pelo HDL não-calcinado, em diversas condições (experimentos a $288 \mathrm{~K}$ ).

\begin{tabular}{ccccc}
\hline $\begin{array}{c}\text { Temperatura } \\
(\mathbf{K})\end{array}$ & $\mathbf{0 , 1} \mathbf{M}(\mathbf{N a C l})$ & $\mathbf{p H}$ & $\begin{array}{c}\text { Adsorção } \\
\text { Máxima } \\
\left(\mathbf{m m o l . g}^{-1}\right)\end{array}$ & Eficiência (\%) \\
\hline 288 & Sim & 7,0 & $9,891 \times 10^{-2}$ & 7,913 \\
298 & Sim & 7,0 & $8,765 \times 10^{-2}$ & 7,010 \\
288 & Não & 7,0 & $7,228 \times 10^{-2}$ & 5,810 \\
298 & Não & 7,0 & $6,424 \times 10^{-2}$ & 5,561
\end{tabular}

Nos experimentos onde há a presença de $0,1 \mathrm{M}$ de $\mathrm{NaCl}$ ao meio, a redução da temperatura de $298 \mathrm{~K}$ para $288 \mathrm{~K}$ proporcionou um aumento na eficiência de adsorção de aproximadamente $13 \%$. Quando não há presença de $0,1 \mathrm{M}$ de $\mathrm{NaCl}$ ao meio, a mesma redução da temperatura causa um aumento na eficiência de aproximadamente $4,5 \%$.

As curvas de variação do potencial eletrocinético para estas isotermas realizadas a 288K são mostradas na figura 4.30 . 

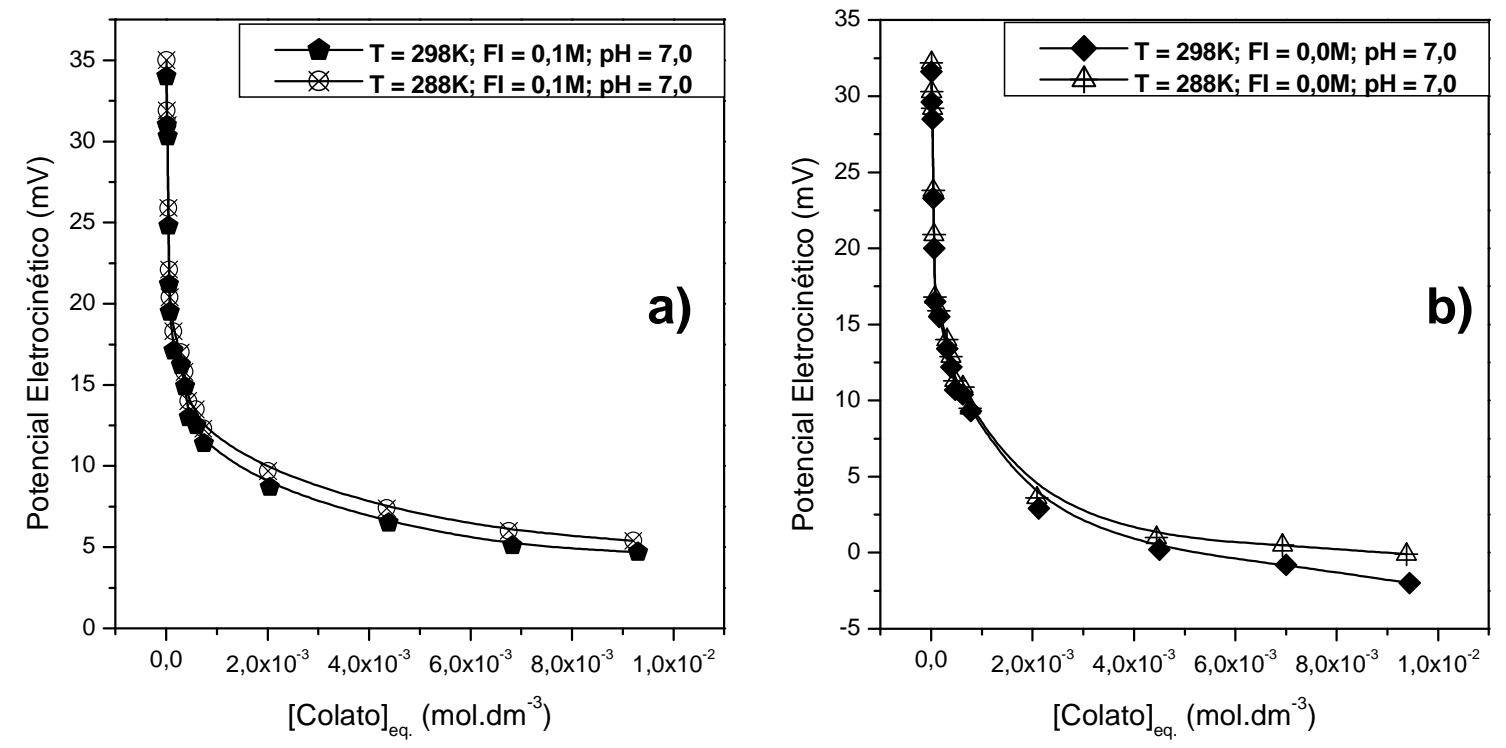

Figura 4.30. Potencial eletrocinético em função da adsorção de colato em HDL, à 288 e $298 \mathrm{~K}$ em pH 7. a) com adição de $0,1 \mathrm{M}$ de $\mathrm{NaCl}$; $b$ ) sem adição de $\mathrm{NaCl}$.

As curvas do potencial eletrocinético relativo à adsorção de colato no HDL, em duas temperaturas diferentes, apresentam perfis bem semelhantes. Com adição de $0,1 \mathrm{M}$ de $\mathrm{NaCl}$, as curvas começam em valores próximos a $35 \mathrm{mV}$, decrescendo, com o aumento da concentração de colato até valores próximos de $7 \mathrm{mV}$. Sem adição de $0,1 \mathrm{M}$ de $\mathrm{NaCl}$, as curvas começam em valores próximos de $33 \mathrm{mV}$ e decrescem até valores próximos a zero. Os valores próximos a zero nos pontos de maior quantidade adsorvida confirmam a proposta de saturação dos sítios adsorventes disponíveis.

Os últimos pontos das isotermas realizadas a $288 \mathrm{~K}$, onde houve maior adsorção, foram submetidos às análises de DRXP e IV-TF, como já descrito anteriormente. Os resultados são mostrados na figura 4.31 . 

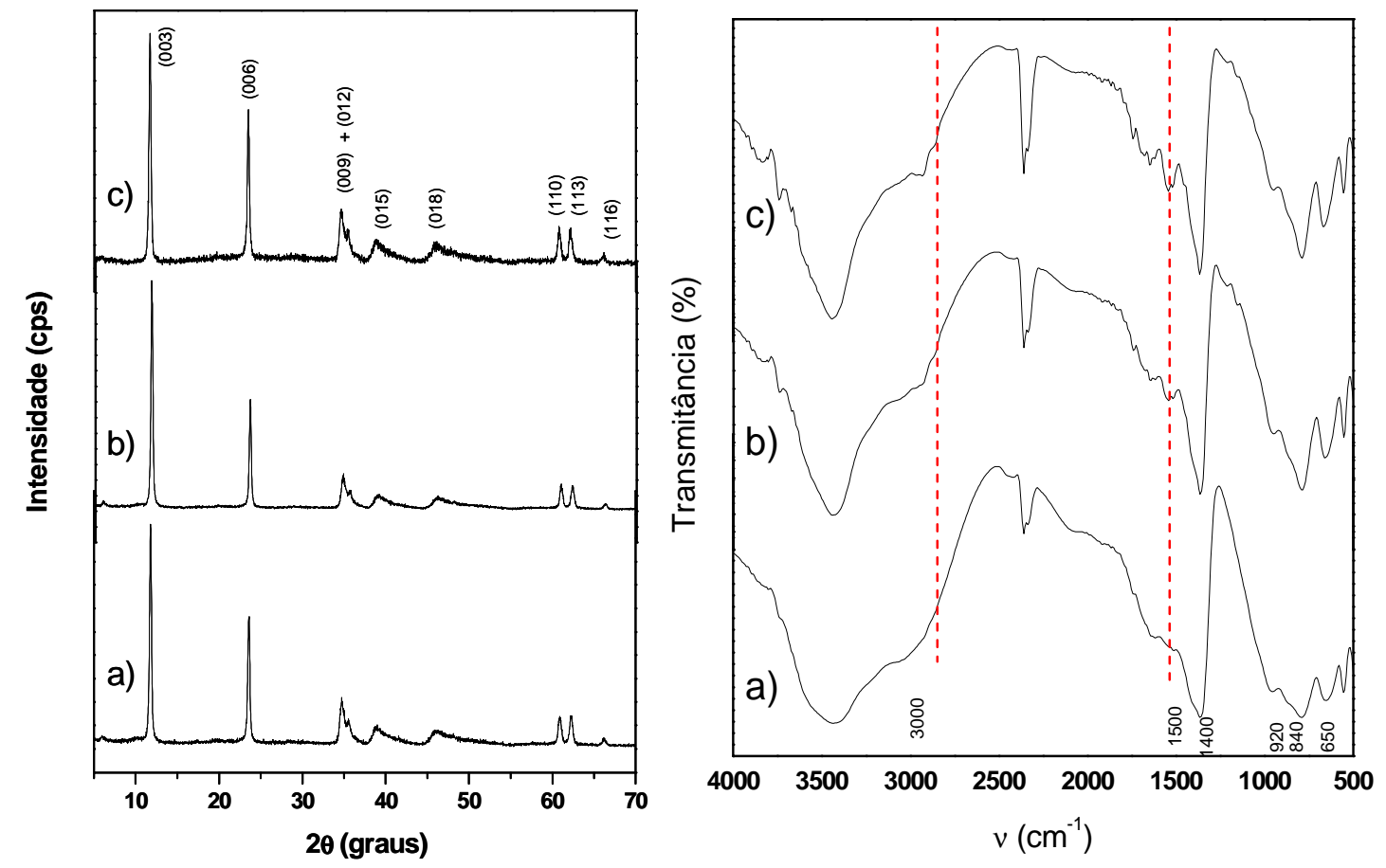

Figura 4.31. DRXP (à esquerda) e IV-TF (à direita) para o HDL adsorvido com colato a 288 K. a) puro; $b$ ) pH 7; c) pH 7 e adição de $0,1 \mathrm{M}$ de $\mathrm{NaCl}$.

Igualmente a todos os casos onde foi empregado o HDL não-calcinado como adsorvente, não houve alteração de seu espaçamento basal (à esquerda), indicando que a adsorção de colato ocorre apenas na superfície do material também a 288K. As bandas características que comprovam a presença do colato adsorvido (3400, 2750-3000 e 1500 $\mathrm{cm}^{-1}$ ) estão presentes no espectro de IV-TF (à direita).

\section{7) Sorção}

Os experimentos para avaliar a sorção de colato foram realizados conforme descrito na Seção 3.7.1. O pH das soluções iniciais de colato foi ajustado para 7, e nos casos dos experimentos de sorção, variou-se apenas a temperatura. As outras variáveis avaliadas no processo de adsorção são de difícil controle no caso da sorção. Não é possível, por exemplo, a adição de $\mathrm{NaCl}$ às soluções de colato. $\mathrm{Na}$ regeneração do precursor calcinado, os ânions cloreto podem ser intercalados na estrutura do HDL. Assim sendo, a obtenção de dados sobre a sorção exclusivamente do colato se torna muito difícil, impossibilitando o estudo da variável força iônica.

A figura 4.32 mostra uma representação esquemática do processo calcinação/sorção realizado no HDL. 


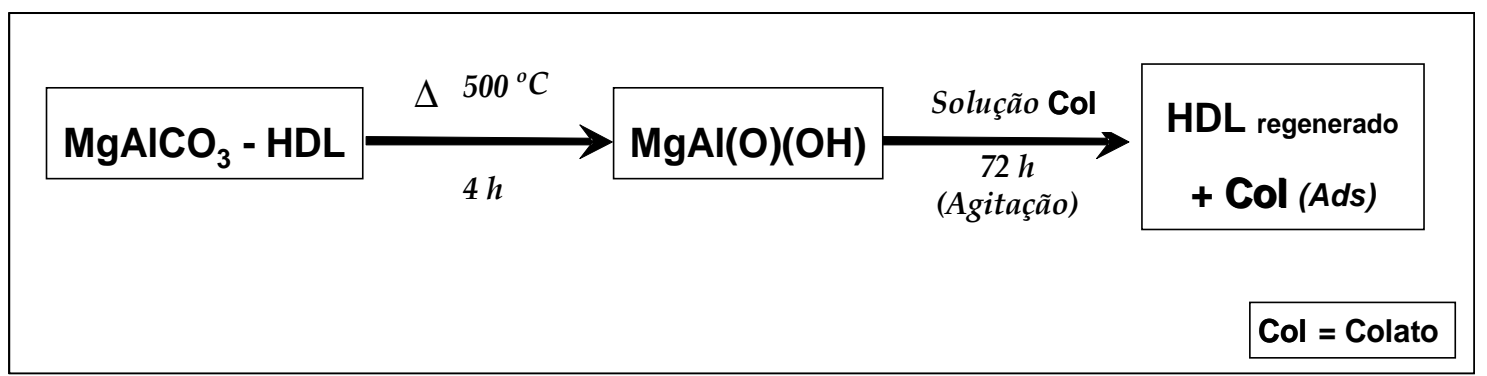

Figura 4.32. Representação esquemática do processo de calcinação/sorção.

Os resultados obtidos experimentalmente referentes à sorção do colato serão discutidos nas seções a seguir.

\subsection{1) Sorção de colato - Efeito da Temperatura}

O efeito da temperatura na sorção de colato foi avaliado utilizando-se o método batelada, tal qual usado nos experimentos de adsorção. Os resultados obtidos são mostrados na figura 4.33 .
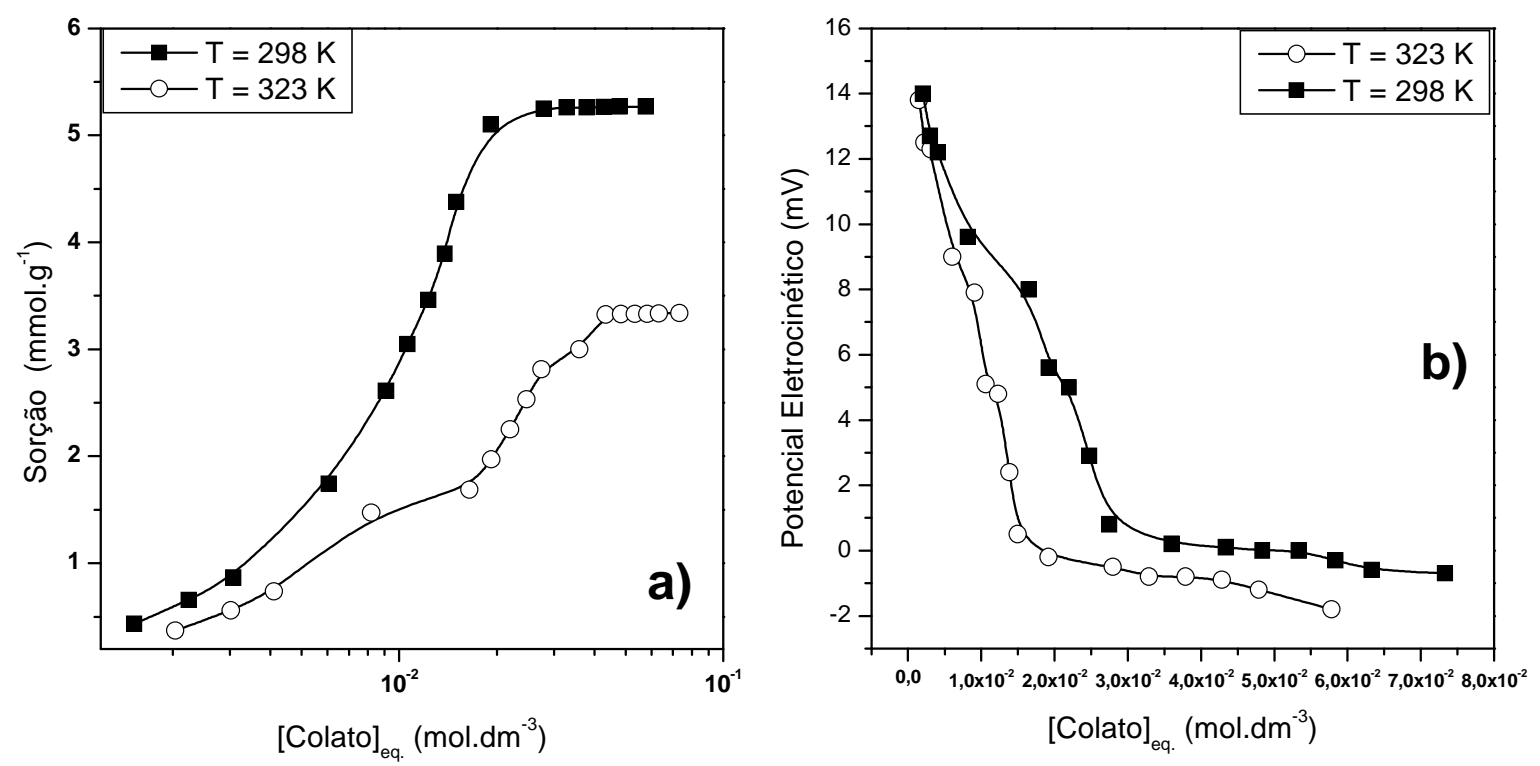

Figura 4.33. Sorção de colato no HDL calcinado a 298 e 323 K. a) Isotermas; $b$ )

Potencial Eletrocinético em função da sorção.

As isotermas de sorção apresentadas na figura $4.33 a$ podem ser classificadas segundo Giles, ${ }^{78,79}$ na classe $S$, subgrupo 2, indicando saturação da monocamada. Nos casos de sorção, o processo predominante é a regeneração do HDL, tendo a adsorção 
como um processo adicional. A classificação das isotermas de adsorção de Giles tem, portanto, pouca aplicabilidade nesses casos. Entretanto, vamos utilizá-la, apenas para verificar o comportamento nesses experimentos.

Analisando as isotermas, verifica-se que o aumento da temperatura implica numa menor quantidade máxima sorvida pelo material calcinado. Esse mesmo efeito já foi discutido na seção 4.2 .

As curvas de variação de potencial eletrocinético (figura 4.33b) são bastante semelhantes, apresentando inicialmente, valores de potencial de ordem de $14 \mathrm{mV}$, que decrescem rapidamente até valores nulos. Esses resultados estão de acordo com o perfil das isotermas. Os resultados nulos nos últimos pontos das curvas confirmam a proposta de saturação dos sítios adsorventes do HDL.

Os experimentos de sorção também foram realizados a temperaturas mais baixas (288 K), assim como foi feito na adsorção. Novamente, em temperaturas mais baixas, a quantidade sorvida foi maior. Esse fator é mostrado na figura 4.34.
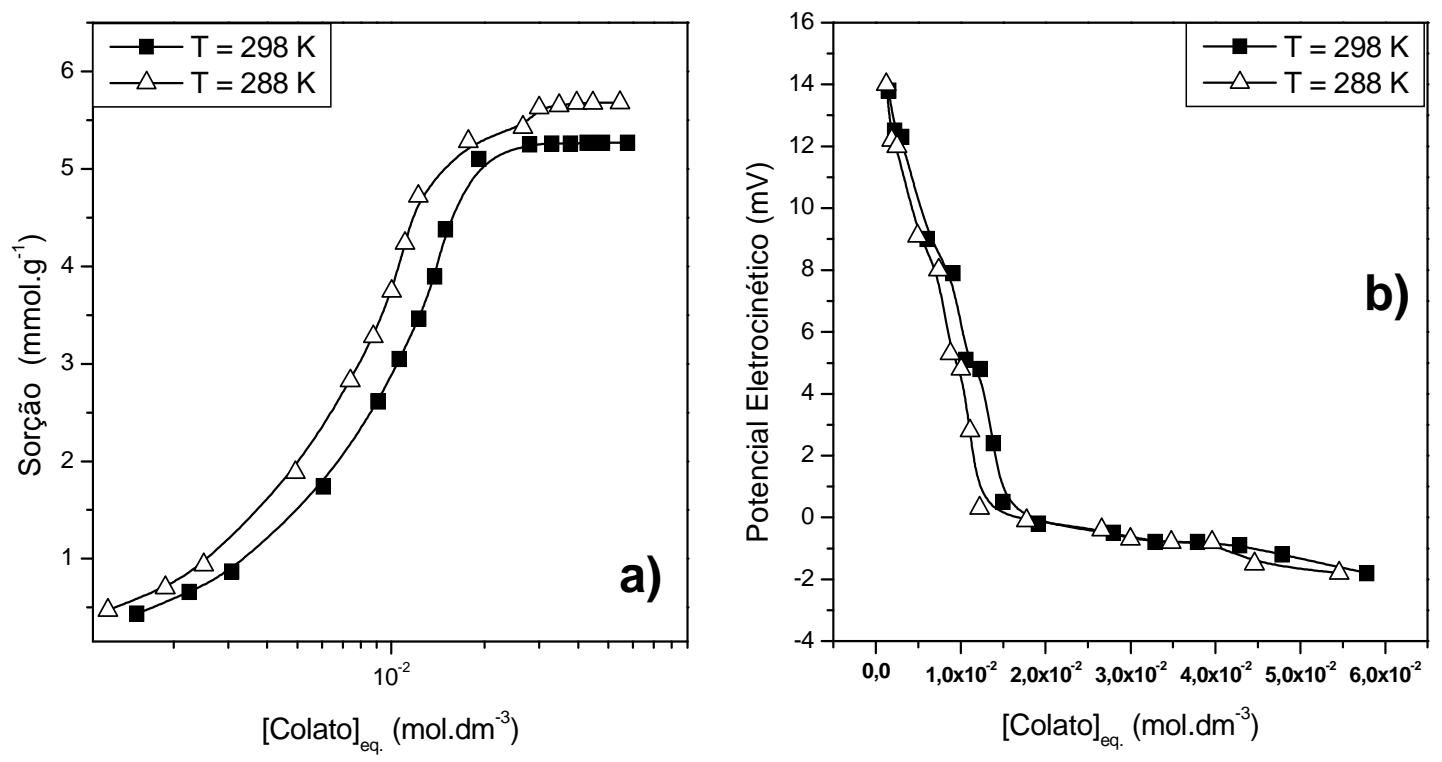

Figura 4.34. Isotermas de sorção de colato no HDL calcinado à 298 e 288 K. a) Isotermas; $b$ ) Potencial Eletrocinético em função da sorção.

A isoterma de sorção a $288 \mathrm{~K}$ também se encaixa na classificação do tipo $\mathrm{S}$, subgrupo 2, proposta por Giles. A $288 \mathrm{~K}$, também há a saturação dos sítios adsorventes nos últimos pontos da isoterma (figura $4.34 a$ ) 
As curvas de variação do potencial eletrocinético seguem perfis praticamente idênticos, começando em valores da ordem de $14 \mathrm{mV}$ e chegando a valores nulos nos seus últimos pontos (figura 4.34b).

A quantidade máxima sorvida e a eficiência de sorção para os experimentos realizados em três temperaturas diferentes, considerando o último ponto da isoterma, são mostradas na tabela 4.14.

Tabela 4.14. Dados sobre a quantidade máxima sorvida pelo HDL calcinado, em diversas temperaturas.

\begin{tabular}{ccc}
\hline $\begin{array}{c}\text { Temperatura } \\
(\mathrm{K})\end{array}$ & $\begin{array}{c}\text { Sorção } \\
\text { Máxima } \\
\left(\mathbf{m m o l . g}^{-1}\right)\end{array}$ & Eficiência (\%) \\
\hline 288 & 5,6784 & 45,427 \\
298 & 5,2689 & 42,157 \\
323 & 3,3380 & 26,704
\end{tabular}

Pelos valores observados, o aumento na temperatura, de 288 para $298 \mathrm{~K}$, causou um decréscimo na eficiência de sorção de aproximadamente 7,2\%. Quando a temperatura é aumentada para $323 \mathrm{~K}$, o decréscimo na eficiência de sorção chega a valores próximos de 41,2\%. Igualmente ao ocorrido nos experimentos de adsorção, o aumento da temperatura influi negativamente o processo de sorção.

Foram realizadas medidas de $\mathrm{pH}$ em cada uma das soluções de sobrenadante obtidas após o contato com o sorvente. A figura 4.35 mostra a variação do pH com a concentração. 


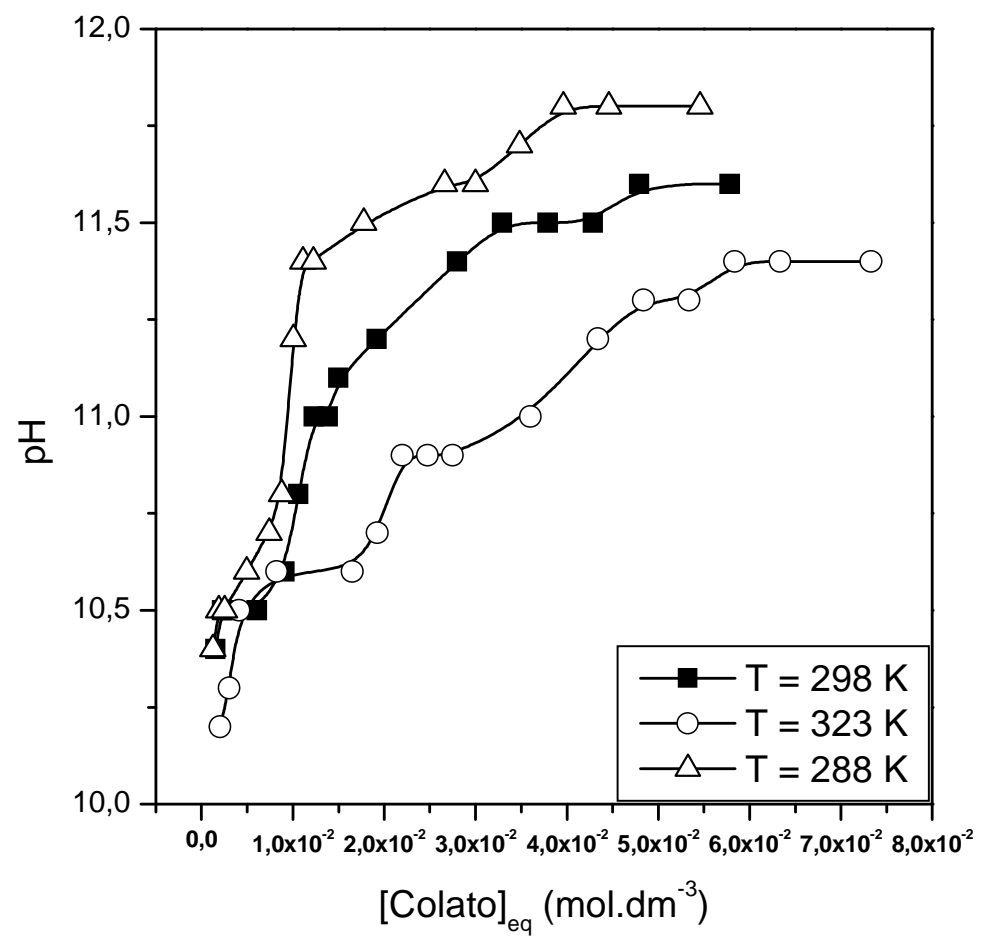

Figura 4.35. Variação do pH do sobrenadante em função da sorção de colato em HDL, à 288,298 e $323 \mathrm{~K}$.

Os perfis das curvas são semelhantes para todos os casos. Nos primeiros pontos, há um aumento brusco em relação ao valor de $\mathrm{pH}$ inicial das soluções de colato $(7,0)$. As curvas começam em valores em torno de 10,2 a 10,5 e convergem rapidamente a valores próximos entre 11,4 e 11,7. Durante a regeneração do HDL, ocorre a hidrólise da água onde íons $\mathrm{H}^{+}$são removidos da solução para a reconstrução da estrutura lamelar, fazendo com que um excesso de ânions $\mathrm{OH}^{-}$permaneça em solução, provocando o aumento no valor do $\mathrm{pH}$. O HDL é reconstituído, incorporando ânions $\mathrm{OH}^{-}$como responsável pelo espaçamento basal e ânions colato intercalados e adsorvidos na superfície. $\mathrm{O} \mathrm{pH}$ atinge um valor máximo a partir do qual ocorre a substituição de $\mathrm{OH}^{-}$por colato no domínio interlamelar. Quando se atinge o equilíbrio (últimos pontos), o $\mathrm{pH}$ passa a ser praticamente constante.

Os sólidos resultantes destes experimentos foram submetidos à análise por DRXP e os resultados obtidos são mostrados na figura 4.36. 


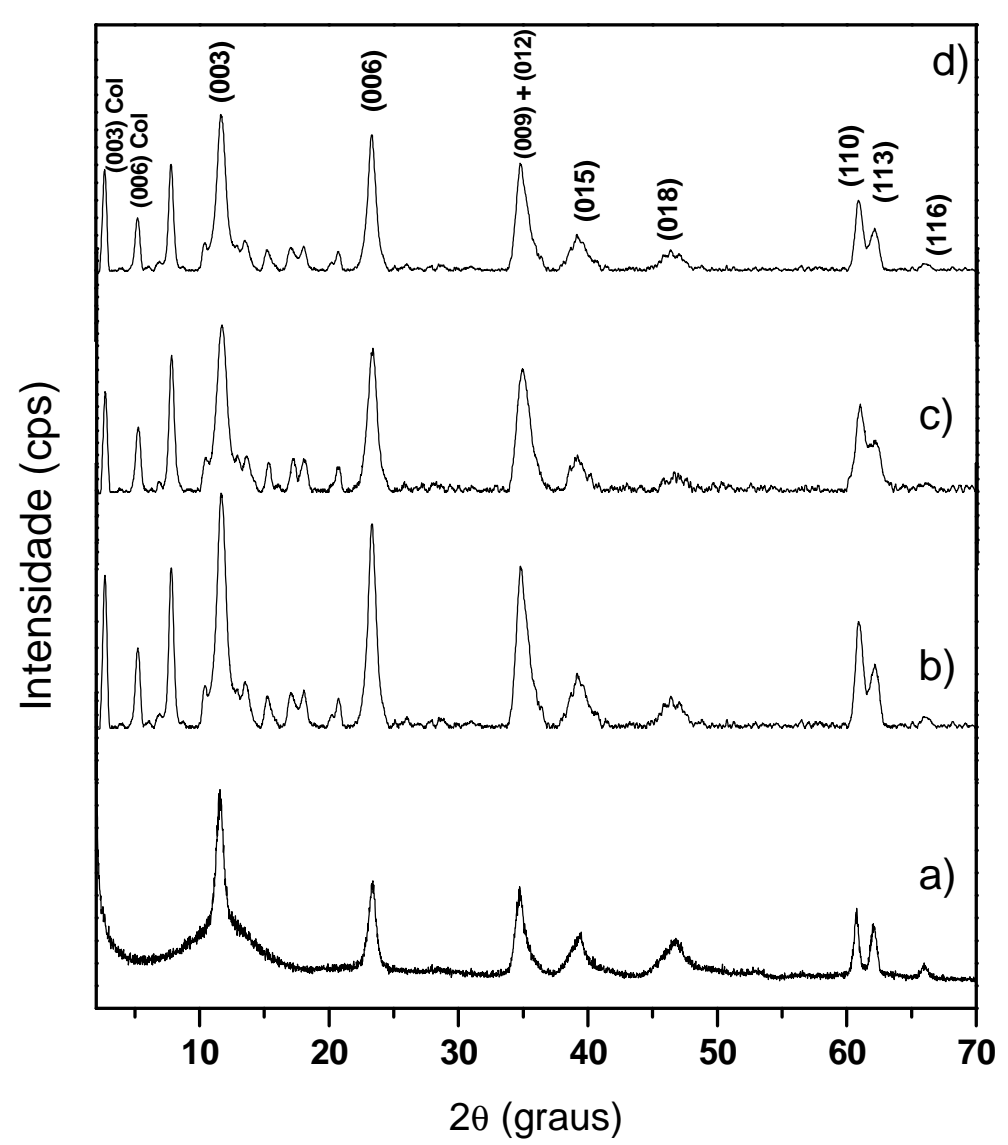

Figura 4.36. DRXP para o HDL sorvido com colato em diferentes temperaturas. a) regenerado em $\mathrm{H}_{2} \mathrm{O}$; b) $323 \mathrm{~K}$; c) $298 \mathrm{~K}$ e $d$ ) $288 \mathrm{~K}$.

Comparando os difratogramas apresentados nesta figura com aqueles observados para o HDL puro e calcinado (figura 4.1), muitas diferenças são notadas. Na figura 4.36a, obtido da regeneração do material calcinado em água, o difratograma é condizente com o de um HDL regenerado com ânions $\mathrm{OH}^{-}$, apresentando picos basais característicos, que resultam num valor de $\mathrm{d}=7,56 \AA$ e uma elevada organização estrutural. $^{7}$ As figuras 4.36b, c e $d$, mostram o difratograma obtido para o HDL regenerado com colato a diversas temperaturas. Em todos os casos, os difratogramas são bastante similares entre si, porém bastante diferentes do HDL regenerado apenas em água. Em todos os difratogramas os picos característicos da regeneração com ânions $\mathrm{OH}^{-}$são observados. Esses picos estão devidamente indexados na figura 4.36. Adicionalmente, aos picos referentes à hidroxila, é notado um pico de alta intensidade em $2 \theta$ igual a $7,5^{\circ}$ e picos de menor intensidade na região entre 15 e $20^{\circ}$. Esses mesmos picos são observados no difratograma do colato de sódio puro (figura 4.12). Pode-se dizer que, como a quantidade de colato sorvida foi bastante significativa, cristais podem 
ter sido incorporados à superfície do HDL, sendo assim detectados por meio de difração de raios-X. Esse mesmo efeito foi observado no estudo cinético, reportado na seção 4.2.

Nos últimos pontos das isotermas (pontos que foram submetidos à análise por DRXP), onde a concentração de colato é suficientemente alta, nota-se também a formação de duas fases distintas. Os difratogramas apresentam picos referentes às reflexões dos planos (003) e (006). O espaçamento basal obtido para estas fases são: $d=$ $34,3 \AA$ e $d=16,9 \AA$ que correspondem à intercalação de colato. Um arranjo dessa intercalação (usando o software de simulação ACD - Chemsketch 4.0) é esquematizado na figura 4.37.

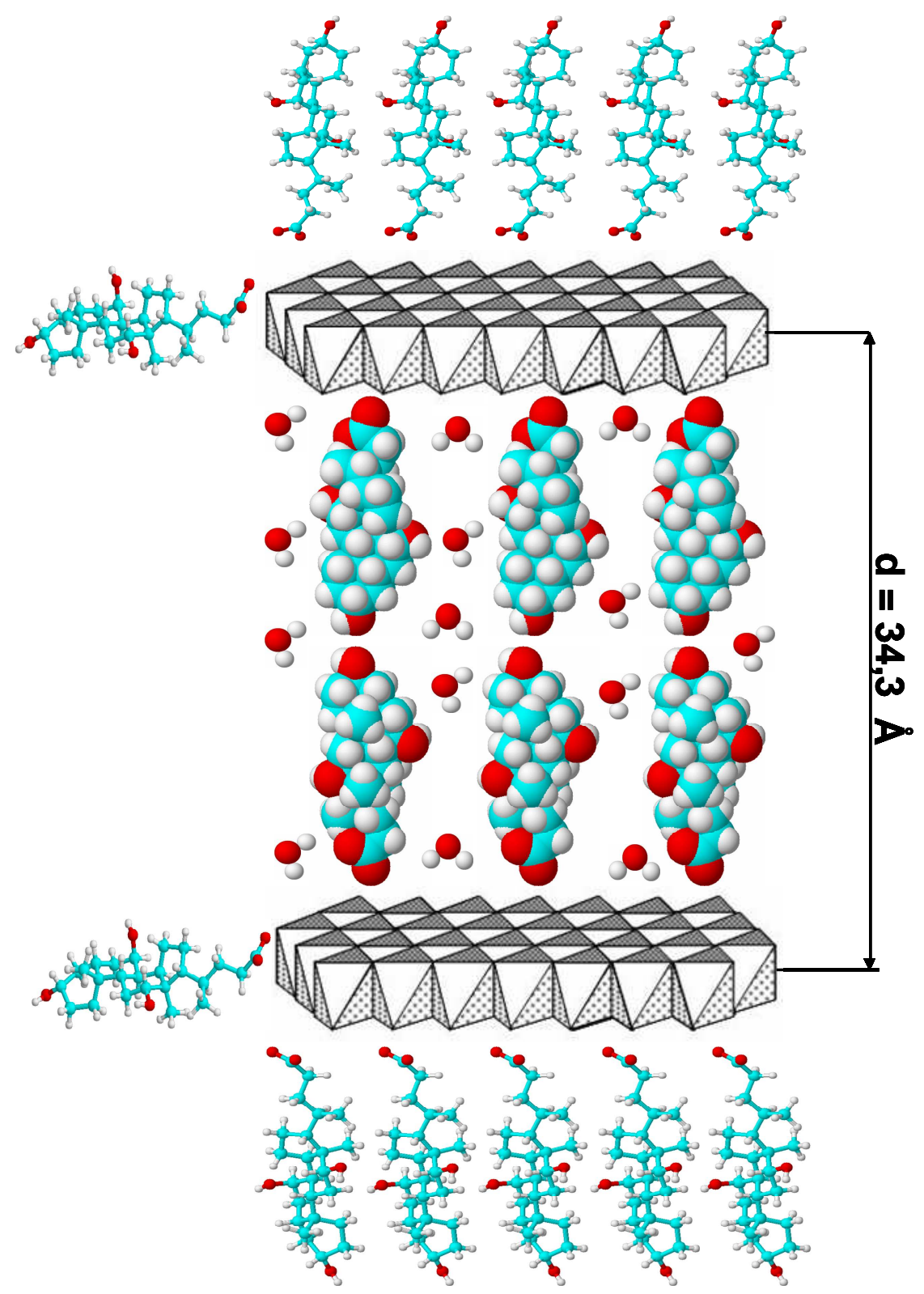

Figura 4.37. Esquema de Sorção de Colato. 
Pelos valores de distâncias interlamelares obtidos, é proposto um arranjo onde há a formação de bicamada de colato intercalado. Cada molécula de colato tem um tamanho de 14,75 A. Ou seja, duas moléculas emparelhadas formando bicamada medem aproximadamente 29,5 A. Esse valor, somado aos 4,8 A da lamela do hidróxido duplo lamelar de magnésio e alumínio, totalizam exatamente $34,3 \AA$, confirmando a teoria de intercalação de colato em bicamada, como proposto.

Os mesmos últimos pontos das isotermas, onde houve maior quantidade sorvida, também foram submetidos à análise de IV-TF. Os resultados são mostrados na figura 4.38.

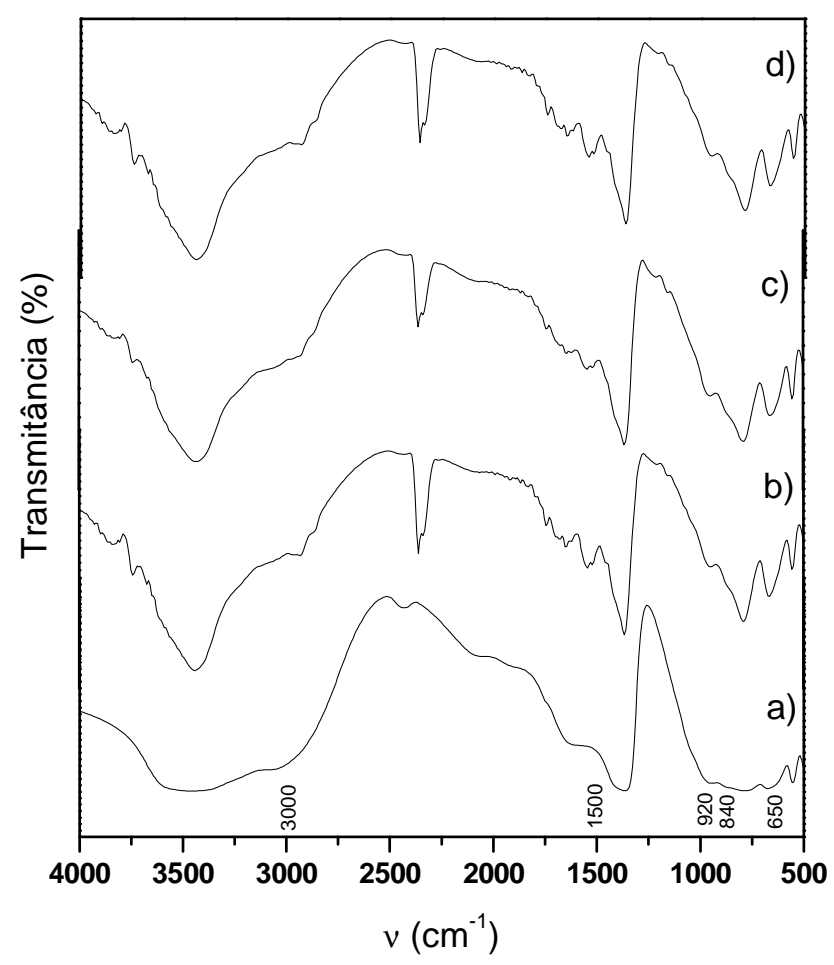

Figura 4.38. IV-TF para o HDL sorvido com colato em diferentes temperaturas. $a$ ) regenerado em $\mathrm{H}_{2} \mathrm{O}$; b) $323 \mathrm{~K}$; c) $298 \mathrm{~K}$ e d) $288 \mathrm{~K}$.

Os espectros obtidos para o material sorvido apresentam perfil diferente daquele obtido para o HDL regenerado apenas em água. São notadas bandas na região de 3400 $\mathrm{cm}^{-1}$, atribuídas à água de hidratação e às hidroxilas das lamelas do HDL e dos ânions do colato. As bandas localizadas entre 2750-3000 $\mathrm{cm}^{-1}$ estão associadas às ligações de hidrogênio existentes entre os dímeros de ânions colato intercalados no domínio interlamelar.

As bandas localizadas na região próxima a $1500 \mathrm{~cm}^{-1}$ comprovam a presença de composto carboxílico no material. Nos compostos em que existem ligações de 
hidrogênio intermoleculares entre ácidos carboxílicos, a banda $\mathrm{C}=\mathrm{O}$ aparece na região de $1700 \mathrm{~cm}^{-1}$. 


\section{Conclusões}

\section{Conclusões}

Tendo como referência os resultados aqui discutidos, podemos concluir que a adsorção e sorção de colato em HDL constituem em um campo de pesquisa que ainda tem muito a ser explorado. O fenômeno da adsorção de colato em HDL tem sido estudado, porém não são muito claros quanto aos mecanismos pelos quais a adsorção ocorre, justamente pelo número de variáveis envolvidas. Este trabalho teve como objetivo tentar auxiliar a compreensão de alguns desses mecanismos. Espera-se que em trabalhos futuros, com o advento de novas técnicas de análise e o avanço de estudos de simulação, seja possível a elaboração de modelos teóricos cada vez mais próximos dos dados experimentais.

Os resultados observados para a adsorção de colato mostraram que o adsorvente é bastante estável em solução aquosa na presença destes, visto que não se observa substituição do ânion inicialmente intercalado $\left(\mathrm{CO}_{3}{ }^{2-}\right)$. Quanto à capacidade de remoção por adsorção, o colato foi removido em quantidades satisfatórias, que poderiam justificar seu emprego numa aplicação prática.

Com base nos resultados obtidos, podemos concluir que o material sintetizado apresentou as propriedades comuns aos hidróxidos duplos lamelares. Essas propriedades foram evidenciadas por diversas caracterizações diferentes, como difração de raios-X no pó, análise térmica e análise térmica diferencial, espectroscopia na região do infravermelho, microscopia eletrônica de varredura, área superficial específica e determinação do potencial de carga zero.

A adsorção em todos os casos mostrou dependência das variáveis estudadas. O aumento na temperatura causa uma diminuição na quantidade adsorvida, pois afeta diretamente a estabilidade termodinâmica do sistema sendo decisiva para a eficiência da remoção, em concentrações mais altas do adsorvato.

Nas condições avaliadas, o aumento na força iônica por meio da adição de um sal neutro causou um efeito positivo, aumentando substancialmente a quantidade adsorvida no material. O sal neutro ajuda a diminuir as forças repulsivas existentes entre os grupos polares do colato, permitindo a formação de agregado mais compacto, e conseqüentemente, aumentando a adsorção do composto em HDL.

$\mathrm{O}$ pH inicial das soluções de colato também exerce influência na adsorção. Dentro da faixa examinada, valores maiores de $\mathrm{pH}$ diminuem sensivelmente a remoção de 
ânions colato. A análise estatística multivariacional realizada com os resultados obtidos no estudo de adsorção, comprovaram e quantificaram a influência de cada variável.

O HDL preparado também foi empregado na sua forma calcinada, o oxi-hidróxido duplo, nos experimentos onde foi observada a capacidade de regeneração. Os resultados mostraram que a intercalação por sorção é um processo que sofre grande dependência da concentração do colato utilizada. A temperatura influi no processo de sorção da mesma maneira de que no processo de adsorção. Na faixa avaliada, o aumento da temperatura causa um decréscimo na quantidade sorvida. Os padrões de raios-X mostram que o HDL é reconstituído predominantemente contendo ânions hidroxila intercalados e a formação de uma nova fase contendo ânions colato intercalados, quando a concentração destes em solução é elevada. O modelo proposto, pelos resultados obtidos, sugere a intercalação de colato formando bicamada no domínio interlamelar.

Finalmente, é possível concluir, de uma maneira geral, que este trabalho alcançou seus objetivos iniciais. O adsorvente foi preparado, caracterizado e utilizado voltado para o estudo da adsorção de colato nos HDL de magnésio e alumínio. Além disso, o adsorvente também foi empregado na forma calcinada onde sua capacidade de adsorção/sorção é fortemente aumentada. Os resultados, quando comparados entre si, mostram que a sorção por regeneração no precursor calcinado é mais eficiente que a adsorção no HDL não calcinado. 


\section{Perspectivas}

O presente trabalho possibilitou uma melhor compreensão do processo de adsorção e sorção de colato em HDL do sistema $\left[\mathrm{Mg}-\mathrm{Al}-\mathrm{CO}_{3}\right]$ e do produto de calcinação do mesmo. Embora ainda hajam lacunas a serem preenchidas quanto às informações aqui reportadas, este estudo abre caminho para muitos outros, associando estes resultados a outros que possam vir, visando o tratamento e reaproveitamento de efluentes ou aplicação em fármacos para a extração do excesso de ânions colato, produzidos pelo organismo humano, devido à elevada eficiência demonstrada na remoção.

Alguns trabalhos complementares ainda podem ser realizados como o estudo da adsorção de colato em outras faixas de temperatura ou com o pH inicial das soluções de colato menor (porém não em valores de $\mathrm{pH}$ muito baixos, para não ocorrer a destruição do HDL). 


\section{Referências Bibliográficas}

1. Dabrowski, A. Adsorption - from theory to practice. Advances in Colloid and Interface Science 2001, 93 (1-3), 135-224.

2. You, Y. W.; Zhao, H. T.; Vance, G. F. Surfactant-enhanced adsorption of organic compounds by layered double hydroxides. Colloids and Surfaces A-Physicochemical and Engineering Aspects 2002, 205 (3), 161-172.

3. Ahmaruzzaman, M.; Sharma, D. K. Adsorption of phenols from wastewater. Journal of Colloid and Interface Science 2005, 287 (1), 14-24.

4. Fungaro, D. A.; da Silva, M. G. Use of zeolite from coal bottom ash as adsorbent of metals from water. Quimica Nova 2002, 25 (6B), 10811085 .

5. Atkins, P. W.; de Paula, J. Atkins' Physical Chemistry; $7^{\mathrm{a}}$ edition ed.; Oxford University Press: 2002.

6. de Roy, A.; Forano, C.; Besse, J. P. Anionic Clays: Trends in Pillaring Chemistry. Abstracts of Papers of the American Chemical Society 1991, (202), 127.

7. Cavani, F.; Trifiro, F.; Vaccari, A. Hydrotalcite-Type Anionic Clays: Preparation, Properties and Apllications. Catalisys Today 1991, 11, 173301.

8. Crepaldi, E. L. Estudo das Propriedades dos Hidróxidos Duplos Lamelares Contendo Cromio (III): Intercalação, Decomposição Térmica e Atividade Catalítica. FFCLRP, Universidade de São Paulo, 2000.

9. Allman, R. Crystal Structure of Pyroaurite. Acta Crystallographica Section BStructural Crystallography and Crystal Chemistry 1968, B 24, 972-\&.

10. Taylor, H. F. W. Mineralogical Magazine 1969, 37, 338-\&.

11. Crepaldi, E. L.; Valim, J. B. Layered double hydroxides: Structure, synthesis, properties and applications. Quimica Nova 1998, 21 (3), 300-311.

12. Feitknecht, W. Über die -form der hydroxide zweiwertiger mettale. Helvetica Chimica Acta 1938, 21, 766-784.

13. Chisem, I. C.; Jones, W. Ion-Exchanhge Properties of Lithium Aluminum Layered Double Hydroxides. Journal of Materials Chemistry 1994, 4 (11), 1737-1744.

14. Chisem, I. C. PhD Thesis. University of Cambridge, 1996.

15. Serna, C. J.; Rendon, J. L.; Iglesias, J. E. Crystal-Chemical Study of Layered $\left[\mathrm{Al}_{2} \mathrm{Li}(\mathrm{OH})_{6}\right]^{+} \mathrm{X}^{-} \cdot \mathrm{NH}_{2} \mathrm{O}$. Clays and Clay Minerals 1982, 30 (3), 180-184. 
16. Besserguenev, A. V.; Fogg, A. M.; Francis, R. J.; Price, S. J.; OHare, D.; Isupov, V. P.; Tolochko, B. P. Synthesis and structure of the gibbsite intercalation compounds $\left[\mathrm{Al}_{2} \mathrm{Li}(\mathrm{OH})_{6}\right]^{+} \mathrm{X}\left\{\mathrm{X}=\mathrm{Cl}, \mathrm{Br}, \mathrm{NO}_{3}\right\}$ and [ $\left.\mathrm{LiAl}_{2}(\mathrm{OH})_{6}\right] \mathrm{Cl}$ center dot $\mathrm{H}_{2} \mathrm{O}$ using synchrotron X-ray and neutron powder diffraction. Chemistry of Materials 1997, 9 (1), 241-247.

17. Vaccari, A. Preparation and catalytic properties of cationic and anionic clays. Catalysis Today 1998, 41 (1-3), 53-71.

18. Wang, J. A.; Morales, A.; Bokhimi, X.; Novaro, O.; Lopez, T.; Gomez, R. Cationic and anionic vacancies in the crystalline phases of sol-gel magnesia-alumina catalysts. Chemistry of Materials 1999, 11 (2), 308313.

19. Vanderpol, A.; Mojet, B. L.; Vandeven, E.; Deboer, E. Ordering of Intercaled Water and Carbonate Anions in Hydrotalcite - AN NMR-Study. Journal of Physical Chemistry 1994, 98 (15), 4050-4054.

20. deRoy, A.; Besse, J. P.; Bondot, P. Structural Approach and Conductivity of Lamellar Hydroxides $\mathrm{Zn}_{2} \mathrm{Cr}(\mathrm{OH})_{6}$-ANION- $\mathrm{NH}_{2} \mathrm{O}$ by XANES, EXAFS and X-RAY-DIFFRACTION. Materials Research Bulletin 1985, 20 (9), 1091-1098.

21. Frondel, C. American Mineralogist 1941, 26, 295.

22. Newman, S. P.; Jones, W. Synthesis, characterization and applications of layered double hydroxides containing organic guests. New Journal of Chemistry 1998, 22 (2), 105-115.

23. El Malki, K.; de Roy, A.; Besse, J. P. Evolution related to hygrometry of two lamellar double hydroxide pillared structures $\left[\mathrm{Cu}---\mathrm{Cr}---\mathrm{SO}_{4}\right]$ and $[\mathrm{Zn}---$ Al---SO ${ }_{4}$ ]. Nanostructured Materials 1993, 2 (2), 169-173.

24. Pinnavaia, T. J. Nanoporous Layered Materials. Materials Chemistry 1995, 245, 283-300.

25. Vaccari, A. Clays and catalysis: a promising future. Applied Clay Science 1999, 14 (4), 161-198.

26. Reichle, W. T. Anionic Clay-Minerals. Chemtech 1986, 16 (1), 58-63.

27. Reichle, W. T. Synthesis of Anionic Clay-Minerals (Mixed Metal-Hydroxides, Hidrotalcite). Solid State Ionics 1986, 22 (1), 135-141.

28. Crepaldi, E. L.; Pavan, P. C.; Tronto, J.; Valim, J. B. Chemical, structural, and thermal properties of $\mathrm{Zn}$ (II)-Cr(III) layered double hydroxides intercalated with sulfated and sulfonated surfactants. Journal of Colloid and Interface Science 2002, 248 (2), 429-442.

29. Kooli, F.; Depege, C.; Ennaqadi, A.; deRoy, A.; Besse, J. P. Rehydration of ZnAl layered double hydroxides. Clays and Clay Minerals 1997, 45 (1), 9298. 
30. Hibino, T.; Yamshita, Y.; Kosuge, K.; Tsunashima, A. Decarbonation behavior of $\mathrm{Mg}-\mathrm{Al}-\mathrm{CO}^{3-}$ hidrotalcite-like Compounds during heat-treatment. Clays and Clay Minerals 1995, 43 (4), 427-432.

31. Aramendia, M. A.; Aviles, Y.; Borau, V.; Luque, J. M.; Marinas, J. M.; Ruiz, J. R.; Urbano, F. J. Thermal decomposition of $\mathrm{Mg} \mathrm{Al}$ and Mg Ga layereddouble hydroxides: a spectroscopic study. Journal of Materials Chemistry 1999, 9 (7), 1603-1607.

32. Kumbhar, P. S.; Sanchez-Valente, J.; Figueras, F. Modified Mg-Al hydrotalcite: a highly active heterogeneous base catalyst for cyanoethylation of alcohols. Chemical Communications 1998, (10), 1091-1092.

33. Beres, A.; Palinko, I.; Kiricsi, I.; Nagy, J. B.; Kiyozumi, Y.; Mizukami, F. Layered double hydroxides and their pillared derivatives - materials for solid base catalysis; synthesis and characterization. Applied Catalysis AGeneral 1999, 182 (2), 237-247.

34. Patel, S. H.; Xanthos, M.; Grenci, J.; Klepak, P. B. Mechanisms and Performance of Hydrotalcite acid Neutralizers in Thermoplastics. Journal of Vinyl \& Additive Technology 1995, 1 (3), 201-206.

35. Lal, M.; Howe, A. T. Studies of Zinc-Chromium Hydroxy Salts .2. Composite Anion Conductors of Pressed Disks of $\left[\mathrm{Zn}_{2} \mathrm{Cr}(\mathrm{OH})_{6} \mathrm{X}^{-} \mathrm{NH}_{2} \mathrm{O}\right.$, where $\mathrm{X}^{-}$ $=\mathrm{F}^{-}, \mathrm{Cl}^{-}, \mathrm{Br}^{-}, \mathrm{L}^{-}, \mathrm{NO}_{3}{ }^{-}$and $1 / 2 \mathrm{CO}_{3}{ }^{2-}$. Journal of Solid State Chemistry 1981, 39 (3), 377-386.

36. Ballarin, B.; Gazzano, M.; Seeber, R.; Tonelli, D.; Vaccari, A. Electrodes coated by hydrotalcite-like clays. Effect of the metals and the intercalated anions on ion accumulation and retention capability. Journal of Electroanalytical Chemistry 1998, 445 (1-2), 27-37.

37. Qiu, J. B.; Villemure, G. Anionic clay modified electrodes: Electron transfer mediated by electroactive nickel, cobalt or manganese sites in layered double hydroxide films. Journal of Electroanalytical Chemistry 1997, 428 (1-2), 165-172.

38. Putyera, K.; Bandosz, T. J.; Jagieo, J.; Schwarz, J. A. Effect of template constraints on adsorption properties of synthetic carbons prepared within the gallery of layered double hydroxides. Carbon 1996, 34 (12), 15591567.

39. Reichle, W. T.; Kang, S. Y.; Everhardt, D. S. The Nature of the ThermalDecomposition of a Catalytically Active Anionic Clay Mineral. Journal of Catalysis 1986, 101 (2), 352-359.

40. Sanfilippo, D. The catalytic process from the laboratory to the industrial plant Papers presented at the 3rd Seminar of Catalysis held in Rimini, Italy, June 19-24, 1994 - Preface. Catalysis Today 1997, 34 (3-4), 259-260. 
41. Pavan, P. C.; Gomes, G. D.; Valim, J. B. Adsorption of sodium dodecyl sulfate on layered double hydroxides. Microporous and Mesoporous Materials 1998, 21 (4-6), 659-665.

42. Albiston, L.; Franklin, K. R.; Lee, E.; Smeulders, J. B. A. F. Rheology and microstructure of aqueous layered double hydroxide dispersions. Journal of Materials Chemistry 1996, 6 (5), 871-877.

43. Yun, S. K.; Pinnavaia, T. J. Water-Content and Particle Terxture of Synthetic hydrotalcite-like Layered Double Hydroxides. Chemistry of Materials 1995, 7 (2), 348-354.

44. Houri, B.; Legrouri, A.; Barroug, A.; Forano, C.; Besse, J. P. Removal of chromate ions from water by anionic clays. Journal de Chimie Physique et de Physico-Chimie Biologique 1999, 96 (3), 455-463.

45. Miyata, S. Anion-Exchange Properties of hidrotalcite-like Compounds. Clays and Clay Minerals 1983, 31 (4), 305-311.

46. Puttaswamy, N. S.; Kamath, P. V. Reversible thermal behaviour of layered double hydroxides: A thermogravimetric study. Journal of Materials Chemistry 1997, 7 (9), 1941-1945.

47. Valim, J.; Kariuki, B. M.; King, J.; Jones, W. Photoactivity of CinnamateIntercalates of Layered Double Hydroxides Molecular Crystals and Liquid Crystals 1992, 211, 271-281.

48. Playle, A. C.; Gunning, S. R.; Llewellyn, A. F. Invitro Antacid and Anti-Pepsin Activity of Hydrotalcite. Pharmaceutica Acta Helvetiae 1974, 49 (9-10), 298-302.

49. Kokot, Z. Studies of Neutralizing Properties of Antacid Preparations. 3.Constant $\mathrm{pH}$ Neutralization of Hydrochloric-acid by Hydrotalcite. Pharmazie 1988, 43 (4), 249-251.

50. Tarnawski, A.; Pai, R.; Itani, R.; Wyle, F. A. The antacid Talcid adsorbs and neutralizes all proteins secreted by $\mathrm{H}$. pylori including VacA cytotoxin: A new mechanism for its ulcer-healing action? Digestion 1999, 60 (5), 449-455.

51. Tronto, J.; Crepaldi, E. L.; Pavan, P. C.; De Paula, C. C.; Valim, J. B. Organic anions of pharmaceutical interest intercalated in magnesium aluminum LDHs by two different methods. Molecular Crystals and Liquid Crystals 2001, 356, 227-237.

52. Tronto, J.; dos Reis, M. J.; Silverio, F.; Balbo, V. R.; Marchetti, J. M.; Valim, J. $\mathrm{B}$. In vitro release of citrate anions intercalated in magnesium aluminium layered double hydroxides. Journal of Physics and Chemistry of Solids 2004, 65 (2-3), 475-480. 
53. Weihrauch, T. R.; Gauler, T. C. Placebo - Efficacy and adverse effects in controlled clinical trials. Arzneimittel-Forschung-Drug Research 1999, 49 (5), 385-393.

54. Miyata, S.; Hirose, T. Adsorption of $\mathrm{N}_{2}^{-} \mathrm{O}_{2}{ }^{-} \mathrm{CO}_{2}$ and $\mathrm{H}_{2}{ }^{-}$on Hydrotalcite-like System $-\mathrm{Mg}^{2+}{ }_{--} \mathrm{Al}^{3+}{ }_{--}\left[\mathrm{Fe}(\mathrm{CN})_{6}\right]_{4}^{-}$. Clays and Clay Minerals 1978, 26 (6), 441-447.

55. Elm'chaouri, A.; Simonot-Grange, M. H. Experimental data and adsorption models for the systems $\mathrm{N}_{2}^{-}(\mathrm{g}) /$ potassium-saturated montmorillonite of camp-berteau and $\mathrm{N}_{2}{ }^{-}(\mathrm{g}) /$ carbonate-saturated hydrotalcite.

Thermochimica Acta 1999, 339 (1-2), 117-123.

56. Pavan, P. C.; Gomes, G. D.; Valim, J. B. Adsorption of sodium dodecyl sulfate on layered double hydroxides. Microporous and Mesoporous Materials 1998, 21 (4-6), 659-665.

57. Pavan, P. C.; Crepaldi, E. L.; Gomes, G. D.; Valim, J. B. Adsorption of sodium dodecylsulfate on a hydrotalcite-like compound. Effect of temperature, $\mathrm{pH}$ and ionic strength. Colloids and Surfaces A-Physicochemical and Engineering Aspects 1999, 154 (3), 399-410.

58. Manju, G. N.; Gigi, M. C.; Anirudhan, T. S. Hydrotalcite as adsorbent for the removal of chromium (VI) from aqueous media: Equilibrium studies. Indian Journal of Chemical Technology 1999, 6 (3), 134-141.

59. Pavlovic, I.; Ulibarri, M. A.; Hermosin, M. C.; Cornejo, J. Sorption of an anionic surfactant from water by a calcined hydrotalcite-like sorbent. Fresenius Environmental Bulletin 1997, 6 (5-6), 266-271.

60. Houri, B.; Legrouri, A.; Barroug, A.; Forano, C.; Besse, J. P. Use of the ionexchange properties of layered double hydroxides for water purification. Collection of Czechoslovak Chemical Communications 1998, 63 (5), 732-740.

61. Fetter, G.; Olguin, M. T.; Bosch, P.; Lara, V. H.; Bulbulian, S. I-131(-) sorption from aqueous solutions by nitrated hydrotalcites. Journal of Radioanalytical and Nuclear Chemistry 1999, 241 (3), 595-599.

62. Kang, M. J.; Chun, K. S.; Rhee, S. W.; Do, Y. Comparison of sorption behavior of I- and TcO4- on $\mathrm{Mg} / \mathrm{Al}$ layered double hydroxide. Radiochimica Acta 1999, 85 (1-2), 57-63.

63. Hermosin, M. C.; Pavlovic, I.; Ulibarri, M. A.; Cornejo, J. Trichlorophenol Adsorption on Layered Double Hydroxide-A potential Sorbent. Journal of Environmental Science and Health Part A-Environmental Science and Engineering \& Toxic and Hazardous Substance Control 1993, 28 (9), 1875-1888.

64. Feitknecht, W. Helvetica Chimica Acta 1942, 25, 131. 
65. Bish, D. L. Anion-Exchange in Takeovite-Applications to other Hydroxide Minerals. Bulletin de Mineralogie 1980, 103 (2), 170-175.

66. Crepaldi, E. L.; Pavan, P. C.; Valim, J. B. Anion exchange in layered double hydroxides by surfactant salt formation. Journal of Materials Chemistry 2000, 10 (6), 1337-1343.

67. Crepaldi, E. L.; Pavan, P. C.; Valim, J. B. A new method of intercalation by anion exchange in layered double hydroxides. Chemical Communications 1999, (2), 155-156.

68. Crepaldi, E. L.; Pavan, P. C.; Valim, J. B. Comparative study of the coprecipitation methods for the preparation of layered double hydroxides. Journal of the Brazilian Chemical Society 2000, 11 (1), 64-70.

69. De Paula, C. C.; Crepaldi, E. L.; Tronto, J.; Pavan, P. C.; Valim, J. B. Organic bilayers intercalated in zinc(II)-chromium(III) layered double hydroxides. Molecular Crystals and Liquid Crystals 2001, 356, 327-335.

70. Boehm, H. P.; Steinle, J.; Vieweger, C. $\left[\mathrm{Zn}_{2} \mathrm{Cr}_{2}(\mathrm{OH})_{6}\right] \mathrm{X} .2 \mathrm{H}_{2} \mathrm{O}$, New Layer Compounds capable of anion-exchange and Intracrystalline swelling. Angewandte Chemie-International Edition in English 1977, 16 (4), 265266.

71. Taylor, R. M. The Rapid Formation of Crystalline Double Hydroxy Salts and Other Compounds by Controlled Hydrolysis. Clay Minerals 1984, 19 (4), 591-603.

72. Indira, L.; Kamath, P. V. Electrogeneration of Base by Cathodic Reduction o anions - Novel one-step route to urinary and layered double hydroxides (LDHs). Journal of Materials Chemistry 1994, 4 (9), 1487-1490.

73. Indira, L.; Dixit, M.; Kamata, P. V. Eletrosynthesis of Layered Double Hydroxides of Nickel with Trivalent Cations. Journal of Power Sources 1994, 52 (1), 93-97.

74. Lopez, T.; Bosch, P.; Ramos, E.; Gomez, R.; Novaro, O.; Acosta, D.; Figueras, F. Synthesis and characterization of sol-gel hydrotalcites. Structure and texture. Langmuir 1996, 12 (1), 189-192.

75. Rives, V.; Ulibarri, M. A. Layered double hydroxides (LDH) intercalated with metal coordination compounds and oxometalates. Coordination Chemistry Reviews 1999, 181, 61-120.

76. Crepaldi, E. L.; Pavan, P. C.; Valim, J. B. A new method of intercalation by anion exchange in layered double hydroxides. Chemical Communications 1999, (2), 155-156.

77. Weiss, A. Surfactant Layers at Interfaces. Chemistry \& Industry 1980, (9), 382387. 
78. Giles, C. H.; Smith, D.; Huitson, A. General Treatment and Classification of Solute Adsorption-Isotherm. 1. Theoretical. Journal of Colloid and Interface Science 1974, 47 (3), 755-765.

79. Giles, C. H.; D'Silva, A. P.; Easton, I. A. A general treatment and classification of the solute adsorption isotherm part. II. Experimental interpretation. Journal of Colloid and Interface Science 1974, 47 (3), 766-778.

80. Emmett, P. H.; Brunauer, S. The Use of Low Temperature van der Waals Adsorpion Isotherms in Determining the Surface Area of Iron Synthetic Ammonia Catalysts. Journal of the American Chemical Society 1937, 59 (8), 1553-1564.

81. Kipling, J. J.; Shooter, P. V.; Sherwood, J. N. Adsorption of Iodine from Organic Solvents by Graphitized Carbon Blacks. Transactions of the Faraday Society 1964, 60 (4942), 401-\&.

82. Roik, N. V.; Belyakova, L. A. Adsorption of cholic acid on surface of organosilicas containing chemically bound quaternary ammonium groups. Russian Journal of Physical Chemistry 2006, 80 (7), 1105-1109.

83. Valcheva-Traykova, M. L.; Davidova, N. P.; Weiss, A. H. ThermalDecomposition of Mg, Al-Hydrotalcite Material. Journal of Materials Science 1993, 28 (8), 2157-2162.

84. Ahmed, M. J.; Hossan, J. Spectrophotometric Determination of Aluminium by Morin. Talanta 1995, 42 (8), 1135-1142.

85. Yan, S. K.; Luo, G. A.; Wang, Y. M.; Cheng, Y. Y. Simultaneous determination of nine components in Qingkailing injection by HPLC/ELSD/DAD and its application to the quality control. Journal of Pharmaceutical and Biomedical Analysis 2006, 40 (4), 889-895.

86. Peterson, C. L.; Perry, D. L.; Masood, H.; Lin, H. H.; White, J. L.; Hem, S. L.; Fritsch, C.; Haeusler, F. Characterization of Antacid Compounds Containing Both Aluminum and Magnesium.1. Cristalline Powders. Pharmaceutical Research 1993, 10 (7), 998-1004.

87. West, A. R. Solide State Chemistry and Its Applications; Chichester, 1987.

88. Bruns, E. Planejamento e Otimização de Experimentos; 5 ed.; Ed. Unicamp: 1993.

89. Hair, J. F.; Anderson, R. E.; Tatham, R. L.; Black, W. C. Análise Multivariada de Dados; 5 ed.; Bookman: Porto Alegre, 2005.

90. Aisawa, S.; Hirahara, H.; Uchiyama, H.; Takahashi, S.; Narita, E. Synthesis and thermal decomposition of Mn-Al layered double hydroxides. Journal of Solid State Chemistry 2002, 167 (1), 152-159. 
91. Brunauer, S.; Deming, L. S.; Deming, W. E.; Teller, E. On Theory of the van der Waals Adsorption of Gases. Journal American chemical Society 1940, 62, 1723-1732.

92. Morrison, R.; Boyd, R. Organic Chemistry; 4 ed.; 1994.

93. dos Reis, M. J. Estudo da Adsorção de Tensoativos Aniônicos Sulfonados em Hidróxidos Duplos Lamelares. FFCLRP - Universidade de São Paulo, 2004. 


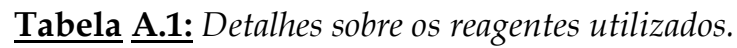

\begin{tabular}{|c|c|c|c|}
\hline Reagentes & $\begin{array}{l}\text { Fórmula } \\
\text { Molecular }\end{array}$ & Marca & $\frac{\text { Pureza }}{(\%)}$ \\
\hline Acetona & $\mathrm{C}_{3} \mathrm{H}_{6} \mathrm{O}$ & Mallinkrodt & $>99$ \\
\hline Acetonitrila & $\mathrm{CH}_{3} \mathrm{CN}$ & Fisher & $>98$ \\
\hline Ácido Acético & $\mathrm{CH}_{3} \mathrm{COOH}$ & EM Science & $>99$ \\
\hline Ácido Clorídrico & $\mathrm{HCl}$ & Merck & $>37$ \\
\hline Ácido Fórmico & $\mathrm{HCOOH}$ & Merck & $>98$ \\
\hline Ácido Nítrico & $\mathrm{HNO}_{3}$ & Merck & $>65$ \\
\hline Ácido Sulfúrico & $\mathrm{H}_{2} \mathrm{SO}_{4}$ & EM Science & $>95$ \\
\hline Alumínio (Padrão) & $\mathrm{Al}\left(\mathrm{NO}_{3}\right)_{3} \cdot 9 \mathrm{H}_{2} \mathrm{O}$ & Carlo Erba & $>99$ \\
\hline Ar Sintético & $80 \% \mathrm{~N}_{2}, 20 \% \mathrm{O}_{2}$ & White-Martins & 99,997 \\
\hline Brometo de Potássio & $\mathrm{KBr}$ & Mallinckrodt & $>37$ \\
\hline Carbonato de Sódio & $\mathrm{Na}_{2} \mathrm{CO}_{3}$ & Mallinckrodt & $>99$ \\
\hline Cloreto de Sódio & $\mathrm{NaCl}$ & Mallinkrodt & $>99$ \\
\hline Colato de Sódio & $\mathrm{C}_{24} \mathrm{H}_{39} \mathrm{NaO}_{5}$ & Acros & $>99$ \\
\hline Dicromato de Potássio & $\mathrm{K}_{2} \mathrm{Cr}_{2} \mathrm{O}_{7}$ & Synth & $>99$ \\
\hline Etanol & $\mathrm{C}_{2} \mathrm{H}_{6} \mathrm{O}$ & Merck & $>99$ \\
\hline Hidrato de Morina & $\mathrm{C}_{15} \mathrm{H}_{10} \mathrm{O}_{7} \times \mathrm{XH}_{2} \mathrm{O}$ & Acros & $>95$ \\
\hline Hidróxido de Sódio & $\mathrm{NaOH}$ & Mallinckrodt & $>98$ \\
\hline Metanol & $\mathrm{CH}_{3} \mathrm{OH}$ & Fisher & $>98$ \\
\hline $\begin{array}{l}\text { Nitrato de Alumínio(III) } \\
\text { Nonahidratado }\end{array}$ & $\mathrm{Al}\left(\mathrm{NO}_{3}\right)_{3} \cdot 9 \mathrm{H}_{2} \mathrm{O}$ & $\begin{array}{l}\text { Riedel-de- } \\
\text { Haën }\end{array}$ & $>98$ \\
\hline $\begin{array}{l}\text { Nitrato de Magnésio } \\
\text { Hexahidratado }\end{array}$ & $\mathrm{Mg}\left(\mathrm{NO}_{3}\right)_{2} \cdot 6 \mathrm{H}_{2} \mathrm{O}$ & Mallinckrodt & $>99$ \\
\hline Nitrogênio & $\mathrm{N}_{2}$ & White-Martins & $>99,997$ \\
\hline Óxido de Magnésio & $\mathrm{MgO}$ & Fisons & $>96$ \\
\hline Oxigênio & $\mathrm{O}_{2}$ & White-Martins & $>99,9$ \\
\hline Zinco Metálico & $\mathrm{Zn}$ & J.T. Baker & $>99$ \\
\hline
\end{tabular}

